\title{
Fifth Annual Report on Federal Agency Use of Voluntary Consensus Standards and Conformity Assessment
}

\author{
Kevin McIntyre \\ Michael B. Moore
}

Office of Standards Coordination and Conformity

Standards Services Division

Technology Services Laboratory 


\title{
Fifth Annual Report on Federal Agency Use of Voluntary Consensus Standards and Conformity Assessment
}

\author{
Kevin McIntyre \\ Michael B. Moore \\ Office of Standards Coordination and Conformity \\ Standards Services Division \\ Technology Services Laboratory
}

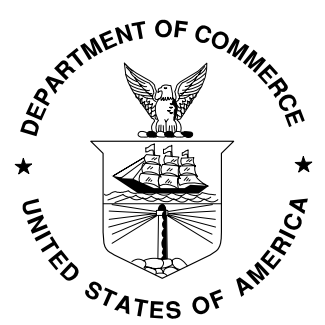

U.S. DEPARTMENT OF COMMERCE

Donald L. Evans, Secretary

TECHNOLOGY ADMINISTRATION

Phillip J. Bond, Under Secretary of Commerce for Technology NATIONAL INSTITUTE OF STANDARDS AND TECHNOLOGY Arden L. Bement, Jr., Director 


\title{
FIFTH ANNUAL REPORT ON
}

FEDERAL AGENCY USE OF

\section{VOLUNTARY CONSENSUS STANDARDS}

\author{
IMPLEMENTATION OF \\ PUBLIC LAW 104-113 AND OMB CIRCULAR A-119 \\ FOR THE PERIOD \\ OCTOBER 1, 2000, THROUGH SEPTEMBER 30, 2001
}

United States Department of Commerce

National Institute of Standards and Technology

Technology Services

Standards Services Division

Gaithersburg, Maryland 20899-2100 


\section{Fifth Annual Report to the Office of Management and Budget (OMB)}

on the Implementation of Public Law 104-113 and OMB Circular A-119

\section{Table of Contents}

EXECUTIVE SUMMARY

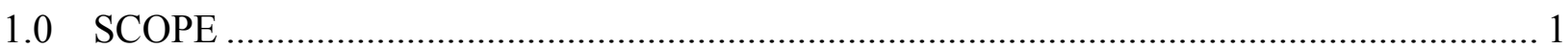

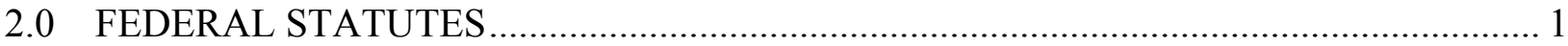

2.1 National Technology Transfer and Advancement Act (NTTAA) (P.L. 104-113).............. 1

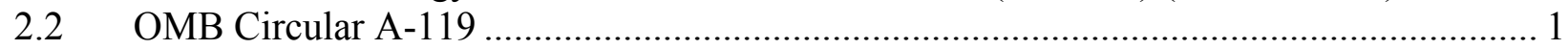

2.2.1 Use of Voluntary Consensus Standards Versus Government-unique Standards ................ 1

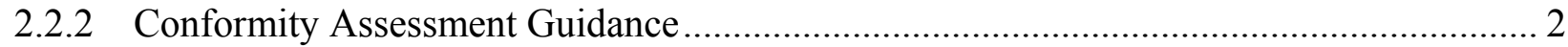

2.2.3 Other Issues Covered by The Circular ........................................................................ 2

3.0 INTERAGENCY COMMITTEE ON STANDARDS POLICY (ICSP) ............................ 2

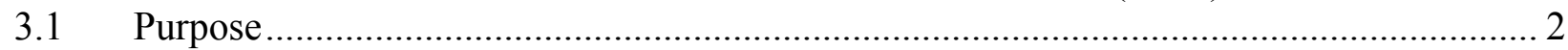

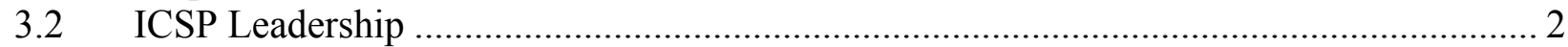

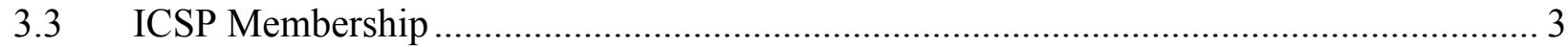

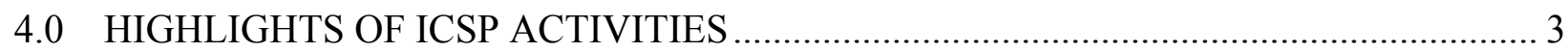

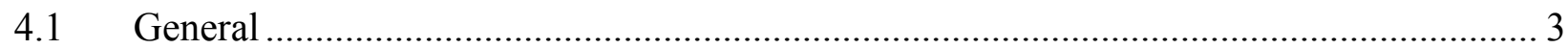

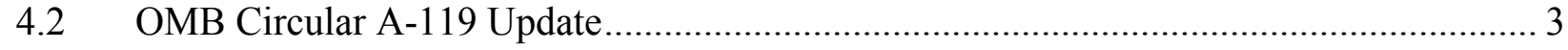

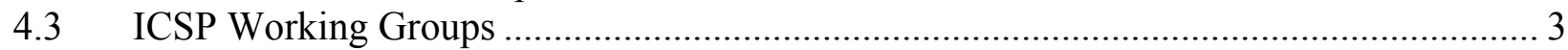

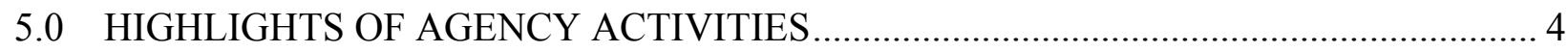

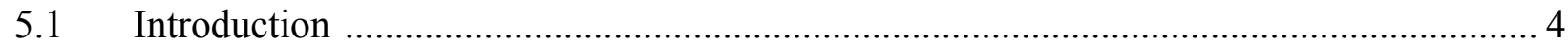

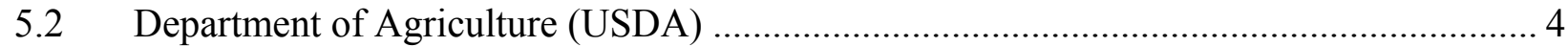

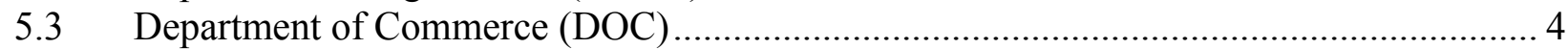

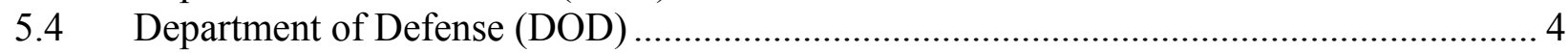

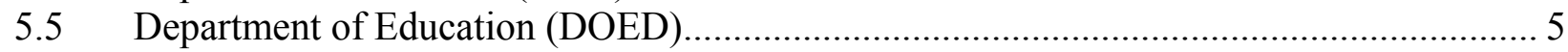

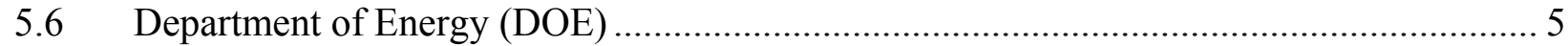

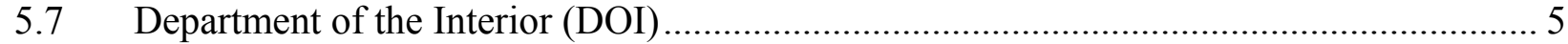

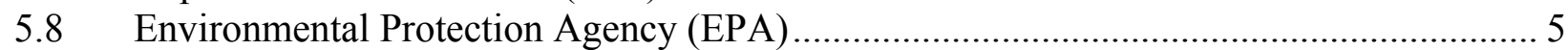

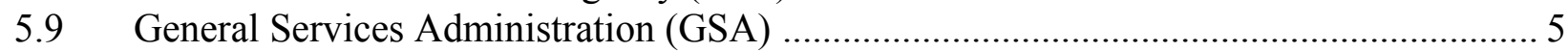

5.10 National Aeronautics and Space Administration (NASA) .............................................. 5

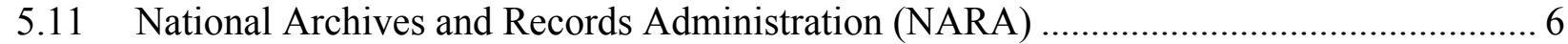

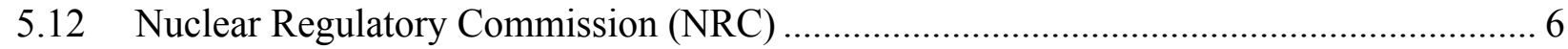

6.0 AGENCY USE OF GOVERNMENT-UNIQUE STANDARDS IN LIEU OF

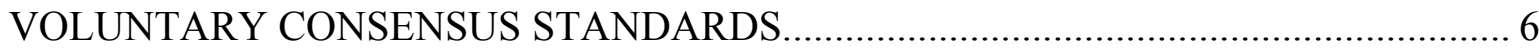

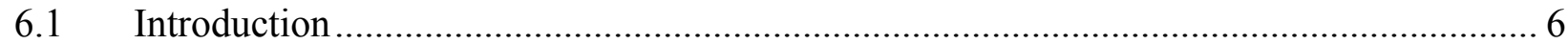

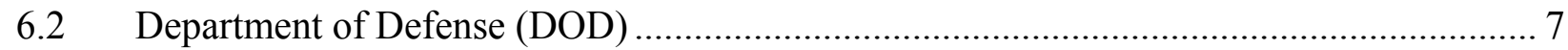


6.3 Department of Energy (DOE) ............................................................................... 7

$6.4 \quad$ National Aeronautics and Space Administration (NASA) ….................................... 7

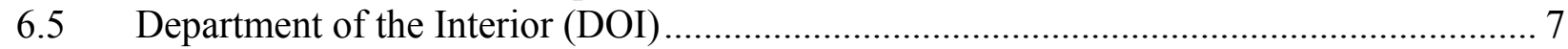

6.6 Department of Labor (DOL) ................................................................................. 7

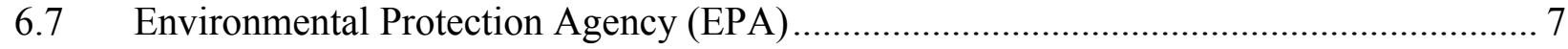

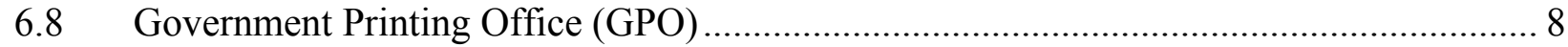

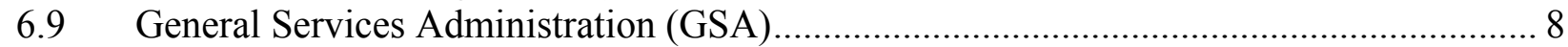

6.10 Department of Health and Human Services (HHS) ................................................. 9

6.11 Department of Housing and Urban Development (HUD) ........................................ 9

6.12 National Archives and Records Administration (NARA) ....................................... 9

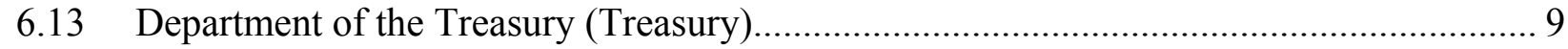

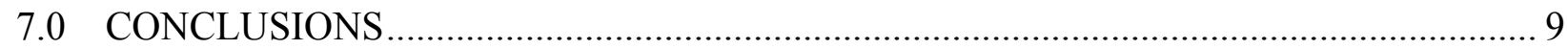

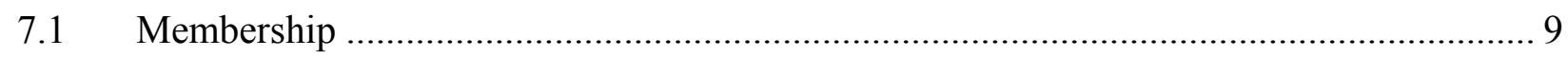

7.2 Use of Voluntary Consensus Standards Instead of Government-unique Standards ......... 10

7.3 Use of Government-unique Standards Instead of Voluntary Consensus Standards ......... 10

7.4 Participation in Voluntary Consensus Committee Activities ........................................ 10

7.5 Use of Voluntary Consensus Standards .............................................................. 10

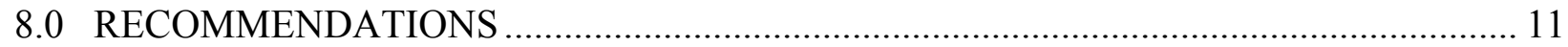

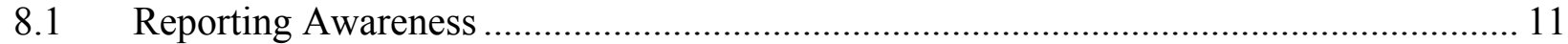

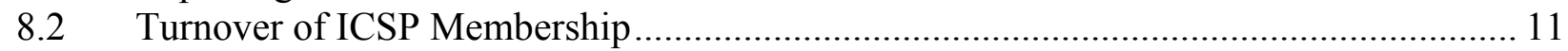

8.3 Timeliness and Completeness of Reports ............................................................... 11

8.4 Clarification of Circular Language ..................................................................... 12

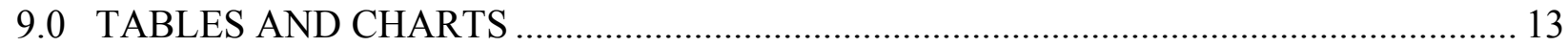

APPENDIX A: CABINET DEPARTMENT REPORTS ……………………….............. A-1

Department of Agriculture (USDA) ..................................................................... A-2

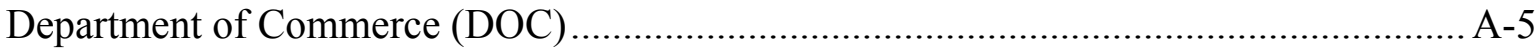

Department of Defense (DOD) .......................................................................... A-14

Department of Defense (DOD)

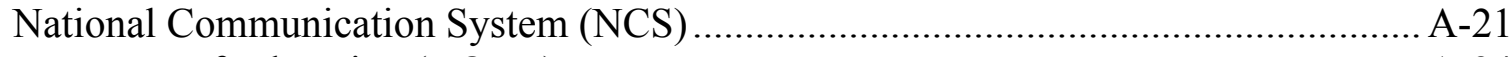

Department of Education (DOED) ................................................................... A-24

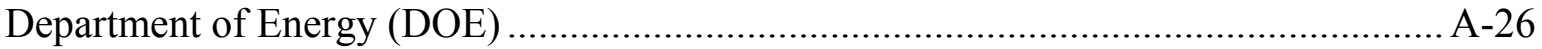

Department of Health and Human Services (HHS)

Food and Drug Administration (FDA) ............................................................... A-35

Department of Housing and Urban Development (HUD) ....................................... A-43

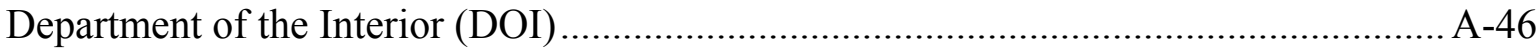

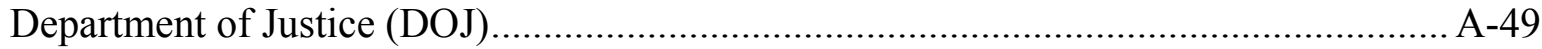

Department of Labor (DOL) .............................................................................. A-53

Department of State (STATE) ........................................................................... A-54

Department of Transportation (DOT) ............................................................... A-56

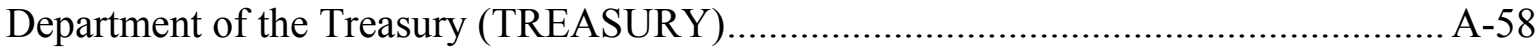

Department of Veterans Affairs (VA) ................................................................. A-60 
APPENDIX B: OTHER AGENCY AND COMMISSION REPORTS .............................. B-1

Agency for International Development (USAID) ................................................. B-2

Consumer Product Safety Commission (CPSC) ….................................................. B-3

Environmental Protection Agency (EPA) ............................................................. B-6

Federal Communications Commission (FCC) ............................................................. B-13

Federal Emergency Management Agency (FEMA) ................................................... B-14

Federal Trade Commission (FTC) ......................................................................... B-15

General Services Administration (GSA) .......................................................... B-17

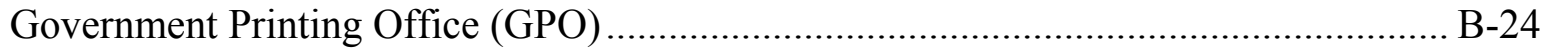

International Trade Commission (ITC) ................................................................... B-26

National Aeronautics and Space Administration (NASA) ....................................... B-28

National Archives and Records Administration (NARA) ........................................ B-31

National Science Foundation (NSF) ................................................................... B-33

Nuclear Regulatory Commission (NRC) ............................................................... B-34

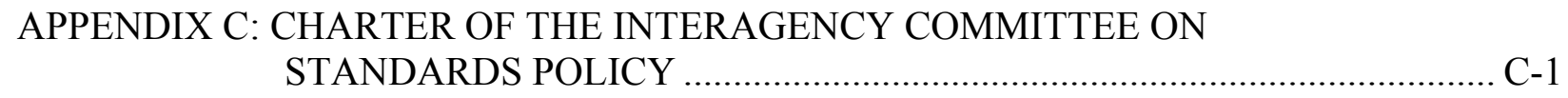

APPENDIX D: MEMBERSHIP OF THE INTERAGENCY COMMITTEE ON

STANDARDS POLICY ..................................................................... D-1

APPENDIX E: LIST OF NATIONAL INSTITUTE OF STANDARDS AND

TECHNOLOGY PUBLICATIONS RELATED TO PUBLIC

LAW 104-113

E-1 


\section{EXECUTIVE SUMMARY}

The National Technology Transfer and Advancement Act (NTTAA) (Public Law (P.L.) 104-113), requires Federal agencies to use voluntary consensus standards to the extent practicable, to report development of agency-unique standards, and to participate in the development of voluntary consensus standards. The Office of Management and Budget (OMB) issued Circular A-119 (the Circular), Federal Participation in the Development and Use of Voluntary Consensus Standards and in Conformity Assessment Activities to implement the NTTAA. The Circular requires the National Institute of Standards and Technology (NIST) to report annually to OMB on the progress Federal agencies make each year toward using voluntary consensus standards rather than government-unique standards and on the participation of Federal agency employees on private-sector voluntary consensus standards organizations. NIST organized and relies on the Interagency

Committee on Standards Policy (ICSP) as the primary means of fulfilling its responsibilities for coordinating Federal standards-related activities under the NTTAA.

On September 19, 2001, NIST, as chair of the ICSP, requested that each agency provide information on the status of its NTTAA implementation activities. The activities that NIST requested reports for included agency use of government-unique standards in lieu of voluntary consensus standards, agency use of voluntary national consensus standards, the number of voluntary standards agencies substituted for government-unique standards, and the number of individual agency employees who participated in voluntary national consensus standards organizations. NIST also requested an agency evaluation of the effectiveness of the policies promulgated in the Circular. Table 1 summarizes this information.

This report covers the period from October 1, 2000, through September 30, 2001 (FY 2001.) It describes NIST's coordination activities, with special emphasis on implementing the NTTAA, ICSP activities, individual agency reports on NTTAA implementation efforts, and suggestions for future courses of action.

This report concludes that agencies continue to make significant progress in implementing the NTTAA. The past five years have been a learning experience during which NIST has found that the agencies have become more aware of the reporting requirements of the NTTAA. As agencies become more aware of the requirements of the NTTAA and the Circular, they improve their participation in and understanding of their NTTAA obligations. While more work is necessary to ensure timely and accurate reporting of standards activities under the NTTAA, overall progress is good.

The reported number of voluntary consensus standards used by Federal agencies seems to indicate a significant decline in such use this year. Such is not the case. The reported decrease in the use voluntary consensus standards reflects adjustments made by the agencies to their reporting process based upon a better understanding of the NTTAA reporting requirements. In the past, the number of voluntary standards reported as "used" 
each year often included standards that were reported as "used" the previous year. This continued reporting of the use of the same standard from year to year leads to "multiple counting" of a standard's use. This year, more agencies are reporting only those standards they "used" for the first time this year. They are not re-reporting those that they reported previously and continue to use.

\begin{tabular}{|c|c|c|c|c|c|c|}
\hline & PART & $\begin{array}{l}\text { Y } 2001 \text { STAT } \\
\text { IPATION IN } \\
\text { VOLUNTA }\end{array}$ & $\begin{array}{l}\text { TICS ON I } \\
\text { YELOPM } \\
\text { Y CONSEI }\end{array}$ & $\begin{array}{l}\text { DERAL AGE] } \\
\text { IT OF AND A } \\
\text { JS STANDAF }\end{array}$ & $\begin{array}{l}\text { CIES' } \\
\text { OOPTION OF } \\
\text { DS }\end{array}$ & \\
\hline $\begin{array}{l}\text { Number of } \\
\text { Voluntary } \\
\text { Consensus } \\
\text { Standards } \\
\text { Activities in }\end{array}$ & $\begin{array}{r}\text { Numbe } \\
\text { Employee } \\
\text { Volunt } \\
\text { Stand }\end{array}$ & $\begin{array}{l}\text { f Agencies' } \\
\text { articipating in } \\
\text { Consensus } \\
\text { ls Bodies }\end{array}$ & $\begin{array}{r}\text { Numbe } \\
\text { Consensus }\end{array}$ & $\begin{array}{l}\text { Voluntary } \\
\text { andards Used }\end{array}$ & $\begin{array}{l}\text { Number of } \\
\text { Voluntary } \\
\text { Consensus } \\
\text { Standards }\end{array}$ & $\begin{array}{c}\text { Number of } \\
\text { Government- } \\
\text { Unique Standards }\end{array}$ \\
\hline $\begin{array}{c}\text { Agencies } \\
\text { Reported } \\
\text { Participation in } \\
\text { FY 2001 }\end{array}$ & FY 2001 & $\begin{array}{c}\text { Change from } \\
\text { FY } 2000\end{array}$ & FY 2001 & $\begin{array}{c}\text { Change from } \\
\text { FY } 2000\end{array}$ & $\begin{array}{l}\text { FY } 2001 \text { for } \\
\text { Government- } \\
\text { Unique Standards }\end{array}$ & $\begin{array}{l}\text { Consensus } \\
\text { Standards in } \\
\text { FY } 2001\end{array}$ \\
\hline 847 & 2,838 & +115 & 3,749 & $-1,704$ & 106 & 54 \\
\hline
\end{tabular}

NIST will be working within the ICSP to provide improved guidance to the Agencies so that they can report the number of voluntary consensus standards they use in a uniform and consistent manner. NIST will suggest that the Committee consider the possibility of developing a cumulative table of data to show more clearly the number of voluntary consensus standards used by the Federal agencies for the first time each year. The current table (Chart 4) displays the total number of standards reported as "used" each year, including those reported as "used" in previous years. The use of a cumulative table will show more accurately the actual trend of the use of new voluntary consensus standards and should eliminate the effect of "multiple-counting" of standards each year.

It should also be noted that as agencies reduce their regulatory activities found on the Semi-Annual Regulatory Agenda, the number of voluntary standards used by the agencies in their regulatory standards development process might also decrease.

The number of government-unique standards used in lieu of voluntary consensus standards increased from 16 to 54 between FY 2000 to FY 2001. Again, this increase reflects a growing awareness of the reporting requirements of the NTTAA and OMB Circular as Agencies reevaluate their standards inventories. A better awareness of the reporting requirements has led to the identification of many standards that may have been overlooked in the past. The use of "agency-specific" standards as well as "governmentunique" standards is now being reported. "Agency-specific" standards are standards that have been developed by an agency to be used by that agency. "Agency-specific" standards are a subset of "government-unique" standards and their use may have been overlooked in the past by some agencies. 
While the number of voluntary consensus standards activities on which agency employees participated declined slightly, the actual number of agency employees participating in voluntary consensus standards bodies increased this year. The slight decline in the number of committees on which agency employees participated most likely reflects a reallocation of resources based upon current agency standards development agendas. In order to better manage financial and human resources, agencies may be reducing participation on committees that are not related directly to their regulatory agendas, while at the same time increasing employee participation on those committees that are related directly to active agency standards activities.

After a significant decline last year, the numbers of employees participating on voluntary consensus standards bodies have returned to FY 1999 levels. Many agencies have recently suffered significant turnover in employment due to retirements of long-term workers. However, in recognition of future staff turnover and the loss of participation by older workers many agencies may be allowing younger workers to join into committee memberships along with and under the mentoring of the outgoing members of the workforce. Such foresight and increased participation ensures a smooth transition and continued participation in standards activities by the agencies as long-term workers leave the workforce.

During this reporting period, many agencies continued to institute new procedures to improve compliance with the NTTAA. For example, EPA provided additional guidance to its regulatory development staff on how the NTTAA can and should be discussed in the preambles of Notices of Proposed Rulemaking and Final Rules. DoD and DOE continued to replace Military Specifications and government-unique standards with voluntary national consensus standards. Other agencies, notably the Department of Health and Human Services, the Nuclear Regulatory Commission, and the Department of Energy convened agency-wide workshops with other agencies and invited key stakeholders to educate their standards personnel about NTTAA activities. Private-sector standards developing organizations instituted briefing sessions with Federal agencies to address the issue of references to out-of-date standards in regulations.

Appendices A and B contain the full reports from 14 Cabinet Departments and 12 other agencies and commissions regarding their NTTAA activities. 



\section{Fifth Annual Report to the Office of Management and Budget (OMB) on the Implementation of Public Law 104-113 and OMB Circular A-119}

\subsection{SCOPE}

This report covers fiscal year (FY) 2001 from October 1, 2000, through September 30, 2001. It describes the progress made by Federal agencies in implementing the National Technology Transfer and Advancement Act of 1995 (NTTAA) (P.L. 104-113) and OMB Circular A-119 (the Circular), through Agency use of voluntary consensus standards and participation in standardization activities. It highlights examples of the Agencies' interactions with private-sector voluntary consensus standards bodies, the Agencies' use of government-unique standards, and the activities of the Interagency Committee on Standards Policy (ICSP). It also discusses the National Institute of Standards and Technology's (NIST's) efforts to coordinate Federal agency standards-related activities including their interaction with key private-sector organizations. Appendices A and B provide copies of the reports that the 14 Cabinet Departments and 12 other Agencies or commissions submitted to NIST to comply with their obligations under the NTTAA. Appendices C and D provide copies of the ICSP Charter and a roster of the ICSP membership, respectively.

\subsection{FEDERAL STATUTES}

\subsection{National Technology Transfer and Advancement Act of 1995 (NTTAA) (P.L.} 104-113) - Section 12(d) of the NTTAA establishes the responsibility for Federal agencies to use national voluntary consensus standards wherever practical. It establishes agency reporting requirements and authorizes NIST to coordinate standards and conformity assessment activities between the Federal agencies and the private sector.

2.2 OMB Circular A-119 (the Circular) - The Circular provides guidance to Federal agencies to assist them with complying with their responsibilities under the NTTAA. On February 19, 1998, OMB revised its Circular A-119, Federal Participation in the Development and Use of Voluntary Consensus Standards and in Conformity Assessment Activities. The purposes of the revisions were "to make the terminology of the Circular consistent with P.L. 104-113, to issue guidance to Agencies on making their reports to $\mathrm{OMB}$, to direct the Secretary of Commerce to issue policy guidance for conformity assessment, and to make editorial changes for clarity. The Circular is reviewed every three years to determine if revisions are necessary to further improve implementation of the NTTAA.

\subsubsection{Use Of Voluntary Consensus Standards Versus Government-Unique}

Standards - The Circular directs Agencies to use voluntary consensus standards in lieu of government-unique standards in regulatory and procurement actions except where such use would be inconsistent with law or otherwise impractical. The policies in the Circular are intended to minimize the reliance of Federal agencies on government-unique standards. 
These policies do not create the basis for discrimination in Agency procurement or regulatory activities among standards developed in the private sector, whether or not voluntary consensus standards bodies develop them.

2.2.2 Conformity Assessment Guidance - The current Circular directed the Secretary of Commerce (the Secretary) to issue guidance to agencies on ways to coordinate their conformity assessment activities. Accordingly NIST, on behalf of the Secretary, published a notice of "final policy guidance" entitled, "Guidance on Federal Conformity Assessment Activities," in the Federal Register on August 10, 2000 (65 FR 48894-48902). This guidance document focuses on ways for Federal agencies to eliminate unnecessary duplication and complexity in their conformity assessment activities.

2.2.3 Other Issues Covered By The Circular - The current Circular also describes policies for Federal agency use of voluntary consensus standards and for participation of Federal agencies on voluntary consensus standards bodies. It further covers the procedures for managing and reporting Federal agency use of standards in procurement and regulations. The Circular also specifies the responsibilities of the Secretary of Commerce, NIST, Agency heads, and Agency Standards Executives in complying with the NTTAA.

2.2.3.1 Role of Secretary of Commerce and NIST - The NTTAA and the Circular assign several policy coordination and implementation tasks to the Secretary of Commerce (the Secretary) and NIST. Specifically, NIST must chair the Interagency Committee on Standards Policy (ICSP) and submit an annual report to OMB on Federal agency activities related to implementing the NTTAA and the Circular. The Secretary, as required every three years by OMB, must re-charter the ICSP. The Secretary did so on October 26, 2000 following the review of and comment on the charter by participating Agencies.

2.2.3.2 Role Of Agency Standards Executives - The Circular delineates the role of Agency Standards Executives particularly with regard to Agency-wide compliance with the NTTAA's legal requirements. The Standards Executive is responsible for coordinating Agency-wide standards-related activities, coordinating the implementation of the Circular, and serving on the ICSP.

\subsection{INTERAGENCY COMMITTEE ON STANDARDS POLICY (ICSP)}

3.1 Purpose - NIST established the ICSP in 1968 to encourage coordination and liaison among Federal agencies on matters related to standards. The Committee's primary mission is to coordinate Federal activities under NTTAA and the OMB Circular. A copy of the current ICSP Charter is found in Appendix C.

3.2 ICSP Leadership - The Deputy Director for Technology Services at NIST chairs the ICSP this year on behalf of the NIST Director and the Secretary of Commerce. The Chief of the NIST Standards Services Division serves as the vice-chair. 
3.3 ICSP Membership - The ICSP membership is composed of representatives of 14 Federal Cabinet Departments, 12 other Federal agencies and commissions, and two offices within the Executive Office of the President. A list of the ICSP membership can be found in Appendix D.

\subsection{HIGHLIGHTS OF ICSP ACTIVITIES}

4.1 General - The ICSP met four times in FY 2001. Even with a considerable amount of turnover in membership the member Agencies maintained good representation at the meetings. The Committee met to discuss a broad range of timely topics related to standards and conformity assessment activities within Federal agencies. Discussions focused on the annual reporting requirements for the NTTAA, educating and recruiting young people into careers involving standards development and management, and ongoing training needs for Federal agencies. Speakers addressed the Committee on subjects such as the Congressional perspective of the current status and future prospects for the NTTAA, and the high level of standards developing organization (SDO) involvement in the Department of Transportation's Intelligent Transportation Systems program. One of the four ICSP meetings was held jointly with the Government Member Council (GMC) of the American National Standards Institute (ANSI) and addressed several topics including initiatives for implementation of the National Standards Strategy.

4.2 OMB Circular A-119 Update - Paragraph 16 of the Circular requires a review of the Circular every three years. The ICSP conducted an internal review of the Circular this year because it was last revised in 1998. During the review, the ICSP identified a number of possible changes to the wording of the Circular that would clarify and simplify the Federal agency reporting requirements. However, after consulting with OMB, the ICSP agreed that the issues the members raised did not merit a full revision of the Circular. The Committee then decided that they would clarify reporting requirements within the ICSP through the distribution of an internal guidance memorandum to the members.

4.3 ICSP working groups - Due to the significant level of time and effort the Committee devoted to reviewing the Circular, the ICSP working groups did not experience the same level of activity this year as last. However, the ICSP did initiate a new workgroup, the Laboratory Accreditation and Conformity Assessment Working Group (LAWG). This new working group is chaired by NIST and will, among other things, advise the full Committee on the coordination of Agency laboratory accreditation activities within government and between government and the private sector. Future plans for the working group include sharing information on Federal agency implementation of the Federal Conformity Assessment Guidance issued by NIST in FY 2000 (65 FR 48894-48902). During the next fiscal year the ICSP plans to review the current slate of working groups. Those that are no longer relevant will be discontinued. 


\subsection{HIGHLIGHTS OF AGENCY ACTIVITIES}

5.1 Introduction. Many of the reporting Agencies continue their active participation in the standards development process on domestic and international levels. While the overall trend of Agency participation in standards development organization (SDO) activities has been downward in the past, this year Agency participation on SDO committees increased slightly. Several Agencies are working on a case-by-case basis with various SDOs to develop voluntary consensus standards that can be adopted in lieu of government-unique standards. This is something that the Department of Defense has been doing for sometime in the procurement area, and the Department continues to increase the amount of national consensus standards it lists for use. Other active Agencies, including GSA and GPO, are working with SDOs to review government procurement specification standards to facilitate replacing them with national standards during the procurement process.

The following paragraphs summarize highlights of activities reported by selected Agencies. Full reports for all Agencies reporting activities are contained in Appendices A and $\mathrm{B}$.

5.2 Department of Agriculture (USDA) - USDA employees participated in several international and domestic standards development organizations addressing the handling of meat products and seed development, including the United Nations/Economic Commission for Europe and the American Society for Testing and Materials (ASTM). USDA staff also participated in committee work of the International Organization for Standardization (ISO) in the areas of quality management and meat products. USDA was also represented in activities of the International Seed Testing Association (ISTA), serving on a task force committee to establish a performance based laboratory accreditation process for laboratory testing of seed samples for the presence of genetically engineered seeds.

5.3 Department of Commerce (DOC) - The Department of Commerce organized and conducted two workshops this past year. Both were well attended. The first, the NIST Centennial Standards Symposium, addressed achievements in standards from 1901 through 2001 and included several ICSP members on the Agenda. The second, a Conformity Assessment Workshop brought together attendees from the government, private industry and standards developing organizations to discuss significant activities in conformity assessment.

5.4 Department of Defense (DoD) - The Department of Defense continues to report stories of success in their efforts to improve the quality of materials and work practices in DoD. For example, the Navy realized that the repair of shipboard piping systems could offer a potential cost saving if new pipefitting technologies, such as the use of mechanically attached fittings (MAF), were developed. As a result, the Navy's MAF lifecycle manager chose to work with industry to develop a national voluntary consensus performance standard for MAF testing. The result was a flexible, but stringent, commercial performance standard, ASTM Standard F1387, Standard Specification for Performance of Mechanically Attached Fittings. 
5.5 Department of Education (DOED) - The U.S. Department of Education's National Center for Education Statistics (NCES) has been actively working with ANSI on developing Electronic Data Interchange (EDI) transaction sets. The work is being accomplished through staff participation on the Accredited Standards Committee (ASC) $\mathrm{X} 12$ to electronically convey administrative educational information between educational Agencies.

5.6 Department of Energy (DOE) - Several DOE facilities are now accredited under the National Institute of Standards and Technology's (NIST's) National Voluntary Laboratory Accreditation Program to perform calibrations in a variety of metrology parameters including dimensional, radiation, physical, and electrical metrology. DOE's Nuclear Weapons Program has been working with the National Cooperation for Laboratory Accreditation (NACLA) to change DOE's policies and procedures with regard to calibration laboratories whose data they accept. This DOE program can now rely on services provided by commercial calibration laboratories accredited by NACLArecognized accreditors.

5.7 Department of the Interior (DOI) - The Bureau of Land Management (BLM) has entered into agreements with State Historic Preservation Officers (SHPOs) to share standards information and data involved with cultural resources.

5.8 Environmental Protection Agency (EPA) - EPA's new standards web site will be completed shortly and will be the primary access point for the public regarding the Agency's voluntary standards activities. Case studies and success stories will be available on the web site, along with EPA standards policies and current news. The URL for the web site will be made available to OMB, Congress and the public as soon as it is established.

5.9 General Services Administration (GSA) - GSA reported a broad array of standards and conformity assessment activities that involved products such as hand tools and accessories, environmentally friendly adhesives, paints and coatings for architectural and aerospace uses, clean air requirements for shipbuilding and ship repair as well as aerospace manufacturing and repair facilities.

5.10 National Aeronautics and Space Administration (NASA) -. NASA has enhanced its use of voluntary consensus standards (VCS) through the web-based NASA Technical Standards System, which currently has the capability to provide full text standards (on-line or hard copy) to all NASA users, notification when standards are modified, and direct links on applicable standards to "lessons learned" and other recommendations for their use.

Statistics to date indicate increasing use of VCS with approximately 6,000 people (NASA and the public) registering in four months to access the system.

The Standards Update Notification System (SUNS) provides users with notices of updates (revisions, cancellations, superseded documents, etc.) to Technical Standards Products that 
NASA has identified as "in use" on their Programs/Projects. The System was made available Agency wide in October 2001.

5.11 National Archives and Records Administration (NARA) - The Deputy Archivist of the United States is actively involved in the development of an international standard addressing records management.

5.12 Nuclear Regulatory Commission (NRC) - In FY 2001, NRC took several actions to increase the effectiveness and efficiency of the process for implementing P. L. 104-113 and OMB Circular A-119. On January 17, 2001, NRC staff met with representatives from the standards development organizations (SDOs) that provide codes and standards for the nuclear industry. The NRC hosts these meetings on a semi-annual basis. The purpose of these meetings is to foster better communication and discuss standards under development, current needs and priorities.

In many cases, the Department of Energy (DOE) and the NRC interact with the same SDOs. Therefore, the NRC and DOE decided to co-host a meeting on standards development interaction and cooperation. This meeting was held on June 27, 2001. The joint meeting format proved to be very beneficial, and the meeting participants requested that NRC and DOE also co-host the next meeting. Hence, a subsequent NRC/DOEsponsored meeting was scheduled for January 2002.

\subsection{AGENCY USE OF GOVERNMENT-UNIQUE STANDARDS IN LIEU OF VOLUNTARY CONSENSUS STANDARDS}

6.1 Introduction - A total of ten Agencies reported using 54 government-unique standards in lieu of voluntary consensus standards. This is an increase of 38 standards over last year. Fifteen Agencies reported that they do not use government-unique standards in lieu of voluntary consensus standards.

NIST believes that the significant increase in fiscal year 2001 in reported usage of government-unique standards by the Agencies resulted from a better understanding of the NTTAA reporting requirements on the part of the agencies - not from an actual increase in the use of government-unique standards. Historical data presented in Table 2 (See Section 9.0) shows that numbers of government-unique standards used has fluctuated over the past several years. It is anticipated that this number will continue to fluctuate over the shortterm as the Agencies gain greater experience with and a better understanding of the NTTAA reporting requirements.

Many Agencies reported their continuing efforts to cooperate and work with interested parties, including the SDOs, to further reduce the need to use government-unique standards. This continued cooperation between the public and private sectors can result in a long-term, downward trend in the numbers of government-unique standards used in the Federal government's regulatory and procurement processes. 
6.2 Department of Defense (DoD) - Because of DoD initiatives such as MilSpec Reform that predate the onset of the NTTAA, the Department began replacing government-unique standards with voluntary consensus standards well before the first report of government standardization activities under the NTTAA was compiled for fiscal year 1997. Consequently, DoD has cumulatively adopted 9,069 standards, only a small portion of which is reported in Table 1 of this report. Further, since the Department of Defense has such a massive number of procurements based upon standards, the Department has chosen to report standards usage on a categorical basis. Rather than compile an itemized list of standards used in each individual procurement, DoD maintains a comprehensive list of standards that can be used in the Department's procurement specifications. The Department relies on MilSpecs and standards in lieu of voluntary consensus documents only when the requirement can be justified as truly military-unique, when a voluntary standard does not exist and development is not imminent, or when there is no industry interest to develop an appropriate voluntary standard.

6.3 Department of Energy (DOE) - The Department of Energy also chooses to report voluntary consensus standards usage on a categorical basis. Therefore, as explained above in paragraph 6.2, an itemized accounting of usage has not been reported, but standards listed for use are reported.

6.4 National Aeronautics and Space Administration (NASA) - Similar to DoD and DOE, the National Aeronautics and Space Administration also reports voluntary consensus standards usage on a categorical basis.

6.5 Department of Interior (DOI) - The Department of Interior reports the use of two government-unique standards in lieu of voluntary consensus standards. This is an increase of two over last year's report. The Bureau of Reclamation (BOR) is required to use the Metadata Standard developed by the U.S. Geodetic Survey for documenting information about all geospatial data including GIS. They also use a BOR Standard Specification for Corrugated Polyethylene Drainage Tubing rather than a voluntary consensus standard because current consensus standards do not ensure the quality of product they need to use.

6.6 Department of Labor (DOL) - The Department of Labor reports the use of three government-unique standards in lieu of voluntary consensus standards. This is an increase of three over last year's report. The Occupational Safety and Health Administration (OSHA) developed three government-unique standards this past year because there were no specific voluntary national consensus standards available at the time of the standards' development. OSHA developed standards for protecting workers in healthcare industries from needle sticks, for maintaining injury and fatality data, and for protecting workers during the erection of steel structures. OSHA developed its standards through prescribed rulemaking processes with the assistance of outside interested parties.

6.7 Environmental Protection Agency (EPA) - The Environmental Protection Agency reports the use of 36 government-unique standards in lieu of voluntary consensus standards. This is an increase of 34 over last year's report. Although EPA determined that 
the voluntary standards listed in their report are not practical for the purposes of the rules, EPA did not create any new government-unique standards. The government-unique standards listed by EPA were previously in effect, but unreported.

The general reason EPA did not use the reported voluntary consensus standards in lieu of the government-unique standards is that EPA believes that the voluntary consensus standards are not practical due to lack of equivalency, documentation, validation data and other important technical and policy considerations. EPA's rules go into more complete technical detail.

EPA reports the use of government-unique standards and the justification for not using potentially applicable voluntary standards as the basis of context. The Agency believes that the public standards developing organizations and industry need to know the context in which the Agency considers the use of a voluntary standard in order to understand the actions of the Agency. They also need to know the context in which EPA uses a voluntary standard in order to evaluate the potential of the standard for possible regulatory applications in future actions. The context will give standards developers a framework from which to consider updates of the standard. For example, industry may determine that use of a particular voluntary standard in regulatory actions is a prime driver for updating that standard, or it may determine that market needs are best served by having both the regulatory and the voluntary standard.

Given this explanation, EPA reserves the right to make the determination of context and to report, when appropriate, multiple rejections of a single VCS. In other cases, the reason for rejection of a VCS in separate rules is so similar in context and involves the same EPA Method, that the use of the government method and consequent rejection of the VCS is counted only once.

6.8 Government Printing Office (GPO) - The Government Printing Office reports the use of four government-unique standards in lieu of voluntary consensus standards. This is the same amount that was reported last year. The primary reason for GPO's continued use of the government standards is that the standards are referenced in contracts that will gradually be corrected in the future to recognize voluntary national consensus standards.

6.9 General Services Administration (GSA) - The General Services Administration reports the use of two government-unique standards in lieu of voluntary consensus standards. This is a decrease from four that were reported last year. GSA uses Federal Specification FF-L-2740 in lieu of UL 768 because the government-unique specification covers certain combination locks used for the protection of classified, national security information. In testing locks under the voluntary standard, GSA found that the locks did not provide the level of protection required by Federal agencies. GSA also uses Federal Specification KKK-A-1822E in lieu of ASTM F-2020 for the purchase of ambulances. They do this because F-2020-1 is currently under review and is being compared to KKKA-1822E. GSA expected the review to be completed in 2002. Once F-2020-1 is reviewed 
and found to be acceptable, it will be cited in future GSA procurements for ambulances in lieu of Federal specification KKK-A-1822E.

6.10 The Department of Health and Human Services (HHS) - The Department of Health and Human Services reports the use of one government-unique standard in lieu of voluntary consensus standards. This is an increase of one over last year's report. HHS uses the National Standard Format (NSF) in lieu of ANSI X12.837 because the NSF is used widely across the health care payment industry and has become a de facto national standard. However, the Centers for Medicare and Medicaid Services (CMS) have directed their contractors to discontinue use of the NSF standard and to replace it with ANSI X12 837 by the beginning of FY 2003.

\subsection{The Department of Housing and Urban Development (HUD) -}

The Department of Housing and Urban Development (HUD) reports the continued use of two government-unique standards in lieu of voluntary consensus standards. HUD reports that it uses 28 CFR 200.935 in lieu of ANSI A 119.1 for its Building-Product Standards and Certification Program. HUD also uses 28 CFR 3280 in lieu of ANSI 119.1 and NFPA 501C for its Manufactured Home and Construction Safety Standards. HUD's use of government-unique standards is necessary to provide specific HUD guidance not found in the voluntary consensus standards.

6.12 National Archives and Records Administration (NARA) - The National Archives and Records Administration reports the use of one government-unique standard in lieu of voluntary consensus standards. This is the same number reported last year. NARA continues to use a number of its own data standards because MARC, EAD, APPM, ISAD $(\mathrm{G})$, and ISAAR (CPF) standards do not meet the needs of the Agency. NARA prefers to use a normalized database approach because other approaches would be too limiting. However, NARA is continuing to bring their individual data elements guidance closer into line with the voluntary standards.

6.13 The Department of the Treasury (Treasury) - The Department of the Treasury reports the continued use of two government-unique standards in lieu of voluntary consensus standards. These are the same two standards reported last year. The customs brokerage industry continues to use the Customs and Trade Automated Interface Requirements (CATAIR) and some parties in the transportation section continue to use the Customs Automated Manifest Interface Requirements (CAMIR). The maintenance of these government-unique standards within Customs applications at Treasury is at the request of the participating industry groups that use those standards.

\subsection{CONCLUSIONS}

7.1 Membership -- The membership on the Interagency Committee on Standards Policy changed significantly during the reporting period. Several ICSP members have left their positions as Standards Executive or Representatives of Standards Executives due to retirements and career reassignments. However, in the midst of these changes, the 
Committee has been able to maintain a strong core of committed members who meet regularly for the purpose of completing the mission of the ICSP.

\subsection{Use of Voluntary Consensus Standards Instead of Government-Unique}

Standards - The number of new voluntary consensus standards substituted for government-unique standards declined from 537 in 2000 to 106 in 2001. This most likely reflects the declining number of government-unique standards needing to be replaced that remain in the government's inventory of standards. As Agencies continue to replace government-unique standards at a rate greater than the need to use them, eventually this number will approach its lower limit.

\subsection{Use of Government-Unique Standards Instead of Voluntary Consensus}

Standards - The number of government-unique standards used in lieu of voluntary consensus standards has risen since the Fourth Annual Report. A review of Table 1 shows the reason for the apparent increase in the use of government-unique standards to be attributed to a single Agency. However, this increase does not represent a shift by that Agency away from the practice of using voluntary consensus standards. Rather, it represents a more comprehensive reporting of government-unique standards already in use by the Agency thereby reflecting a greater Agency awareness of the reporting requirements.

7.4 Participation in Voluntary Consensus Committee Activities - The total number of Federal employees participating in voluntary consensus committee activities rose from 2,723 to 2,838 during fiscal year 2001. This is the first reported increase since these annual reports were initiated. At the same time, Federal agencies participated in 847 activities this year compared to 885 activities in 2000. The reported increase in Federal employee participation coupled with the decrease in agency-level participation most likely indicates a more focused approach to allocating agency resources. Employee participation seems to be directed more towards those voluntary consensus standards activities most directly related to on-going Agency standards projects, thus representing a greater awareness of the need to participate in activities relevant to the agency mission.

7.5 Use of Voluntary Consensus Standards -- As indicated by the data reported in Table 1, individual Agencies reported both significant increases and decreases in new uses of voluntary consensus standards (VCS). The cumulative figure shows a decrease in reported new VCS use government-wide. However, much of this decrease was not a result of an actual decline in new VCS use by Federal agencies. Instead, a considerable portion of the apparent decline resulted from of the inability of some Agencies to fully report for this category for FY 2001. It appears that internal reorganizations and personnel turnover affected the ability of a number of Agencies to both participate in and report on their activities in both standards usage and conformity assessment. Such internal changes seemed to affect mostly those Agencies that had only recently begun to make significant headway in organizing and managing their standards-related activities. 


\subsection{RECOMMENDATIONS}

8.1 Reporting Awareness - The ICSP discovered through the course of its ongoing discussions that there is far more positive activity taking place within the federal government with respect to the NTTAA and the Circular than is being reported. This is primarily due to a lack of awareness within various organizational levels of the Federal agencies about the NTTAA, its principles, and its reporting requirements. This lack of awareness causes relevant activities to go unrecognized as being applicable to NTTAA reporting requirements.

8.1.1 Federal agencies should consider placing additional emphasis on training appropriate personnel to increase their general awareness of the NTTAA, its principles, and its requirements.

8.1.2 NIST, with the cooperation of OMB, should conduct a joint NIST/OMB Workshop for new Agency standards development employees at least once a year that covers the reporting requirements under NTTAA and the Circular. Items to be covered during the workshop should include the basics of the NTTAA, the Circular, required reporting elements, definitions of terms, and the importance of timely and accurate reporting.

8.2 Turnover of ICSP Membership - It is ever more important for Federal agencies to recognize the dynamic nature of the Federal workforce and the constant need to review Agency assignments to the ICSP and other standards management positions. This is true for employees assigned as Standards Executives and their Representatives as well as for employees who serve as Agency representatives to standards developing organization committees.

8.2.1 Federal agencies should consider developing individual Agency plans to accommodate changes in personnel and their responsibilities, particularly where these responsibilities include representation in activities related to standards and conformity assessment.

8.3 Timeliness and Completeness of Reports - Some Federal agencies continue to experience a varying degree of difficulty in reporting their standards related activities to NIST in a complete and timely manner. By observation, NIST finds that the accuracy and timeliness of Agency reports varies in direct proportion to an agency's ability to systematically maintain data about its standards related activities. An ideal standards management mechanism would allow Agencies to report their significant activities on an almost instantaneous basis in contrast to having to exert significant effort to compile the required data at the end of each year.

8.3.1 NIST should work with the Agencies through the workshops recommended earlier to implement new or improve existing standards management systems to ensure timely and accurate reporting of standards related activities. 
8.3.2 NIST should consider the development of a web-based system similar to the current reporting system that would allow Agencies to continually update standards related activities at any time during the reporting year.

8.4 Clarification of Circular Language -- The ICSP subgroup tasked with reviewing the OMB Circular A-119 found that it is has become necessary to clarify the meaning of some of the language in the Circular

8.4.1 NIST, with input from the ICSP, should coordinate and develop a glossary of terms found to be unclear in the language of the Circular. 


\subsection{Tables and Charts}

\begin{tabular}{|c|c|c|c|c|c|c|c|}
\hline \multicolumn{8}{|c|}{$\begin{array}{l}\text { Table } 1 \text { - Federal Agency Information On Participation/Adoption Of Voluntarty } \\
\text { Standards Acivities Required by OMB Circular A-119 (Data as of 9/30/2001) }\end{array}$} \\
\hline Agency & \begin{tabular}{|c|} 
Government \\
Unique \\
Standards \\
Used In Lieu \\
Of VCS
\end{tabular} & $\begin{array}{c}\text { VCS } \\
\text { Substituted } \\
\text { for Govt. - } \\
\text { Unique } \\
\text { Standards }\end{array}$ & $\begin{array}{c}\text { VCS Used } \\
\text { in FY } \\
2001\end{array}$ & $\begin{array}{c}\text { Agency } \\
\text { Employees } \\
\text { Participating in } \\
\text { VCS Activities }\end{array}$ & $\begin{array}{l}\text { Change } \\
\text { From FY } \\
2000\end{array}$ & $\begin{array}{c}\text { VCS } \\
\text { Activities In } \\
\text { Which there } \\
\text { is Agency } \\
\text { Participation }\end{array}$ & $\begin{array}{l}\text { Change } \\
\text { From FY } \\
\quad 2000\end{array}$ \\
\hline USDA & 0 & 0 & 95 & 59 & 0 & 39 & 0 \\
\hline DOC & 0 & 0 & 3 & 440 & 0 & 168 & 0 \\
\hline DOD & - & 74 & 104 & 540 & 94 & 55 & -16 \\
\hline NCS & 0 & 0 & 0 & 10 & 0 & 18 & 0 \\
\hline ED & 0 & 0 & 17 & 2 & 2 & 1 & 1 \\
\hline DOE & - & 0 & 1,025 & 663 & -13 & 58 & -1 \\
\hline HHS & 1 & 1 & 578 & 281 & 40 & 57 & 11 \\
\hline HUD & 2 & 1 & 300 & 10 & 2 & 5 & -1 \\
\hline $\mathrm{DOI}$ & 2 & -- & -- & 69 & -- & 5 & 0 \\
\hline $\mathrm{DOJ}$ & 0 & 0 & 59 & 5 & 0 & 3 & 0 \\
\hline $\mathrm{DOL}$ & 3 & 0 & 125 & 76 & -13 & 35 & -46 \\
\hline DOS & 0 & 0 & 0 & 8 & 0 & 1 & 0 \\
\hline DOT & 0 & 8 & 246 & 177 & -34 & 168 & 22 \\
\hline TRES & 2 & 0 & 5 & 67 & 57 & 8 & 2 \\
\hline $\mathrm{VA}$ & 1 & 0 & 0 & 12 & 0 & 24 & -2 \\
\hline USAID & 0 & 0 & 0 & 0 & 0 & 0 & 0 \\
\hline CPSC & 0 & 1 & 1 & 31 & 3 & 9 & 1 \\
\hline EPA & 36 & 2 & 64 & 46 & 23 & 20 & 5 \\
\hline $\mathrm{FCC}$ & 0 & 0 & 0 & 5 & 0 & 1 & 0 \\
\hline FEMA & 0 & 0 & 0 & 7 & 0 & 4 & 0 \\
\hline FTC & 0 & 0 & 0 & 0 & 0 & 0 & 0 \\
\hline GSA & 2 & 19 & 25 & 41 & -6 & 107 & 26 \\
\hline GPO & 4 & 0 & 116 & 2 & 0 & 2 & -1 \\
\hline USITC & 0 & 0 & 0 & 1 & 0 & 1 & 0 \\
\hline NASA & - & 0 & 922 & 139 & -17 & 32 & -6 \\
\hline NARA & 1 & 0 & 0 & 5 & 0 & 6 & 0 \\
\hline NSF & 0 & 0 & 0 & 3 & 0 & 2 & -1 \\
\hline NRC & 0 & 0 & 64 & 139 & -2 & 18 & 0 \\
\hline OMB & 0 & 0 & 0 & 0 & 0 & 0 & 0 \\
\hline USPS & 0 & 0 & 0 & 0 & 0 & 0 & 0 \\
\hline USTR & 0 & 0 & 0 & 0 & 0 & 0 & 0 \\
\hline TOTAL & 54 & 106 & 3749 & 2838 & 136 & 847 & -6 \\
\hline
\end{tabular}


The data represented in Table 1 under the heading "VCS Used in FY2001" represents different interpretations of the term "use" by individual agencies. For example, some agencies reported only those VCS used for the first time in FY2001, while others reported the total number of VCS in use in FY2001. Due to the nature of their use of standards, agencies such as DoD and DOE maintain large inventories of standards they incorporate by reference. Therefore, these agencies only report the first time use or addition of a standard to their inventories. Other agencies report their use of a standard once in the year that the standard is first referenced and again in each subsequent year that the standard continues to be referenced.

A survey of agencies indicates a range of interpretations of the term "use." OMB Circular A-119 does not provide specific guidance on this issue. While it appears that individual agencies have reported consistently from year to year based on their own interpretation of the term "use," it is not possible to determine whether these differing interpretations have resulted in higher or lower reported use of voluntary consensus standards in this report, or in previous reports.

For future reports, NIST is working in conjunction with the Interagency Committee on Standards Policy to provide more specific guidance to Federal agencies regarding reporting on voluntary consensus standards use. Application of this guidance should result in cumulative data that is more reflective of the actual use of standards by Federal agencies during the reporting year.

\section{Table 2 Federal Agency Standards Substitutions}

\begin{tabular}{|c|c|c|}
\hline & $\begin{array}{c}\text { Number of VCS Substituted for } \\
\text { Government-Unique Standards }\end{array}$ & $\begin{array}{c}\text { Number of Government-Unique } \\
\text { Standards Used in Lieu of VCS }\end{array}$ \\
\hline 1997 & 187 & 7 \\
1998 & 146 & 4 \\
1999 & 542 & 88 \\
2000 & 537 & 16 \\
2001 & 106 & 54 \\
\hline Totals & 1,412 & 115 \\
\hline
\end{tabular}


Chart 1: Number of Voluntary Consensus Standards

Substituted for Government-Unique Standards

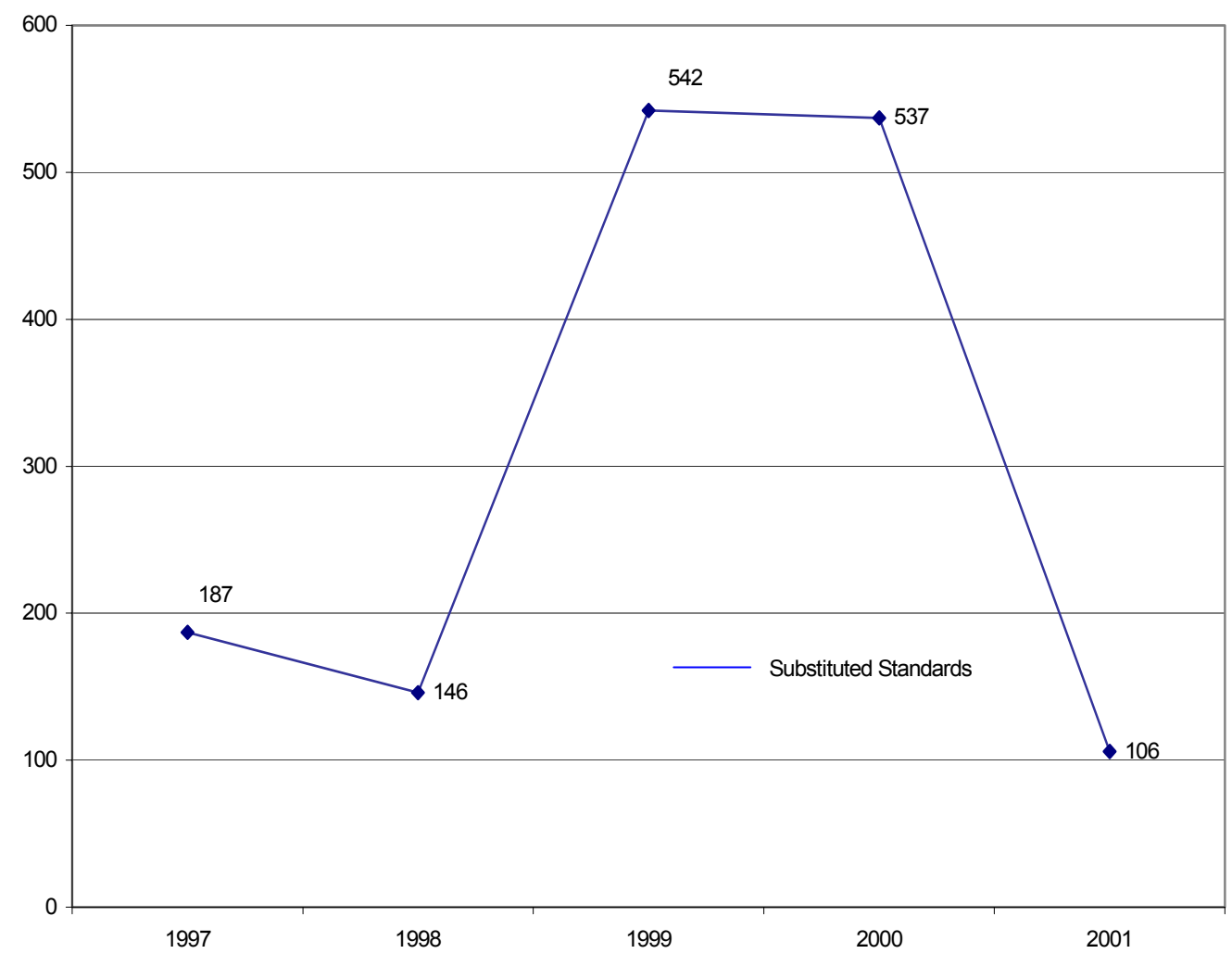

Chart 2: Number of Federal Agency Employees Participating in Voluntary Consensus Standards Activities

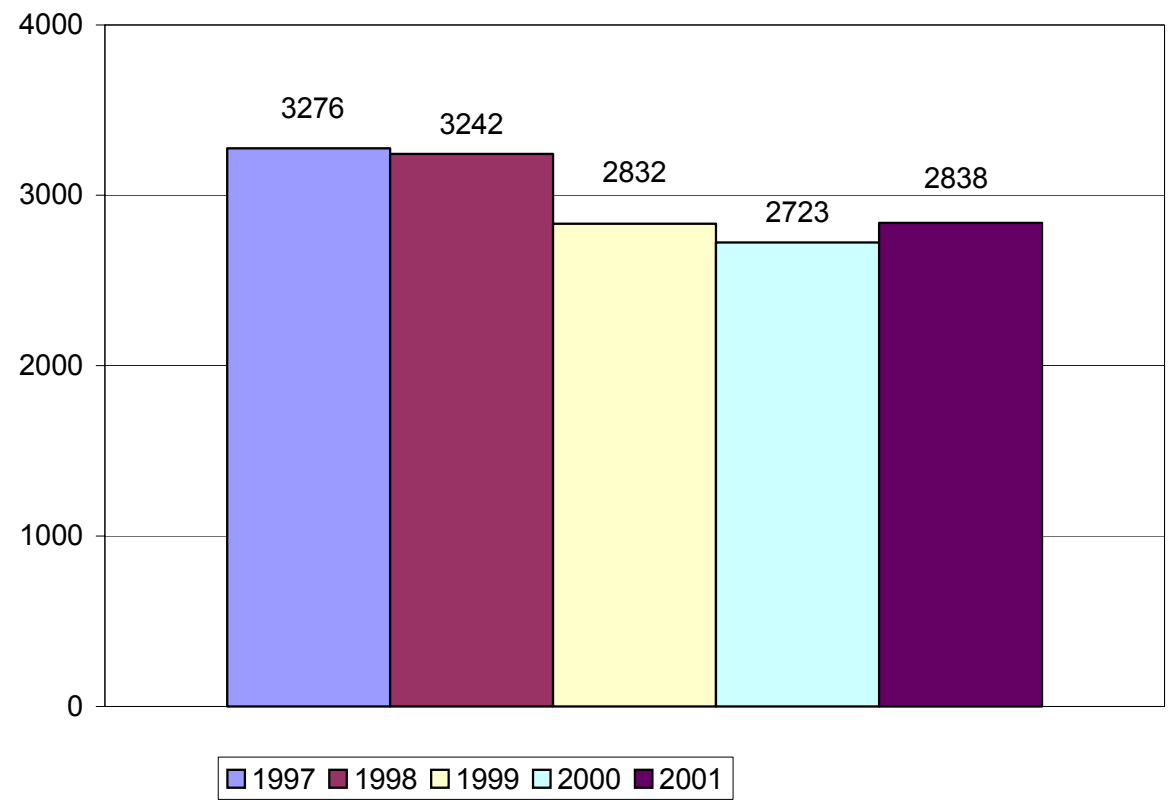


Chart 3: Number of Voluntary Consensus Standards

Bodies in Which Agencies Participate

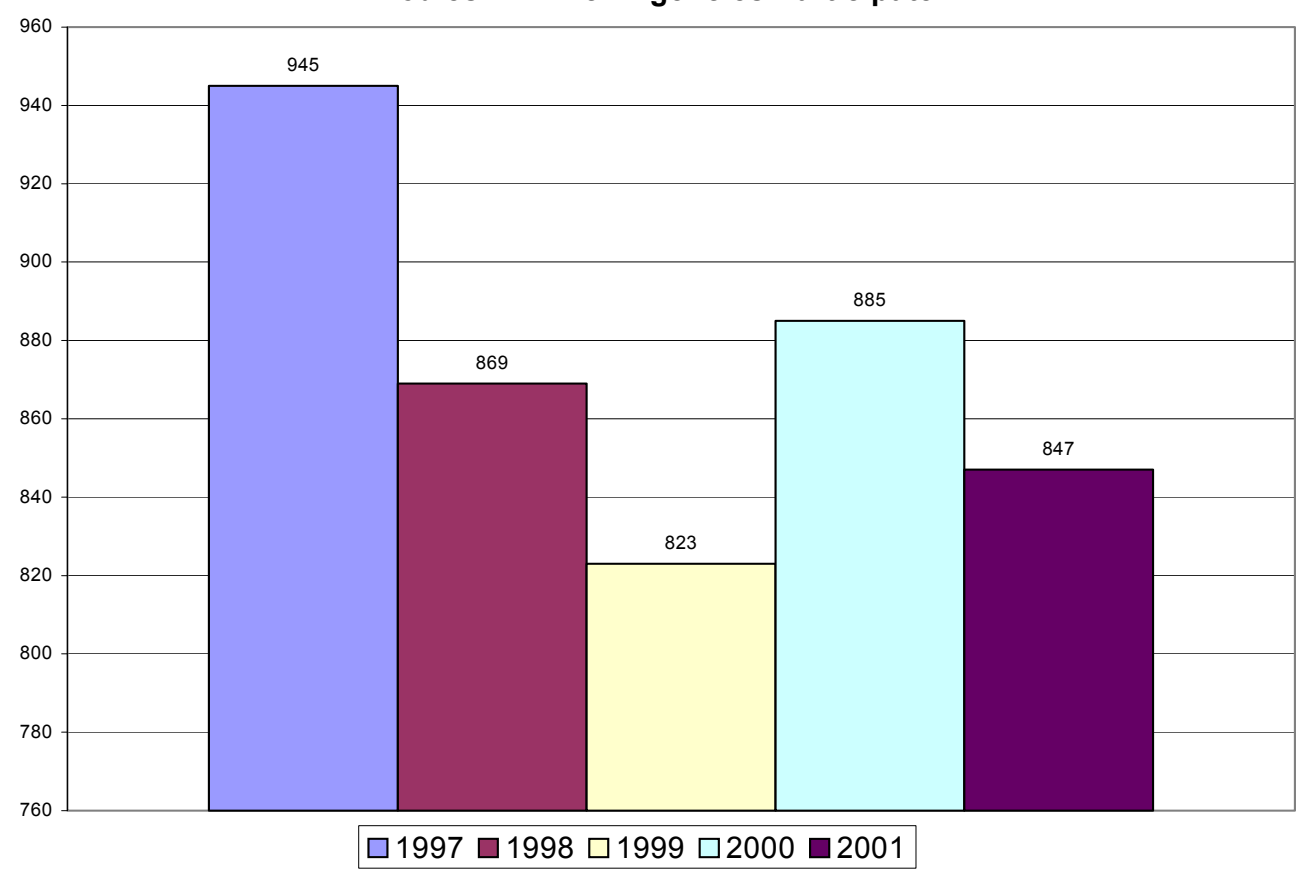

Chart 4: Number of Voluntary Standards "Used" by Federal Agencies

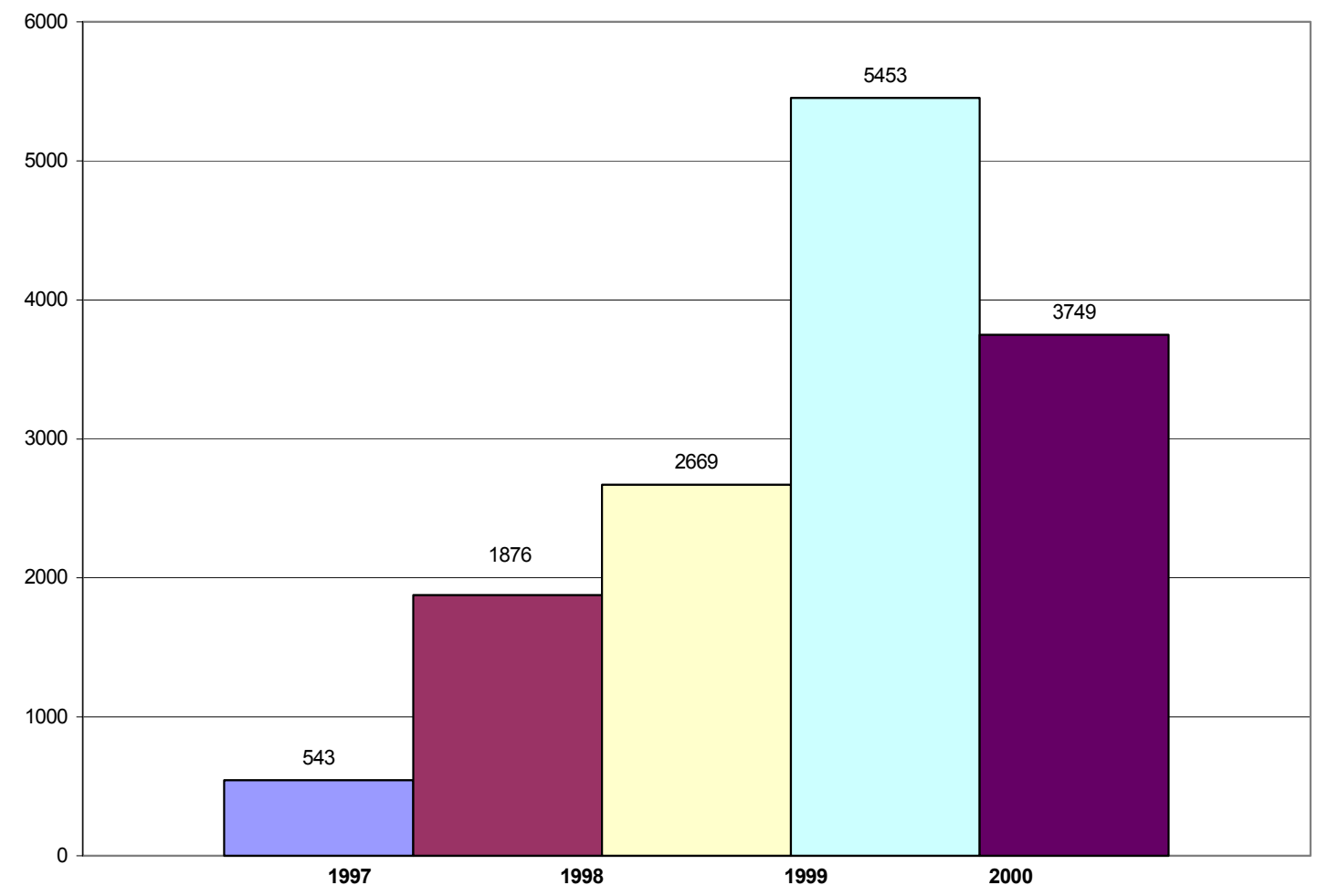




\section{Appendix A:}

\section{Cabinet Department Reports}




\section{DEPARTMENT OF AGRICULTURE (USDA)}

1. Number of Government Unique Standards Used in Lieu of Voluntary Standards

0

2. Number of Voluntary Consensus Standards Substituted for Government Unique Standards

0

3. Number of Voluntary Consensus Standards used in FY 2001

95

4. Number of Agency Employees Participating In Voluntary Consensus Standards Activities

59

5. Number of Voluntary Consensus Standards Bodies In Which There is Agency Participation

39

6. Provide an Evaluation of the Effectiveness of Circular A-119 Policy and

Recommendations for any Changes

USDA concurs that the standards policy stated in Circular A-119 is effective in reducing duplicate systems of standards. It effectively defines the role and coordinates the use of government-unique standards in the marketplace.

7. Provide the Conformity Assessment Activities in Which the Agency has been Involved

United Nations/Economic Commission for Europe Committee for Trade Industry and

Enterprise Development, Meeting of Experts for the Standardization of Meat, April 25-27, 2001 Geneva, Switzerland (finalized beef cutting and quality standard)

American Society for Testing and Materials (ASTM) International. ASTM is a voluntary standards development organization providing a forum for the development and publication of voluntary consensus standards for materials, products, systems, and services. Participated in the formation of ASTM Committee F10 on Livestock, Meat, and Poultry Evaluation Systems on July 11, 2001, and in the organizational meeting of ASTM Committee F10 on November 15 - 16, 2001. 
International Organization for Standardization (ISO) Technical Committee 176 for Quality Management and Quality Assurance. Livestock and Seed voted on numerous draft standards before the committee related to standardization in the field of generic quality management, quality systems, quality assurance, generic supporting technologies and the applied use of these standards.

ISO Technical Committee 34 for Food Products/Subcommittee 6 for Meat and Meat Products. This committee is administered by the U.S. Technical Advisory Group to TC34/SC6, which develops ISO standards in the field of meat and meat product foodstuffs, as well as sampling, methods of test and analysis, product specifications and requirements for packaging, storage, and transportation of meat and meat products.

International Seed Testing Association (ISTA). Participated in an ISTA study to determine if large lots of grass seeds are sufficiently homogenous to be shipped in international trade. Attended the 2001 ISTA Congress and served as the U.S. voting delegate. Served on the ISTA GMO Task Force Committee to establish a performance based laboratory accreditation process for laboratories testing seed samples for the presence of genetically engineered seeds.

Participated in an International Seed Testing Association (ISTA) study to determine if large lots of grass seeds are sufficiently homogenous to be shipped in international trade. USDA served as a technical assessor for an ISTA accreditation audit of a government seed laboratory in the United Kingdom.

8. Provide any Examples or Case Studies of Standards Successes

None reported.

\section{Comments}

Representatives of the Department of Agriculture participate in the following standards developing organizations:

3A Sanitary Standards Program

3A/NSF Meat and Poultry Equipment Standards

International Dairy Federation

Codex Committee on Milk and Milk Products

American Society for Testing Materials (ASTM)

International Standards Organization (ISO)

Universal Standards Agreement

United Nations Economic Commission for Europe (UNECE)

Standardization of Fresh Fruits and Vegetables

Standardization of Dry and Dried Fruit

Codex Committee on Fresh Fruits and Vegetables 
International Organization for Standardization (ISO) Technical Committee 176 for Quality Management and Quality Assurance

ISO Technical Committee 34 for Food Products/Subcommittee 6 for Meat and Meat

Products

International Seed Testing Association (ISTA)

Organization for Economic Co-operation and Development (OECD)

Accredited Standards Committee

American Wood Preservers' Association

Institute of Electrical \& Electronic Engineers

Insulated Conductors Committee and Subcommittee

National Rural Electric Cooperative Association

American Standards Institute

American Society of Civil Engineers

Insulated Cable Engineers Association

National Electric Codemaking Panel 16

T1 Telecommunications Committee

Water Environment Federation Small Systems Committee

AWWA Small Systems Committee

Engineers Joint Contract Document 


\section{DEPARTMENT OF COMMERCE (DOC)}

1. Number of Government Unique Standards Used in Lieu of Voluntary Standards 0

2. Number of Voluntary Consensus Standards Substituted for Government Unique Standards

0

3. Number of Voluntary Consensus Standards used in FY 2001

3

4. Number of Agency Employees Participating In Voluntary Consensus Standards Activities

440

5. Number of Voluntary Consensus Standards Bodies In Which There is Agency Participation

168

6. Provide an Evaluation of the Effectiveness of Circular A-119 Policy and Recommendations for Any Changes:

In compliance with OMB Circular A-119, a subgroup of ICSP representatives met several times during FY01 to prepare for the triennial review and update of the Circular. Over the course of several meetings, the subgroup raised a number of issues related to standards management and reporting guidance provided to Federal agencies in the Circular. However, after conferring with $\mathrm{OMB}$, a consensus was reached that, based on the nature of the comments raised, a revision of the Circular was not warranted. Instead, the ICSP would, if deemed necessary, draft a memorandum of clarification to provide clarifications for Federal agencies in those areas that were discussed during the subgroup meetings. To date, the ICSP has not found it necessary to exercise this option. Thus, the feeling of NIST is that Circular A-119 continues to serve as an effective policy document.

7. Provide the Conformity Assessment Activities in Which the Agency has been Involved:

NIST has evaluated and recognized the American National Standards Institute (ANSI) program to accredit private sector certifiers as competent to accredit Telecommunications 
Certification Bodies (TCBs) on behalf of NIST, in support of the Federal Communications Commission TCB program. NIST recommends accredited organizations to the FCC for designation as TCBs. This program operates in conformance ISO/IEC Guide 61, and accredits candidate TCBs to ISO/IEC Guide 65 and ISO/IEC 17025.

NIST's Standards Services Division (NIST/SSD) participates in the ANSI International Conformity Assessment Committee (ICAC), which serves as the U.S. Technical Advisory Group (TAG) to ISO's Council Committee on Conformity Assessment (CASCO). SSD staff participates in CASCO Working Group 25, on alignment of ISO/IEC 17025 with ISO 9000/2000; Working Group 22, on a code of good practice for conformity assessment, and Working Group 20, on the revision of ISO/IEC Guide 7 on the inclusion of conformity assessment requirements in standards. SSD staff also participates in working groups of the International Accreditation Forum (IAF).

NIST/SSD serves on the ANSI committee that is responsible for accrediting certification bodies and on the U.S. National Committee to the IECEE (IEC System for Conformity testing and Certification of Electrical Equipment), a worldwide scheme that allows manufacturers to obtain a test certificate from an approved U.S. National Certification Body (NCB) and to use this test report to obtain certification marks in other participating countries.

NIST/SSD also participates in the U.S Technical Advisory Group (TAG) to ISO TC 176, the ISO committee responsible for the development and maintenance of the ISO 9000 standards series and in American Society for Quality (ASQ) Z-1, the U.S. committee responsible for their adoption as U.S. national standards.

The Chief of NIST/SSD serves as the Chair of the ANSI-Registrar Accreditation Board (RAB) National Accreditation Program (NAP) Environmental Management Systems (EMS) Council. The Council is responsible for accrediting registrars that assess facilities for conformance to the ISO 14001 standard.

NIST/SSD has published a number of directories and reports on conformity assessmentrelated issues, including ten guides to various European Union (EU) directives to assist manufacturers in understanding the directives and a new edition of NIST SP 739, Directory of U.S. Private Sector Product Certification Program. NIST/SSD also maintains a website (http://www.ts.nist.gov/ca) that provides a one-stop-shopping source for information on various conformity assessment issues.

National Cooperation for Laboratory Accreditation (NACLA)

Section 12b of the National Technology Transfer and Advancement Act (NTTAA) of 1995 directed NIST to coordinate conformity assessment activities of Federal, state, and local entities to eliminate any unnecessary duplication of conformity assessment activities. In response, NIST has been a driving force behind the creation of NACLA. NACLA is composed of organizations in the United States, with observers from Mexico and Canada, that actively support development of a system for recognizing the competence of testing 
and calibration laboratories leading to worldwide acceptance of test and calibration reports from those laboratories. Concerned with costly, multiple, duplicate assessments, and the lack of domestic or international recognition of laboratory accreditations, the group has explored solutions that could lead the United States, and perhaps eventually its North American Free Trade Agreement (NAFTA) partners, toward the goal of having only one assessment of a laboratory in a given field of testing, based on internationally accepted procedures. The NACLA vision is for a U.S. laboratory accreditation system that achieves the following goals:

For the testing laboratory, a single accreditation in a given field of testing, with worldwide recognition of the laboratory's competence.

For the manufacturer/supplier, a test performed once, with worldwide acceptance.

For the acceptance body (that is a government agency or an industry specifier), an accreditation based on uniform criteria and intended to ensure that a laboratory is qualified to provide data of consistent quality.

NACLA made significant strides domestically and internationally during FY 2001 include the following.

On the domestic front, the Department of Energy's nuclear weapons laboratories changed their policies and procedures with regard to calibration laboratories whose data they accept. In the past, this unit of DOE conducted periodic audits of these laboratories in order to establish confidence in their competence. Under the new policy, DOE will rely on laboratories accredited by accreditation bodies recognized by NACLA. As a result of foregoing audits by DOE personnel, DOE will save thousands of dollars annually.

On the international front, NACLA and the Standards Council of Canada (SCC) signed a memorandum of understanding, whereby laboratories accredited by NACLA-recognized accreditation bodies are also recognized in Canada, and SCC-accredited laboratories are recognized by NACLA-recognized accreditation bodies.

NACLA also continued its work of evaluating seven accreditation bodies that have applied for NACLA recognition. Further, it conducted a training session for candidates wishing to be qualified for service on NACLA evaluation teams.

The Director of NIST/SSD is a member of the NACLA Operations Council and chairs the NACLA International Affairs Committee. Under the NIST-NACLA Memorandum of Understanding, signed July 2000, NIST recognizes NACLA as a suitable private sector alternative to NIST's National Voluntary Conformity Assessment System Evaluation (NVCASE) program. NIST relies on NACLA recognition of qualified accreditation bodies in support of NIST responsibilities as a designating authority under the U.S.European Union Mutual Recognition Agreement (MRA), the APEC Telecommunications MRA, and the CITEL MRA. A total of more than 100 laboratories have been designated 
as Conformity Assessment Bodies (CABs) under the provisions of the U.S.-EU and APEC MRAs, pursuant to this MOU.

National Voluntary Laboratory Accreditation Program - NIST/SSD's National Voluntary Laboratory Accreditation Program (NVLAP) operates in conformance with ISO Guide 58 and accredits calibration and testing laboratories to ISO/IEC 17025. NVLAP operates programs in support of several Federal agencies, including the Department of Energy, Nuclear Regulatory Commission, Food and Drug Administration, Department of Defense, Environmental Protection Agency, Federal Communications Commission; and in support of State and local governments.

National Information Assurance Partnership (NIAP) - To help consumers select commercial off-the-shelf IT products that meet their security requirements and to help manufacturers of those products gain acceptance in the global marketplace, NIST and the National Security Agency (NSA) have established a program under the National Information Assurance Partnership (NIAP) to evaluate IT product conformance to international standards. The program, officially known as the NIAP Common Criteria Evaluation and Validation Scheme for IT Security, or Common Criteria Scheme in abbreviated form, is a partnership between the public and private sectors.

NAIP assessment programs are based on national and international IT security standards and criteria. The initial assessment programs will focus on the testing and evaluation of commercial IT products; follow-on programs will address the assessment of IT systems and networks to support the system certification and accreditation processes. Present IT product testing programs under the NIAP Common Criteria Evaluation and Validation Program (see more at http://niap.nist.gov/cc-scheme/) and the NIST Cryptographic Module Validation Program (see http://csrc.nist.gov/cryptval/).

\section{Provide Any Examples or Case Studies of Standards Successes:}

In May 2001, NIST's Information Technology Laboratory (ITL) signed a Memorandum of Understanding with the Information Technology Industry Council (ITI) to fast track the Common Industry Format (CIF) for Usability Test Reports Standard through the National Committee for Information Technology Standards (NCITS). Two NIST researchers initiated and led the technical development work on this standard through the Industry Usability Reporting (IUSR) Project Workshops in an effort to increase the visibility of software usability. Prominent suppliers of software and representatives from large consumer organizations participate in the IUSR Project Workshops. After public review, the CIF standard was unanimously approved by NCITS at their November 2001 meeting. For additional information, see http://www.ncits.org/press/2001/CIFfasttrackpr.htm.

\section{Comments:}

\section{Department of Commerce (DOC)}


The DOC encourages its staff to participate in standards committee activities relating to the mission of the Department, subject to resource availability. Agency employees participate in the standards development activities of: (1) U.S. private sector standardization bodies; (2) local, state, and federal governments; and (3) both private and governmental (treaty and nontreaty) international standardization organizations. Standards of interest to the Department cover a broad range of technical areas including: (1) energy conservation, (2) information and computer technology, (3) telecommunications, (4) environmental safety and health, (5) meteorological work, and (6) a variety of other product sectors and fields of technology.

The Standards Committee Participation (SCP) Database in NIST/SSD is designed to collect and disseminate information on DOC staff participation in standards development activities. NIST publishes an annual directory containing statistics on all DOC standards committee participation, alphabetical listings of staff participants and standards organizations and committees, and a list of acronyms and abbreviations.

The DOC standards participant information contained in the SCP Database is divided into two parts -- NIST and other (non-NIST) DOC agencies. 440 DOC staff participated in the standards writing activities of 168 (113 national and 55 international) standards developing organizations. NIST had 389 participants in the activities of 135 standards organizations (92 national and 43 international). NIST participated on 441 committees and held 1,302 memberships on these committees. Twelve of the standards organizations in which NIST staff members participated had 20 or more NIST memberships. Fifty-one staff members of other DOC agencies participated in 49 committees of 33 standards organizations (21 national and 12 international). They held 92 memberships on those committees. Eight of those standards organizations had five or more other DOC participants.

The following organizations/agencies accounted for 61 percent (56) of the 92 other DOC committee memberships:

Organizations with Other DOC Members

American National Standards Institute International Organization for Standardization

NCITS (National Committee for Information Technology Standards)

Federal Committee for Meteorological Service and Supporting Research

International Telecommunication Union - Telegraph

Department of Defense/Federal Aviation

Administration/Department of Commerce

Telecommunications Industry Association

Department of State
Committee $\underline{\text { Memberships }}$ 
Listed below are 12 standards organizations and the American National Standards Institute (ANSI) in which NIST holds at least 20 committee memberships along with the exact number of committee memberships. The organizations/agencies accounted for 74 percent (964) of the 1,302 other DOC committee memberships:

Organizations with NIST Members

American Society for Testing and Materials

American National Standards Institute International Organization for Standardization Institute of Electrical and Electronic Engineers

American Society of Mechanical Engineers International Electrotechnical Commission

CIE (International Commission on Illumination)

NCITS (National Committee for Information Technology Standards)

CGPM (Conférence Générale des Poids et Mesures)

International Organization of Legal Metrology

Telecommunications Industry Association

American Concrete Institute

Telecommunications Industries of America
Committee Memberships

Total 985

\section{DOC AGENCIES (EXCLUDING NIST): SUMMARY OF STANDARDS- RELATED ACTIVITIES}

a. International Trade Administration (ITA) -- The ITA participates in 4 CODEX committees, 1 ICAO committee and one Committee of the U.S.-Russia Working Group Standards for Chemicals. This year, ITA's work in standards furthered toy safety standardization and international civil aviation standards adoption and acceptance worldwide.

b. National Oceanic and Atmospheric Administration (NOAA) -Standardization of data acquisition and data management practices is vital to the mission at NOAA. NOAA seeks to establish voluntary standards with selected industrial associations, academia, and national organizations of state and local governments (e.g., the American Association of State Climatologists), as well as through participation in professional societies (e.g., American Meteorological Society). All NOAA line organizations participate in standards development activities. In general, standards used in many NOAA activities are established in conjunction with other Federal agencies (e.g., 
DOD, Federal Aviation Administration, U.S. Department of Agriculture) either through joint participation in international organizations such as the World Meteorological Organization, or by means of bilateral and multilateral agreements with other nations. These standardization activities apply to all phases of environmental data acquisition, processing, and distribution.

National Telecommunications and Information Administration (NTIA) -- The NTIA contributes to the development and application of national and international telecommunication standards by participating and holding leadership roles in various voluntary standards committees at the national and international levels (e.g., Telecommunications Industry Association, International Telecommunication Union). These standards enhance the quality and reliability of the domestic telecommunications infrastructure, promote healthy competition in telecommunications products and services, and expand international trade opportunities for U.S. telecommunications firms.

Patent and Trademark Office (PTO) -- The PTO participates and contributes to the resolution of identified requirements for international standards, primarily through the Permanent Committee on Industrial Property Information of the World Intellectual Property Organization. PTO staff also participates in standardization activities of the International Patent Classification Union and the ANSI-Accredited Committee on Patent Standards.

Bureau of the Census -- DOC's Bureau of the Census is active in the development of standards and specifications for: (1) the capture and storage of geographic information in computer-readable formats along with metadata documenting the characteristics of those data; and (2) the definitions of statistical, economic, and geographic terms. The Census Bureau participated in the following groups in FY2000: Federal Geographic Data Committee -- various subcommittees and working groups; ANSI/NCITS-L1 Geographic Information Systems; ISO Technical Committee 211; Ad hoc Baseline Committee on the U.S. International Boundary; U.S.G.S. Spatial Data Transfer Standards (SDTS) Technical Review Board; International Cartographic Association, Commission on National and Regional Atlases; U.S.G.S. National Atlas of the United States Steering Committee; and the Open GIS Consortium (OGC).

\section{NATIONAL CENTER FOR STANDARDS AND CERTIFICATION $\underline{\text { INFORMATION (NCSCI) }}$}

NCSCI is the U.S. focal point for standards-related information at home and abroad; it provides information on U.S., foreign, regional, and international voluntary standards bodies, mandatory government regulations, and conformity assessment procedures for nonagricultural products. NCSCI maintains an extensive collection of reference materials, including U.S. military and other Federal Government specifications, U.S. industry and national standards, international standards, and selected foreign national standards. Staff members respond to requests for specialized standards information, arrange for translations of foreign standards and regulations, and disseminate information to U.S. industry 
concerning proposed foreign regulations and general standards issues. Also, two telephone hotlines provide weekly updates on draft European standards and on proposed foreign technical regulations that might significantly affect trade.

In direct response to U.S. obligations resulting from the World Trade Organization (WTO) Agreement on Technical Barriers to Trade (TBT Agreement) and the North American Free Trade Agreement (NAFTA), NCSCI serves as the U.S. national inquiry point responsible for responding to questions concerning U.S. standards, technical regulations and conformity assessment procedures. NCSCI also serves as the U.S. member of the International Organization for Standardization (ISO) Information Network (ISONET). NCSCI, with other national WTO and NAFTA inquiry points and ISONET members, is part of a network that regularly exchanges standards-related information and has access to foreign trade-related technical standards, regulations and conformity assessment procedures.

Signatories to the WTO TBT Agreement are required to notify the WTO Secretariat in Geneva of proposed technical regulations that could affect trade and provide a recommended 60 day comment period to allow other WTO Members to review and comment on the proposals. NCSCI staff receive copies of the one-page notifications and disseminates them through a web-based, free subscription service established in 2001 called Export Alert! NCSCI also acquires the full text of the proposed technical regulations from the relevant foreign inquiry point. NCSCI staff is also responsible for notifying the WTO Secretariat of proposed U.S. technical regulations that may affect trade.

\section{FEDERAL INFORMATION PROCESSING STANDARDS (FIPS)}

Under the Information Technology Management Reform Act (Public Law (P.L.) 104-106), the Secretary of Commerce approves standards and guidelines that are developed by NIST for Federal computer systems. Under section 513 of the Information Technology Management Reform Act of 1996 and the Computer Security Act of 1987, P.L. 104-106, NIST develops standards, guidelines, and associated methods and techniques for federal computer systems, including those needed to ensure the cost-effective security and privacy of sensitive information in federal computer systems, when there are compelling federal requirements and there are no existing voluntary industry standards. These standards and guidelines are issued by NIST as FIPS for use Government-wide. FIPS address federal requirements for the interoperability of different systems, for the portability of data and software, and for computer security. When FIPS are considered necessary, NIST announces proposed FIPS in the Federal Register for public review and comment.

During FY 2001, NIST made the following FIPS announcements:

January 2001 - NIST published for comment a draft Federal Information Processing Standard for the Keyed-Hash Message Authentication Code (HMAC). The draft specifies 
an algorithm for applications requiring message authentication. It allows for authentication of both the source of a message and its integrity.

February 2001 - NIST announced it was soliciting public comments on Draft FIPS 197, the Advanced Encryption Standard. The AES algorithm is a symmetric block cipher that can encrypt (encipher) and decrypt (decipher) information. Encryption converts data to an unintelligible form called cipher text; decrypting the cipher text converts the data back into its original form, called plaintext.

June 2001 - NIST announced the Draft Federal Information Processing Standard (FIPS) 180-2, Secure Hash Standard (SHS), for public review and comment. This standard specifies a Secure Hash Algorithm (SHA-1) that is required for use with the Digital Signature Algorithm (DSA) as specified in the Digital Signature Standard (DSS) and whenever a secure hash algorithm is required for federal applications.

July 2001 - NIST announced proposed changes to FIPS 186-2, Digital Signature Standard (DSS) and request for public comments. This standard specifies a suite of algorithms that can be used to generate a digital signature.

Federal Register: June 27, 2001 (Volume 66, Number 124)

This notice announced FIPS 140-2, Security Requirements for Cryptographic Modues, a standard that will be used by Federal organizations when these organizations specify that cryptographic-based security systems are to be used to provide protection for sensitive or valuable data. 


\title{
DEPARTMENT OF DEFENSE (DoD)
}

1. Number of Government Unique Standards Used in Lieu of Voluntary Standards

The Department of Defense reports voluntary consensus standards usage on a categorical basis; therefore, this information is not available.

2. Number of Voluntary Consensus Standards Substituted for Government Unique Standards

74

\begin{tabular}{l}
\multicolumn{1}{c}{$\begin{array}{c}\text { Voluntary } \\
\text { Standard }\end{array}$} \\
SAE-MA14489 \\
SAE-MA14298 \\
SAE-MA14242 \\
SAE-J2363 \\
SAE-AS92001 \\
SAE-AS91001 \\
SAE-AS51007 \\
SAE-AS29561 \\
SAE-AS29513 \\
SAE-AS29512 \\
SAE-AS28772 \\
SAE-AS27196 \\
SAE-AS27194 \\
SAE-AS5877 \\
SAE-AS5201 \\
SAE-AMS-STD-184 \\
SAE-AMS-STD-182 \\
SAE-AMS-QQ-A-367 \\
SAE-AMS-QQ-N-290 \\
NEMA-WC27500 \\
NASM91524 \\
NASM28728-5 \\
NASM28728-4 \\
NASM28728-3 \\
NASM28728-2 \\
\end{tabular}

\author{
Government \\ Standard
}

DS14489

DS14298

DS14242

A-A-52306A

MS9200C

MS9100B

MS51007C

MS29561A

MS29513C

MS29512C

MS28772

MS27196B

MS27194

MIL-N-5877E

AND10052

FED-STD-185A

FED-STD-182B

QQ-A-367H

QQ-N-290A

MIL-DTL-27500H

MS91524E

MIL-D-28728/5B

MIL-D-28728/4B

MIL-D-28728/3A

MIL-D-28728/2B 


$\begin{array}{ll}\text { NASM28728-1 } & \text { MIL-D-28728/1B } \\ \text { NASM28728 } & \text { MIL-D-28728B } \\ \text { NASM27976 } & \text { MS27976E } \\ \text { NASM27120 } & \text { MS27120A } \\ \text { NASM21384 } & \text { MS21384E } \\ \text { NASM5501-32 } & \text { MIL-PRF-5501/32A } \\ \text { NASM3926-4 } & \text { MIL-K-3926/4 } \\ \text { NASM3826-2 } & \text { MIL-K-3926/2A } \\ \text { ASTM-D6576 } & \text { MIL-R-6130C } \\ \text { ASTM-C1289 } & \text { HH-I-1972 } \\ \text { SAE-MA14272 } & \text { DS14272 } \\ \text { SAE-MA14241 } & \text { DS14241 } \\ \text { SAE-J2362 } & \text { A-A-52039B } \\ \text { SAE-AS90991 } & \text { MS9099C } \\ \text { SAE-AS35769 } & \text { MS35769B } \\ \text { SAE-AS29561 } & \text { MS29561A } \\ \text { SAE-AS28778 } & \text { MS28778C } \\ \text { SAE-AS27198 } & \text { MS27198B } \\ \text { SAE-AS27197 } & \text { MS27197B } \\ \text { SAE-AS27195 } & \text { MS27195A } \\ \text { SAE-AS9881 } & \text { MS9881B } \\ \text { SAE-AS9374 } & \text { MS9374A } \\ \text { SAE-AS5201 } & \text { MS33677A } \\ \text { SAE-AMS-HH-G-101 } & \text { HH-G-101E } \\ \text { SAE-AMS-STD-184 } & \text { FED-STD-184B } \\ \text { SAE-AMS-STD-66 } & \text { FED-STD-66D } \\ \text { SAE-AMS-QQ-C-320 } & \text { QQ-C-320B } \\ \text { SAE-AMS-I-23053/3 } & \text { MIL-I-23053/3A } \\ \text { SAE-AMS-23053/2 } & \text { MIL-I-23053/2C } \\ \text { NASM91525 } & \text { MS91525F } \\ \text { NASM91522 } & \text { MS91522A } \\ \text { NASM90120 } & \text { MS90120C } \\ \text { NASM51939 } & \text { MS51939A } \\ \text { NASM51929 } & \text { MS51929A } \\ \text { NASM28728-8 } & \text { MIL-D-28728/8B } \\ \text { NASM28728-7 } & \\ \text { NASM28728-6 } & \end{array}$


NASM21387

NASM21382

NASM5501-31

NASM3926-3

NASM3926-1

ASTM-F2087

ASTM-F1604

ASTM-E2073

ASTM-E2072

ASTM-E2030

ASTM-E786

ASTM-D3128
MS21387E

MS21382E

MIL-PRF-5501/31A

MIL-K-3826/3A

MIL-K-3926/1A

MIL-P-70343

A-A-50183

MIL-L-3891B

MIL-L-3891B

MIL-L-3891B

NNN-D-345A

O-E-780B

3. Number of Voluntary Consensus Standards used in FY 2001

104

4. Number of Agency Employees Participating In Voluntary Consensus Standards Activities

540

5. Number of Voluntary Consensus Standards Bodies In Which There is Agency Participation

55

6. Provide an Evaluation of the Effectiveness of Circular A-119 Policy and Recommendations for any Changes

The current OMB Circular A-119 provides clear guidance on using voluntary consensus standards and participating in voluntary consensus standards bodies. As written, this Circular reinforces our DoD policies regarding use of voluntary standards, reliance on performance documents, and encouragement of participation in voluntary standards bodies. We believe the Circular's plain language format greatly enhances its effectiveness. The Department does not believe additional changes are required at this time.

7. Provide the Conformity Assessment Activities in Which the Agency has been Involved N/A

8. Provide any Examples or Case Studies of Standards Successes 


\section{CASE STUDY}

\section{Mechanically Attached Pipe Fittings}

Following the end of the Cold War, the Navy sought to lower the cost of maintenance while maintaining fleet material readiness. Repair of shipboard piping systems offered potential cost savings. In the 1980s, a new pipefitting technology, the mechanically attached fitting (MAF), was developed, promising substantial improvements over other existing pipe-joining technologies such as welding and brazing. The Navy needed proof that MAFs could provide the same or better integrity than brazing or welding before authorizing their use in the fleet. The Navy needed a universal test standard to ensure it would get the best fitting at the best price for a given application. The Navy had a choice; it could write a military product standard(s) for one or more of the already approved MAF types or it could write a universal performance standard for testing that would apply to all current and future MAF products. Developing a universal test standard would be a more difficult task as it would need to address all of the differing MAF technologies and would require reaching consensus on acceptable test procedures among all the MAF manufacturers. Developing new military specifications for MAFs, while offering an easier solution, had the potential of limiting competition, proliferating military documents, and possibly discouraging innovation. The Navy's MAF life-cycle manager chose to work with industy to develop a voluntary consensus performance standard for MAF tesing. The approach prevailed because increasing competition, stimulating innovation, and helping drive down unit costs outweighed the added effort to reach consensus on a voluntary consensus standard.

\section{Comments}

At the last ICSP meeting there was some discusion about including the addresses of NGSBs with DoD participants. The following is our list:

Aerospace Industries Association

Air Conditioning \& Refrigeration Institute

Air Movement and Control Association

Alliance for Telecommunications Industry Solutions

Aluminum Association

American Architectural Manufacturers Association

American Association of Textile Chemists and Colorists

American Bearing Manufacturers Association

American Boat and Yacht Council

American Concrete Institute

American Conference of Governmental Industrial Hygienists

American Dental Association

American Gear Manufacturers' Association

American Hardboard Association

American Industrial Hygiene Association 
American Institute of Aeronautics and Astronautics

American Institute of Steel Construction

American Institute of Timber Construction

American Leather Chemists Association

American National Metric Council

American National Standards Institute

American Petroleum Institute

American Railway Engineering \& Maintenance-of-Way Assoc

American Society for Nondestructive Testing

American Society For Quality

American Society for Testing and Materials

American Society of Cinematographers

American Society of Civil Engineers

American Society of Heating, Refrigerating, and Air-Conditioning Engineers

American Society of Mechanical Engineers

American Society of Sanitary Engineering

American Water Works Association

American Welding Society

American Wood Preservers Association

Architectural Woodwork Institute

Association for Information and Image Management

Association for the Advancement of Medical Instrumentation

BOCA International Contact:

Builders Hardware Manufacturers Association

Canadian General Standards Board

Cast Iron Soil Pipe Institute

Compressed Gas Association

Construction Specifications Institute

Construction Specifications Institute

Cooling Technology Institute

Cordage Institute

Data Interchange Standards Association, Inc.

Deep Foundations Institute

Electrical Generating Systems Association

Electronic Components Assemblies \& Materials Association

Electronic Industries Alliance

Electrostatic Discharge Association

Government Electronics \& Information Technology Association

Graphic Communications Association

Hardwood Plywood \& Veneer Association

High Frequency Industry Association

Human Factors and Ergonomics Society, Inc.

Illuminating Engineering Society of North America

Information Technology Industry Council

Institute for Interconnecting and Packaging Electronic Circuits 
Institute of Clean Air Companies

Institute of Electrical and Electronics Engineers

Institute of Environmental Sciences \& Technology

Insulated Cable Engineers Association

International Alliance for Interoperability

International Association of Plumbing and Mechanical Officials

International Electrotechnical Commission

International Organization For Standardization

Internet Engineering Task Force

Joint Electron Device Engineering Council

Magnetic Materials Producers Association

Manufacturers Standardization Society of the Valve and Fittings Industry

Master Painters Institute

NACE International

National Association of Architectural Metal Manufacturers Sisco

National Association of Relay Manufacturers

National Fire Protection Association

National Fluid Power Association

National Hardwood Lumber Association

National Information Standards Organization

National Institute of Building Sciences

National Petroleum Management Association

NSF International

Parachute Industry Association

Plumbing and Draining Institute

Plumbing-Heating-Cooling Contractors Association

Quarter-Inch Cartridge Drive Standards, Inc.

Resistance Welders Manufacturers Association

Rubber Manufacturers Association

Scientific Apparatus Makers Association

Sheet Metal \& Air Conditioning Contractors Nat'l. Assoc.

Simulation Interoperability Standards Organization

Society for Protective Coatings

Society of Allied Weight Engineers

Society of Automotive Engineers

Standards Engineering Society

Steel Door Institute

Steel Founders Society of America

Steel Window Institute

The Open Group

The Soap and Detergent Association

The Tire and Rim Association, Inc.

TIA

Truck Trailer Manufacturers Association 
UN Centre for Facilitation of Procedures \& Practices for Administration, Commerce e \& Transport

Underwriters Laboratories

VITA Standards Organization

Western Wood Products Association

Window and Door Manufacturers Association

Workflow Management Coalition

World Wide Web Consortium 


\section{DEPARTMENT OF DEFENSE (DoD)}

\section{National Communications System (NCS)}

1. Number of Voluntary Consensus Standards Bodies in Which There is Agency Participation:

18

2. Number of Agency Employees Participating in Voluntary Consensus Standards Activities:

10

3. Number of Voluntary Consensus Standards Used in FY 2000:

0

4. Number of Voluntary Consensus Standards Substituted for Government-Unique Standards:

0

5. Number of Government-Unique Standards Used in Lieu of Voluntary Standards:

0

6. Provide an Evaluation of the Effectiveness of Circular A-119 Policy and Recommendations for Any Changes:

N/A

7. Provide the Conformity Assessment Activities in Which the Agency has been Involved:

N/A

8. Provide Any Examples or Case Studies of Standards Successes:

N/A

9. Comments: 
Within the NCS, the Chief, Technology and Programs Division also chairs the Federal Telecommunications Standards Committee (FTSC). As part of these duties, the Chief is the focal point for telecommunications and related information system standards for the Office of the Manager, National Communications System (OMNCS).

The FTSC prepares standards and recommendations on matters affecting national security and emergency preparedness (NS/EP) and in other areas of communications approved by the committee on the basis of requests from members. It also provides advice to members on how to best represent the Government's NS/EP interests in work in industry and international standards committee.

The FTSC and members of the OMNCS work extensively with voluntary standards organizations to ensure that Government requirements are considered as the standards are developed. The OMNCS has 10 employees who participate in industry voluntary standards activities. The following paragraph lists the committees in which they participate.

Staff of the OMNCS participates in the following voluntary standards related committees:

Organizations Accredited by the American National Standards Institute (ANSI):

- Committee T1, Telecommunications, and its technical subcommittees

- Telecommunications Industry Association (TIA) committees TR-41, TR45, and TR-46

- Institute of Electrical and Electronics Engineers (IEEE)

Commercial and Multi-National Organizations Not Accredited by ANSI:

- $\quad$ ATM Forum

- Internet Engineering Task Force (IETF)

- Network Interconnection Interoperability Forum (NIFF)

- Telecommunications and Internet Protocol Harmonization Over Networks (TIPHON)

- TeleManagement Forum

- Electronic Communications Implementation Committee (ECIC) Federal, State, and Local Committees

- Federal Telecommunication Standards Committee (OMNCS furnishes Chair and Executive Secretary)

- International Telecommunications Advisory Committee and its study groups (Department of State)

- Multiservice Switching Forum (MSF)

- Parlay Group Inc. (for Application Programming Interfaces)

- Mobile Wireless Internet Forum (MWIF)

- International Multimedia Telecommunications Consortium (IMTC) 
- Distributed Management Task Force (DMTF)

International Organizations:

- International Telecommunications Union-Telecommunications Sector (ITU-T) (OMNCS heads U.S. delegations to 3 study groups)

- International Telecommunications Union-Radio Sector (ITU-R) 


\section{DEPARTMENT OF EDUCATION (DOED)}

1. Number of Government Unique Standards Used in Lieu of Voluntary Standards 0

2. Number of Voluntary Consensus Standards Substituted for Government Unique Standards

0

3. Number of Voluntary Consensus Standards used in FY 2001

17

4. Number of Agency Employees Participating In Voluntary Consensus Standards Activities

2

5. Number of Voluntary Consensus Standards Bodies In Which There is Agency Participation

1

6. Provide an Evaluation of the Effectiveness of Circular A-119 Policy and

Recommendations for any Changes

None

7. Provide the Conformity Assessment Activities in Which the Agency has been Involved

None

8. Provide any Examples or Case Studies of Standards Successes

None

9. Comments

Since 1989, The U.S. Department of Education's National Center for Education Statistics (NCES) has been actively working with the American National Standards Institute (ANSI) on developing Electronic Data Interchange (EDI) transaction sets 
through the Accredited Standards Committee (ASC) X12 committee to electronically convey administrative educational information between educational agencies.

This effort is now known as the Standardization of Postsecondary Education Electronic Data Exchange (SPEEDE) and Exchange of Permanent Records Electronically for Students and Schools (ExPRESS) Project. SPEEDE/ExPRESS represents the combined efforts of many organizations focused upon the development of ANSI ASC X12 Electronic Data Interchange Standards for Education. For more information, please visit http://nces.ed.gov/edi/speedeExp.asp

The following are ANSI Transaction Sets that are of interest to the Educational Community. Each of the transaction sets described below should be wrapped in electronic envelopes that provide routing, time stamp, and security information. These envelopes consist of the ISA/IEA and GS/GE Control Segments. In addition to the transactions sets listed, Transaction Set 997 - Functional Acknowledgment is an integral part of the EDI process. For more information, please visit http://nces.ed.gov/edi/tstable.asp

Transaction Sets Relating to Individual Student Records

* TS 130 - Student Educational Record (Transcript)

* TS 131 - Student Educational Record (Transcript) Acknowledgment

* TS 138 - Testing Results Request and Report

* TS 146 - Request for Student Educational Record (Transcript)

* TS 147 - Response to Request for Student Educational Record (Transcript)

* TS 189 - Application for Admission to Educational Institutions

* Implementation Guides are available at http://nces.ed.gov/edi/IGs.asp

Transaction Sets Relating to Human Resource Data

* TS 132 - Human Resource Information

Transaction Sets Relating to Student Financial Aid Records

* TS 135 - Student Loan Application

* TS 139 - Student Loan Guarantee Result

* TS 144 - Student Loan Transfer and Status Verification

* TS 190 - Student Enrollment Verification

* TS 191 - Student Loan Pre-Claims and Claims

Transaction Sets Relating to Institutional Records

* TS 133 - Educational Institution Record

* TS 152 - Statistical Government Information used to transmit CCD, IPEDS and Library surveys to NCES

* TS 188 - Educational Course Inventory 


\section{DEPARTMENT OF ENERGY (DOE)}

1. Number of Government Unique Standards Used in Lieu of Voluntary Standards 0

2. Number of Voluntary Consensus Standards Substituted for Government Unique Standards

0

3. Number of Voluntary Consensus Standards used in FY 2001

1,025

4. Number of Agency Employees Participating In Voluntary Consensus Standards Activities

663

5. Number of Voluntary Consensus Standards Bodies In Which There is Agency

Participation

58

6. Provide an Evaluation of the Effectiveness of Circular A-119 Policy and

Recommendations for any Changes

The guidance in OMB Circular A-119 appears to be sufficient in terms of outlining the basic functions and responsibilities of Federal agency standards management and standards participation activities. It allows sufficient latitude for each Federal agency to develop its own approach tailored to specific agency needs, and places the emphasis on outcomes rather than processes. Some simplification and clarification of "use" and transactional and categorical reporting may be necessary.

7. Provide the Conformity Assessment Activities in Which the Agency has been Involved

National Voluntary Laboratory Accreditation Program (NVLAP); Department of Energy Laboratory Accreditation Program (DOELAP); National Cooperation for Laboratory Accreditation (NACLA); DOE Voluntary Protection Program (VPP); and assessment, certification, and testing done under DOE Topical Committees (TCs), including the Metrology TC, Accreditation TC, Environmental Management Systems TC (EMS TC), Quality Assurance Special Interest Group/Topical Committee (QA SIG 
TC), High Efficiency Particulate Air (HEPA) Filter Qualification Testing /HEPA TC, Biota Dose Assessment Topical Committee (BDATC), and Meteorology TC.

\section{Provide any Examples or Case Studies of Standards Successes}

The Department of Energy (DOE) is involved in several conformity assessment activities, including:

National Voluntary Laboratory Accreditation Program (NVLAP) - DOE facilities, including Sandia National Laboratories, Pacific Northwest National Laboratory, Honeywell Federal Manufacturing and Technologies, Bechtel BWXT Idaho, and Oak Ridge Metrology Center, are accredited under National Institute of Standards and Technology (NIST) NVLAP to perform calibrations in a variety of metrology parameters, including dimensional, radiation, physical, and electrical metrology. The scope of accreditation of each laboratory can be obtained from the NVLAP web site located at http://ts.nist.gov/ts/htdocs/210/214/214.htm.

Department of Energy Laboratory Accreditation Program (DOELAP) - Through DOELAP, DOE establishes specific performance testing requirements and site assessment criteria for accreditation of DOE personnel dosimetry systems and radiobioassay. DOELAP incorporates standards (including ISO/IEC Guide 25, General Requirements for the Competence of Calibration and Testing Laboratories, Health Physics Society (HPS) Standards, and DOE Technical Standards), establishes DOE organizational responsibilities and accreditation processes, and establishes procedures for administering DOELAP and for acquiring accreditation. DOELAP evaluates the respective DOE personnel dosimetry or radiobioassay program's laboratory performance, based on performance testing criteria, and their operational competence, based on established "quality system" criteria regarding good laboratory practice. DOELAP is used for worker monitoring and protection at DOE and DOE contractor sites and facilities, as required in Tile 10, Code of Federal Regulations, Part 835, "Occupational Radiation Protection."

National Cooperation for Laboratory Accreditation (NACLA) - DOE representatives have been active in founding and supporting NACLA, and are currently member organizations of NACLA and participate in managing NACLA activities. NACLA recently recognized its first three competent accreditation bodies and has signed an important Memorandum of Understanding with NIST.[dr1]

DOE Voluntary Protection Program (VPP) - DOE has established VPP criteria for its facilities' occupational safety and health programs, based on the Occupational Safety and Health Administration's (OSHA) VPP. These criteria establish a baseline that denotes compliance with all occupational safety and health standards, rules, and regulations. DOE conducts on-site evaluations to establish how successful DOE applicants for VPP have exceeded the baseline criteria.

DOE Topical Committees (TCs) - The Department of Energy Technical Standards Program (TSP), within DOE's Office of Environment, Safety and Health, has chartered a number of DOE Topical Committees that directly and indirectly advocate and support conformity assessment activities across DOE. These topical committees are composed of DOE and DOE contractor subject matter experts, and generally include 
members and observers from other Federal agencies, industry, and standards development organizations. The TCs are chartered to coordinate with these groups on standards activities, including conformity assessment. DOE Topical Committees involved in conformity assessment activities include the following:

Metrology TC - Comprised of representatives from laboratories across the DOE complex, the Metrology TC coordinates the efforts of many DOE organizations involved in metrology and actively interacts with NIST, NASA, DOD and other Federal agencies in its activities. The group has developed a web site (http://www.sandia.gov/metrology/mchome.html) that contains information on metrology capabilities at the various DOE laboratories, past meeting minutes, committee members and contacts, white papers on metrology issues, and future meeting announcements. The group is in the process of developing information on calibration uncertainty analysis procedures and supplier certification programs used in the various DOE laboratories.

Accreditation TC - Comprised of representatives from laboratories across the DOE complex, the Accreditation TC promotes unified laboratory accreditation activities across DOE and actively interacts with NACLA, ASCI, ISO and other organizations to promote nationally and internationally recognized accreditation standards. The group has also developed a web site (http://www.sandia.gov/accreditation/) that contains information on past committee meetings, committee membership and contacts, and white papers on accreditation issues.

Environmental Management Systems TC (EMS TC) - The EMS TC provides information and assistance to DOE organizations interested in establishing ISO 14000 certified environmental management programs. Several DOE sites achieved accreditation during the year.

Quality and Safety Management Special Interest Group/Quality Assurance Topical Committee (QSM SIG/QA TC) - The QA TC develops, improves, and provides management information related to quality and safety issues involving the U.S. Department of Energy (DOE) community, including information and assistance to DOE organizations interested in ISO9000 criteria or a move from DOE specific standards to industry consensus standards.

High Efficiency Particulate Air (HEPA) Filter Qualification Testing/HEPA TC - The DOE conducts functional and quality testing of HEPA filters, used in critical applications at DOE facilities, at a designated facility for HEPA filters to ensure conformance with ASTM standards and to help ensure adequate performance in safety applications.

Biota Dose Assessment Topical Committee (BDATC) - The BDATC has broad representation from DOE Offices, national laboratories, universities, and the private sector. The BDATC brings together the expertise in health physics, radioecology, environmental monitoring, and risk assessment as a resource base for DOE on biota dose assessment. It coordinates these interests to establish common standards and processes for biota dose assessment across DOE, the US, and internationally. Through its standard, the BDATC provides radiation dose evaluation methods that can be used to meet DOE requirements. The international community, including the IAEA and the 
Atomic Energy Control Board (AECB) of Canada, are interested in broader application of the DOE BDATC standard.

Meteorology TC - The DOE Meteorology TC (MTC) works across DOE, with other Federal agencies, and with ANS to help promote the use of ANS 3.11 as a replacement for various agency standards. The MTC can also provide on-site evaluations of on-site meteorology programs to support implementation of the new ANS 3.11 standard.

9. Comments

FISCAL YEAR 2001 ANNUAL REPORT TO THE OFFICE OF MANAGEMENT AND BUDGET

\section{DEPARTMENT OF ENERGY}

The Department of Energy (DOE) implements the Federal guidance and requirements of OMB Circular A-119 (OMB A-119) and the statutory requirements of Public Law (PL) 104-113 (15 USC 272) on the use of voluntary consensus standards through specific Departmental directives (policy, requirements, guides, and technical standards) and supporting management systems.

Foremost is DOE's Integrated Safety Management System (ISMS). ISMS is a system that integrates management of DOE's worker, public, and environmental health and safety with its business management, using standards as one of its primary tools.

DOE policies provide the top tier of requirements that implement standards-related Federal Law and Policy. DOE P 251.1, "Directives System," establishes a Directives System for managing DOE requirements and guidance documents. The Directives System focuses on DOE's environment, safety and health requirements and guidance. Technical standards (i.e., as defined in PL 104-113) are a key element of this system. The Directives System policy clearly states DOE's preference to "... adopt National Consensus Standards and other commercial and industry standards..." in the conduct of DOE's activities. Directives System documents reference appropriate voluntary consensus standards that are acceptable for meeting requirements. This policy also limits the use of mandated government-unique standards in DOE rulemaking, Orders, and procurement processes.

Another policy, DOE P 410.1A, "Promulgating Nuclear Safety Requirements," requires notice and comment to promulgate new nuclear safety requirements. New nuclear safety requirements developed by DOE are "performance-based" rules and orders that promote the adoption of voluntary consensus standards as acceptable methods to implement requirements. DOE also specifies responsibilities for managers and organizations in managing and implementing PL 104-113 and OMB A-119 requirements in its "Functions and Responsibilities (FAR) Manual."

These DOE policies, requirements, and responsibilities on the use of voluntary consensus standards are implemented at the working level through a DOE-wide 
management system and infrastructure established through DOE Order 252.1, "Technical Standards Program," an accompanying "plain language" program Guide, DOE-G-252.1-1, "Technical Standards Program Guide," and Technical Standards Program Procedures (TSPPs).

DOE Order 252.1 establishes the DOE Technical Standards Program (TSP). The TSP in turn functions to implement pertinent Federal and DOE technical standards requirements, and manages internal standards development activities across DOE. DOE O 252.1 incorporates references to PL 104-113 and the February 1998 revision to OMB Circular A-119. This Order also reinforces the Federal requirement for DOE elements to use voluntary consensus standards in preference to Federal and DOE (i.e., government-unique) standards, consistent with PL 104-113 and OMB A-119. The TSP further encourages staff participation in the planning, development, and coordination activities of national and international Standards Development Organizations.

The TSP Guide and TSPPs provide information on the TSP functions and management systems, program resources and services, and stipulates the DOE processes and procedures for selecting, developing, and maintaining DOE Technical Standards and using voluntary consensus standards. The TSP Guide also provides basic information on reporting the use of government-unique standards in both regulation (DOE is nominally self-regulating in key areas such as nuclear safety) and procurement (where most reporting is category-based). The DOE TSP is developing additional reporting procedures to assist program officials conducting procurements. The DOE TSPPs incorporate working level processes developed and approved through our Technical Standards Managers Committee that implement the technical standards provisions of PL 104-113 and OMB A-119. DOE currently manages its technical standards activities in conformance with Federal policy and requirements.

Another function that served DOE implementation of PL 104-113 and OMB A-119 was the Department Standards Program, established to institute "standards" (in this application, "standards" include policy, laws, rules, guides, and technical standards) as the basis for work throughout the Department. Under this program, a DOE-wide process (the "Work Smart Standards" process) that enables DOE contractors to select voluntary consensus standards as the basis for their work was developed and implemented. In the process, voluntary consensus standards can be selected and used in-lieu-of DOE-developed or other government-unique standards, when such standards are appropriate for the work and work-related hazards. This "Work Smart Standards" process now enables DOE laboratory and management and operating or integrating contractors, with DOE approval, to identify and apply the set of standards (including voluntary consensus standards) that best fit their activities and adequately address related hazards. This approach focuses on outcomes and performance, rather than detailing "how" things are to be done within DOE. The process is part of the DOE ISMS and is supported by performance-based contracting designed to more closely link performance expectations with contractual obligations based on standards. 
Key DOE policy and requirements documents define the "Work Smart Standards" approach. These include DOE P 450.3, "Authorizing Use of the Necessary and Sufficient Process for Standards-Based Environment, Safety and Health Management," and DOE M 450.3-1, "The Department of Energy Closure Process for Necessary and Sufficient Sets of Standards." The "Work Smart Standards" approach is now applied across a broad range of DOE sites, facilities, and activities. DOE has also developed guidance and standards to support the "Work Smart" process.

The DOE Standards Executive, Richard L. Black, Director, Office of Nuclear and Facility Safety Policy, is responsible for developing and implementing the DOE TSP through DOE's Technical Standards Program Manager and the TSP. Through Mr. Black's participation on the Interagency Committee on Standards Policy, DOE supports ICSP activities and policy implementation, and provides "lessons-learned" information to other Federal agencies on the DOE's approach to establishing a standards-based culture.

As noted above, DOE Order 252.1 emphasizes the use of voluntary consensus standards within the Department. DOE's Technical Standards Program Office (TSPO) operates under this order to implement program policy, support the conversion of Department standards to voluntary consensus standards, identify voluntary consensus standards that can suit Department needs, develop and maintain data bases to support the program and meet reporting requirements, and coordinate day-to-day Department technical standards activities. The TSPO has developed procedures, methods, and training approaches to implement the DOE TSP and communicate the policy to use voluntary consensus standards throughout DOE, and support participation in Standards Development Organization activities related to DOE missions and functions. The TSPPs establish a five-year standards review cycle to check for the technical adequacy and continued applicability of DOE-developed standards. The procedures also provide guidance on the conversion of Department standards to voluntary consensus standards.

Information on the TSP and the TSPO can be accessed at the following Internet address (URL):

http://tis.eh.doe.gov/techstds/

To coordinate consistent implementation of Federal and DOE policy and requirements at the working level, DOE senior managers have designated Technical Standards Managers (approximately 70 individuals) representing the various Department headquarters, field, laboratory, and contractor organizations. Established in 1992, the Technical Standards Managers' Committee (comprised of these Technical Standards Managers) operates under the DOE TSP, supports the DOE sites in technical standards activities, facilitates communications on program implementation issues, and participates in establishing program goals and procedures. Databases documenting the voluntary consensus standards adopted by DOE and the personnel participating in the activities of Standards Development Organizations are maintained by the TSPO. The 
information in these databases is compiled by the TSPO and provided to OMB annually.

During FY 2001, the TSP continued the recognition of "topical" standards committees within DOE. Topical Committees provide a venue for DOE-wide coordination with national and international Standards Development Organizations and other Federal agencies in such diverse areas as laboratory accreditation, metrology, fire protection, environmental management systems, meteorology, biota dose assessment, chemical safety, emergency management, and nuclear safety training. These committees are composed of subject matter experts from across the DOE community, and serve as a focal point for standards activities in specific technical areas. The topical committees provide a forum for all interested DOE parties to join and participate in reviewing technical standards produced by counterpart Standards Development Organizations, address standards application issues within their area of technical expertise, and work to develop DOE and Federal positions on standards issues. Several topical committees include observers and participants from other Federal agencies and industry. As of November 2001, the TSP has recognized 26 DOE topical committees. (These committees are listed at the Internet address provided above.)

DOE also has an Information Technology Standards Program (Internet address is (http://cio.doe.gov/standards) that is conducted in conjunction with the DOE TSP. Staff from DOE's Office of the Chief Information Officer manages the DOE Information Technology Standards Program with assistance from over 70 designated DOE and contractor Information Technology Points-of-Contact representing key programs and sites. It coordinates information technology standards activities Department-wide, including the identification, adoption, implementation, and retirement of nongovernment and government information technology standards in support of the DOE Information Architecture. This program has stressed the use of international and voluntary consensus information technology standards over development of internal standards in its adoption processes.

The Department also implements a legislatively mandated, multi-year effort to improve the energy efficiency in the Nation's buildings through energy efficiency standards, codes and guidelines for buildings, building equipment, and appliances through its Office of Energy Efficiency and Renewable Energy (Internet address is http://www.eren.doe.gov/). The Department is required to promulgate amended energy efficiency standards designed to achieve the maximum improvement in energy efficiency that the Secretary determines are technically feasible and economically justified. The Department's codes and standards development efforts in these areas are closely coordinated with standards development organizations and include early involvement of industry and state stakeholders and relevant Federal agencies.

DOE continues to take a "pro-active" approach to standards and standards management even as its mission continues to evolve in response to the conclusion of the Cold War and shrinking Congressional appropriations. Within DOE, a number of programs and 
facilities have shifted their focus from production, research, and/or development to environmental remediation and restoration, where DOE will literally be breaking new ground and setting standards for others to follow. In addition, Department staffing levels are declining to meet Congressional budget constraints. Still, in the face of a changing mission and a reduced work force, DOE continues to actively use and support the development of voluntary consensus standards to meet its needs.

In FY 2001, the number of voluntary consensus standards adopted for use increased to 1,025 (in comparison to 1,012 in 2000; 916 in 1999; 840 in 1998, and 809 in 1997). The number of individuals participating in voluntary consensus standards activities decreased slightly to 663 in FY2001 (in comparison to 676 in 2000; 668 in 1999; 681 in 1998, and 871 in 1997), and the number of documented participations by those individuals in standards developing groups decreased to 1353 (in comparison to1385 in 2000; 1306 in 1999; 1321 in 1998, and 1540 in 1997). The decreases reflect continued personnel and budget cuts experienced by DOE and its contractor organizations.

Also, DOE (through the TSPO) is continuing its initiative with ASCE/ANS to convert DOE Technical Standards to voluntary consensus standards, although this is proving to be a lengthy process. DOE is also routinely meeting with ASME to evaluate standards activities and identify candidate DOE standards for conversion to ASME voluntary consensus standards. The DOE and Nuclear Regulatory Commission (NRC) are also jointly sponsoring coordination meetings with various standards development organizations to review standards activities, identify issues, and coordinate development efforts.

In accordance with the reporting requirements iterated in OMB A-119, information has been developed for the OMB Annual Report and has been submitted to NIST to report use of voluntary consensus standards within DOE and DOE participation in standards development activities. The information includes both mandatory agency reporting requirements and voluntary conformity assessment reporting information.

The following summarizes and qualifies the mandatory agency reporting requirements for FY 2001. DOE participated in 58 voluntary consensus standards bodies. There were 663 agency employees participating in voluntary consensus standards activities (These individuals were involved in 1384 activities due to multiple participations). DOE used 1,025 voluntary consensus standards during FY 2001. This is based on the number of voluntary consensus standards actively used by DOE Federal and DOE contractor organizations directly in support of DOE missions and functions, as stated in DOE Directives, contracts, safety analysis reports, standards/requirements identification documents, work smart standards sets, and other operating basis documents for DOE facilities. A standard is counted as "used" only once, even though it is used multiple times in multiple facilities across DOE. DOE identified no additional voluntary consensus standards that have been substituted for governmentunique standards. This is primarily because DOE does up front screening of existing voluntary consensus standards as part of the process for assessing out standards needs. 
DOE did not mandate the use of any government-unique standards in lieu of suitable voluntary consensus standards during FY 2001. 


\section{DEPARTMENT OF HEALTH AND HUMAN SERVICES (HHS) Food and Drug Administration (FDA)}

1. Number of Government Unique Standards Used in Lieu of Voluntary Standards

1

\section{Government \\ Standard \\ National Standard \\ Format (NSF)}

\author{
Voluntary \\ Standard \\ ANSI X12 837
}

\section{$\underline{\text { Explanation }}$ \\ The NSF is used widely across the health care payment industry and has become a defacto national standard. However, the Centers for Medicare and Medicaid Services (CMS) have directed their contractors to discontinue use of the NSF standard and replace it with ANSI X12 837 by the beginning of FY 2003.}

2. Number of Voluntary Consensus Standards Substituted for Government Unique Standards

1

Voluntary Standard

ISO 17025

\section{Government Standard}

Variety of FDA Laboratory Standards

3. Number of Voluntary Consensus Standards used in FY 2001 578

4. Number of Agency Employees Participating In Voluntary Consensus Standards Activities 
5. Number of Voluntary Consensus Standards Bodies In Which There is Agency Participation

\section{7}

6. Provide an Evaluation of the Effectiveness of Circular A-119 Policy and Recommendations for any Changes

\section{U.S. Food and Drug Administration}

The policy and recommendations contained in Circular A-119 are consistent with FDA's framework for standards management as announced in the Federal Register on October 11, 1995, and enhanced by the Food and Drug Administration Modernization Act (FDAMA). Resource constraints oblige the agency to focus attention on the highest priority activities and to strive to make its participation in those activities very effective. FDA participates in 559 standards development activities within 48 voluntary consensus standards bodies.

For FDA, voluntary consensus standards are most relevant for medical devices, where they are used extensively in the agency's regulatory work and where the majority of the agency's standards activities are centered. Voluntary consensus standards are less relevant in the areas of human and veterinary pharmaceuticals, biological products and food, where such standards are generally not available nor being developed, and where standards of other national or international organizations such as the U.S. Pharmacopeia (USP), the World Health Organization (WHO), the Food and Agriculture Organization (FAO), the Organization for Economic Cooperation and Development (OECD), and the International Conference on Harmonization of Technical Requirements for Registration of Pharmaceuticals for Human Use (ICH) predominate.

The central purpose for FDA involvement in the development and use of standards is to assist the agency in fulfilling its domestic public health and regulatory missions. The agency participates widely in the development of standards, both domestic and international, and adopts or uses standards when this action enhances its ability to protect consumers and increases the effectiveness or efficiency of its regulatory efforts. Further, using standards, especially international ones, is a means to facilitate the harmonization of FDA regulatory requirements with those of foreign governments, and thus to improve domestic and global public health protection. Therefore, FDA encourages participation in the development of standards as a useful adjunct to regulatory controls.

FDA has been involved in standards activities for more than twenty years. In January 1977 the agency promulgated a final regulation now found at 21 CFR 10.95 covering participation by FDA employees in standards development activities outside the agency. This regulation encourages FDA participation in standards activities that are in the public interest, and specifies the circumstances under which FDA employees can participate in various types of standards bodies. The agency built upon that rule with a final policy statement published in the Federal Register on October 11, 1995, entitled International 
Harmonization; Policy on Standards. It provides the agency's overall policy on development and use of standards for all product areas regulated by the agency.

Center for Devices and Radiological Health (CDRH)

The Food and Drug Administration Modernization Act of 1997 (FDAMA) allows the agency to recognize voluntary consensus standards established by international and national standards development organizations that may be used to satisfy identified portions of device pre-market review submissions or other requirements. CDRH has made available a standards relevant document on their web site. The document, "CDRH Standard Operating Procedures for the Identification and Evaluation of Candidate Consensus Standards for Recognition," establishes internal CDRH procedures for the identification and evaluation of consensus standards for recognition through publication of a notice in the Federal Register.

CDRH continues to maintain a database to track the standards activities of its employees and has established and uses searchable ROM databases of voluntary consensus standards to facilitate reference to current voluntary consensus standards by agency reviewers.

CDRH continues to participate in Steering Committee and Study Group Activities of the Global Harmonization Task Force (GHTF), an intergovernmental consortium to foster medical device regulatory harmonization. During FY 2001, FDA published draft guidance on a pilot program that will be used to evaluate the feasibility of using the Summary Technical Document (STED) and an Essential Principles Document instead of standard $\mathrm{CDRH}$ procedures for certain premarket submissions.

Finally, the GHTF has a Memorandum of Understanding with TC 210, the ISO Committee responsible for many aspects of device standards.

Center for Drugs Evaluation and Research (CDER) / Center for Biologics Evaluation and Research (CBER)

Voluntary consensus standards are less applicable to pharmaceutical and biological products. CDER and CBER therefore have limited involvement in such activities, but do participate on relevant committees of a number of voluntary consensus standards bodies.

CDER's and CBER's major involvement in standards setting activities is with USP, ICH, OECD and WHO. Numerous employees are involved in the standards development activities of the USP, a private, voluntary, not-for-profit national standards setting body of health care professionals, recognized authorities in medicine, pharmacy, and allied sciences. USP publishes and revises the United States Pharmacopeia and the National Formulary (NF), the legally recognized compendia of drug standards in the U.S.

Both CDER and the CBER participate in the ICH. This ongoing project, begun in 1989, has been undertaken by government agencies responsible for regulation of pharmaceuticals 
and by industry trade organizations. The European Union (EU), Japan, and the U.S. bring together regulatory authorities and experts from the pharmaceutical industry in the three regions to discuss scientific and technical aspects of new product registration. The work products, created in working groups of experts from the regulatory agencies and industry, consist of a series of consensus guideline documents to harmonize pharmaceutical testing guidelines. During FY 2001, FDA approved the harmonized Common Technical Document (CTD). This document will become the standard format for marketing application submissions of pharmaceutical products.

FDA officials also participate in a consensus standards development activity sponsored by the Council for International Organizations of Medical Sciences that is aimed at standardizing the safety-related terminology used in adverse experience reporting.

FDA actively participates with the WHO in developing international standards for ensuring the quality of pharmaceutical and biological products, and the OECD on good laboratory practices for animal studies.

Although FDA's work with USP is specifically excluded from reporting under Circular A119 , and ICH, OECD and WHO do not meet the definition of voluntary consensus standard bodies under the Circular, substantial agency resources are devoted to the development of standards with these organizations. This work is the core part of FDA's overall standards activities for pharmaceutical and biological products.

Center for Food Safety and Applied Nutrition (CFSAN) / Center for Veterinary Medicine (CVM)

The principal international standards activities in the areas of food and veterinary medicine fall under the activities of the Codex Alimentarius Commission of the FAO and the WHO, as well as the Office of International Epizootics (for veterinary medicine). FDA experts from CFSAN, CVM, and other parts of the agency are actively involved in Codex Alimentarius activities, and in activities of methods validation organizations on which Codex Alimentarius relies, such as ISO, the Association of Official Analytical Chemists (AOAC) International and the International Dairy Federation (IDF). CFSAN has provided the U.S. Delegate or Alternate Delegate to $80 \%$ (17 out of 21 ) of the technical committees and task forces and also provided technical experts to assist on the work of developing more that 90 Codex standards and guidelines. CVM has also provided numerous technical experts to assist on Codex task forces, especially those related to the Codex Committee on Residues of Veterinary Drugs and Foods (CCRVDF). Currently, the Director of CVM serves as the chair of the CCRVDF.

Voluntary consensus standards have limited relevance to food and veterinary medicine products. However, since the standards activities of multilateral organizations such as the WHO, FAO, the World Trade Organization (WTO) and the OECD are important in these areas, CFSAN and CVM are actively engaged in standards and policy development with these organizations. CFSAN is also engaged in standards review in the International 
Organization for Standardization in Microbiology.

CVM is active in a harmonization initiative similar to the ICH for human pharmaceuticals, that is, developing harmonized requirements for the registration of veterinary pharmaceuticals and biological veterinary medicinal products. It is known as VICH, for Veterinary ICH. Agency employees participate on numerous committees that are drafting VICH guidelines related to veterinary pharmaceuticals.

International/Treaty Standards-Related Activities

FDA takes part in a variety of international standards activities that fall under treaty organizations, and thus are not reportable under the provisions of Circular A-119. These standards activities are nonetheless important to the agency in fulfilling its public health regulatory mission. Some of these are referred to above, i.e. WHO, FAO, and OECD.

The agency participates in international trade discussions within the WTO, specifically with committees on the Agreement on Technical Barriers to Trade (TBT), and the Agreement on the application of Sanitary and Phytosanitary (SPS) Measures; with the implementation of the counterpart committees of the North American Free Trade Agreement (NAFTA); and with the negotiation of an upcoming trade agreement by 2005 for the Free Trade Area of the Americas where sanitary and phytosanitary measures fall within the scope of the negotiations. In addition, FDA is participating in negotiations with Chile on a free trade agreement. FDA in engaged in these negotiations to ensure that the agency's requirements are preserved and its regulatory practices can remain focused on fulfilling the agency's mission to protect the public health while being supportive of emerging, broader U.S. government obligations and policies. FDA has participated in several initiatives that are part of the Asia Pacific Economic Cooperation (APEC) forum. FDA topics have included food safety, food labeling, bulk drugs, standards for latex gloves and condoms, and medical device regulation.

7. Provide the Conformity Assessment Activities in Which the Agency has been Involved

\section{U.S. Food and Drug Administration}

The CDRH has liaison with the ANSI Accreditation Committee, the ANSI International Conformity Assessment Committee, ANSI Board Committee on Conformity Assessment, and ASTM Committee E-36 on Conformity Assessment. The Center uses suppliers' declaration of conformity as described in ISO/IEC Guide 22 in its standards recognition program and has developed an MRA with the European Union on mutual recognition of each other's conformity assessment procedures related to manufacture and marketing of medical devices.

The Office of Regulatory Affairs (ORA) actively participates with the National Cooperation for Laboratory Accreditation (NACLA). An ORA official is a member of the NACLA Executive Board of Directors and has the role of participating in the NACLA 
Recognition Committee for Accrediting Bodies who apply for mutual recognition. Other FDA officials participate with NACLA in the evaluation of accrediting bodies under ISO/IEC 58 and ISO/IEC 17025 and sit on NACLA technical committees.

ORA officials are also involved with Codex Alimentarius activities, especially in the area of pesticide residues, which relies on methods development by ISO and AOAC. Other activities include participation and the coordination of Federal-State conferences to develop uniformity in the reporting of food testing results. The ISO/IEC 17025 standard is the foundation in this coordination effort.

Within ORA, the field laboratories are continuing the process to become ISO 17025 accredited. The ORA has completed its first series of staff training to conform to the ISO 17025 standard and quality assurance managers have been hired to coordinate the change over to an ISO 17025 based quality system.

CDER supports the concept of working within our agency, with other government agencies, the private sector, and other governments to avoid duplication in standards setting activities. Within FDA, they coordinate with other Centers in the development of "Guidance to Industry" documents. FDA also coordinates activities with other agencies, such as the Environmental Protection Agency, the U.S. Fish and Wildlife Service, the Consumer Product Safety Commission, the Drug Enforcement Agency, and the National Institute for Standards and Technology (NIST).

Finally, a majority of standards setting activities are focused on interactions with national and international standards setting bodies such as USP, ICH, OECD, WHO, and the Pan American Health Organization (PAHO). An innovative approach to harmonizing international standards is being undertaken with PAHO. The primary mission of PAHO is to strengthen national and local health systems and improve the health of the peoples of the Americas. In the Americas there is a need to promote harmonization to facilitate the availability of safe, effective, and good quality pharmaceuticals and thereby protect public health. The regulation of pharmaceuticals and the harmonization of technical standards have emerged as an important component of the economic integration. As a result, a Pan American Network for Drug Regulatory Harmonization (PANDRH) with biennial Pan American conferences was established. The mission of the Network is accomplished by conferences that promote regulatory harmonization for all aspects of quality, safety and efficacy of pharmaceutical products as a contribution to the quality of life and health care of the citizens of the countries of the Americas.

Harmonization in this context is understood to be the search for common ground within the framework of recognized standards, taking into account the existence of different political, health, and legislative realities among the countries of the region. A steering committee was formed to enable progress between conferences by coordinating, promoting, facilitating, and monitoring harmonization processes in the Americas. A major aspect of PANDRH is to provide training to the regulatory agencies of the Americas. It is felt that training to the same standards will eventually lead to harmonized standards. 


\section{Centers for Medicare and Medicaid Services (CMS)}

Although CMS was involved in a limited number of conformity assessment activities to assure adherence by their contractors to the national health care payment standards, it is anticipated that these activities will increase significantly in future years. In addition, CMS participated in interagency efforts to harmonize health care standards implementation activities under HIPAA with other Federal agencies, including the Department of Defense, the Veterans Administration and State Medicaid Agencies. They also conducted a review of private sector certification services available that could assist in establishing a mechanism to better certify the use of health care standards by contractors. A contract to develop this mechanism is expected to be awarded in FY 2002.

CMS is also participating with the National Forum for Health Care Quality Measurement and Reporting in the endorsement of standards for performance measures of quality among various providers. This effort brings together all stakeholders to make a determination founded in a membership-driven consensus process and an evidence base for the subject matter. The various endorsements will occur over the next two years.

\section{Provide any Examples or Case Studies of Standards Successes}

\section{U.S. FDA/ CDRH}

\section{Ignition Test for Medical Oxygen Regulators}

Oxygen regulators are devices used with high pressure gas cylinders to control the pressure and flow of oxygen to patients. A rare, but serious, risk associated with these devices is flash fires and explosions, which have resulted in dozens of serious injuries and one death. To reduce the prevalence and severity of these types of incidents, FDA, in conjunction with NIOSH, initiated development of an ignition test for medical oxygen regulators. In the spring of 1999, initial research supporting the development of the test was undertaken in partnership with the NASA White Sands Test Facility and a private research firm (Wendell Hull \& Associates). These facilities were consulted because they have specialized equipment, test facilities and fire safety provisions that FDA does not have for performing this type of ignition testing. Their staff, along with FDA staff, health care workers, oxygen regulator manufacturers, and other technical experts participated in development of a standard incorporating the ignition test through a committee of the American Society for Testing and Materials (ASTM). The initial research was completed and a provisional standard developed and approved in October 2000, approximately 1-1/2 years after the initial research began. Validation testing showed that damage produced from the laboratory simulation test is consistent with that observed in clinical use for problematic regulator designs. This shows that the test can be used to prevent unsafe designs from entering the market in the future. Key members of industry have already used the test to assess the safety of their products and incorporated design improvements accordingly. Also, the agency has used the test 
to evaluate proposed design changes for regulators that were recalled because of problems with fires. Testing of one problematic model showed that the firm's proposed retrofit will not completely resolve the fire hazards associated with their device. In addition to benefiting FDA, the test method will benefit the space program because it will help ensure use of safe oxygen regulators during space flight. Eventually, the test method may have applicability to other types of regulator technology, such as welding and scuba regulators

\section{Comments}

For a regulatory agency such as FDA neither a categorical nor a transactional designation correctly describes how we use these standards. Five hundred seventy-four (574) is the total number of voluntary consensus standards listed by FDA as of the end of the current reporting period that can be referenced by applicants for market approval of medical devices. Applicants can reference these standards in lieu of submitting data to meet approval requirements. For the Department, the total number of standards recognized is 578 and includes standards used by the Centers for Medicare and Medicaid Services. 


\section{DEPARTMENT OF HOUSING AND URBAN DEVELOPMENT (HUD)}

1. Number of Government-Unique Standards Used in Lieu of Voluntary Standards 2

2. Number of Voluntary Consensus Standards Substituted for Government-Unique Standards

1

3. Number of Voluntary Consensus Standards Used in FY 2001

300

4. Number of Agency Employees Participating in Voluntary consensus Standards Activities.

10

5. Number of Voluntary consensus Standards Bodies In Which There is Agency Participation.

5

6. Provide an Evaluation of the Effectiveness of Circular A-119 Policy and

Recommendations for Any Changes.

This policy has been effective in replacing Federal Standards with public-domain standards. This has resulted in more timely, up-to-date, and technically accurate standards. The Department of Housing and Urban Development (HUD) suggests Circular A-119 use stronger language to encourage agencies to be more active in determining which standards are applicable to the agency's activities and when standards are identified, direct the agency to be more assertive in enforcing their uses. For example, in the area of correspondence, OMB should assure that each agency have the definition of the USPS's standard for addressing mail and ensure that agency correspondences use it.

7. Provide the Conformity Assessment Activities in Which the Agency Has Been Involved.

All of HUD's 25 conformity assessment (CA) programs, under the HUD BuildingProducts Standards and Certification Programs, are in compliance with the ISO guidelines and procedures. These are the same standards used by ANSI and other nationally recognized third-party certification agencies. 


\section{Provide Any Examples or Case Studies of Standards Successes.}

SUCCESS 1: Construction Definitions for Information Systems in Housing Construction. The housing construction industry has identified the need for standard definitions that can be used when applying information technology in the construction process. Applying information systems and web based ordering systems for materials and products presents unique opportunities for substantially reducing the costs of construction. Adhering the same technical language and being able to speak quickly and accurately is a big challenge. Applying Information Technology (IT) seemed to be one solution. HUD's Office of Policy Development and Research (PD\&R) manages the PATH program (Partnership for Advancing Technology in Housing). Rather than developing Federal standard definitions, PATH brought together a private industry group to discuss the need for consensus based industry driven definitions that could be used by various home construction entities. This was done at the request of a group from the timber manufacturing industry that asked PATH to convene meetings and task groups to develop such a common language (in this case, through XML tag sets) so that it would become an industry "de facto" standard. Even though it's just one vocabulary set within a much large group, this development has been a big success because it is one of the first industry-based attempts to develop and gain acceptance for such standard definitions (most attempts have been top-down and unsuccessful). The government served only in a facilitation capacity, industry did all the work. HUD's PATH program plan is to continue this work encouraging various groups in the construction industry to develop similar standard definitions until the entire construction process is covered.

SUCCESS 2: Building Products For Construction (Authority 24 CFR Part 200.935). The Department of Housing and Urban Development reviews new and innovative products for inclusion in the FHA mortgage insurance program. The purposes of this effort are to prevent product failures and misrepresentations of products, to expedite introduction of new or innovative building products, to alleviate safety hazards associated with building materials, long-term durability problems, and misleading test results, and to assure that the building products arriving at the job site comply with the designated standards. To achieve these ends, the Department now uses validation of private sector certifications manufacturer's self-certification to assure compliance rather than Federal standards. Laboratories are subject to periodic reaccreditations. An authorized mark or label is affixed by manufacturer or by a third party administrator. More than thirty thirdparty administrators participate in the HUD Building Products Certification program for building products including: solid fuel type heaters, fireplace stoves, plastic plumbing fixtures, aluminum windows, storm doors, sliding glass doors, storm windows, wood window units, wood sliding patio doors, sealed insulating glass units, carpet, carpet with attached cushion, PVC window units, lumber, solar water heating systems, EIFS, construction adhesives, fasteners, particleboard interior stair tread, acrylic and polycarbonate glazing. Manufacturers are obligated to cease marking products that do not meet required standards. Products in these programs enjoy a wide degree of reciprocal recognition, including other Federal agencies, state agencies, private sector organizations, 
foreign governments, and international organization. There are participating organizations in Canada for certain building products.

SUCCESS 3: Manufactured Housing Standards (Authority: National Manufactured Housing Construction and Safety, Standards Act, P.L. 93-382, 42 U.S.C. 5407. 24 CFR Part 3280.). Since 1976, the Department of Housing and Urban Development has been required to develop, maintain and enforce standards for construction of manufactured Housing. The propose of these standards is to provide uniform standards to reduce the number of personal injuries and deaths, cost of insurance, and property damage resulting from manufactured home accidents and to improve the quality and durability of manufactured homes. Rather than the Federal government continuing to develop these standards, HUD now uses a private consensus-based standards process to develop and maintain these standards. HUD, through a Memorandum of Understanding (MOU) with the National Fire Protection Association (NFPA), is relying on that organization to develop and process recommendations and changes to the HUD standard. While the standard is eventually promulgated as a Federal regulation, HUD has transferred the development of these standards this ANSI-consensus based body (NFPA), which has established a special body to develop and modernize the HUD standards. Based upon NFPA's consensus based work HUD has developed a proposed new rule that will amend 24 CFR 3280 to include over 110 changes to the HUD code. The NFPA consensusbased standards itself utilizes hundreds of private reference standards for identified materials and products. HUD will now be asking that same consensus-based body to develop standards for the installation of manufactured homes. The Department also uses a nationwide certification program to enforce these manufactured housing standards. Private third party certification of manufactured housing designs and quality assurance manuals, and in-plant inspection assure compliance with standards.

\section{Comments}

HUD's ten participants in standards developing organization activities are from the Office of Policy, Research, and Development; the Office of Healthy Homes \& Lead-Hazard Control; the Office of Housing-Federal Housing Commissioner and the Office of the Chief Information Officer. The Standards Developing Organizations (SDO's) in which they participate are the American Society of Testing and Materials (ASTM), the Federal Geographic Data Committee (FGDC), the International Committee for IT Standards ([INCITS], the International Standards Organization [ISO], and the National Fire Protection Association (NFPA) 


\section{DEPARTMENT OF INTERIOR (DOI)}

1. Number of Government Unique Standards Used in Lieu of Voluntary Standards 2

2. Number of Voluntary Consensus Standards Substituted for Government Unique Standards

0

3. Number of Voluntary Consensus Standards used in FY 2001

0

4. Number of Agency Employees Participating In Voluntary Consensus Standards Activities

69

5. Number of Voluntary Consensus Standards Bodies In Which There is Agency Participation

5

6. Provide an Evaluation of the Effectiveness of Circular A-119 Policy and Recommendations for any Changes

None

7. Provide the Conformity Assessment Activities in Which the Agency has been Involved

None

8. Provide any Examples or Case Studies of Standards Successes

The BLM has been cooperating with State representatives in the area of cultural resources to use standards in the Geographic Information System area for archeological information between the State Historic Preservation Officers (SHPOs) and the BLM's cultural resources program. Agreements have been made to share information, and plans are underway to develop data sharing agreements with SHPOs and with other organizations involved with cultural resources. At present, the attempt is to create standard formats for SHPOs to access and use State BLM data. A user team has been formed of BLM, Forest 
Service, and SHPO representatives to work out standard issues and implementation of data sharing arrangements.

In the area of interagency data standards, the BLM has participated in the development of standards for National and Historic Trails. This arrangement is under the umbrella of the National Park Service, but includes participants from NPS, BLM and Forest Service. The interagency team is now in the process of defining data requirements as a prelude to defining standards not only for National and Historic trails, but also for scenic and recreational trails.

The BLM also participates in the National Digital Elevation Program (NDEP) and the National Digital Orthophoto Program, both of which involve sharing information among Federal agencies. The NDEP was established to promote the exchange of accurate digital land elevation data among government, private, and non-profit sectors and the academic community, and to establish standards and guidance that will benefit all users. The NDEP is composed of agencies from the Department of the Interior, Commerce, and Agriculture, as well as the National Imagery and Mapping Agency, National Aeronautics and Space Administration, US Army Corp of Engineers, and the Federal Emergency Management Agency, with representation from State governments through the National States Geographic Information Council.

The National Digital Orthophoto Program (NDOP) was established to promote the cooperative production of digital orthophotoquads (DOQ) among participating Federal agencies. Over the years the focus has broadened to include orthophotography acquired by State and local governments. Members include BLM participants as well as the following agencies: (USDA) Farm Service Agency, Natural Resources Conservation service, US Forest Service; (DOI) U.S. Geological Survey, Bureau of Land Management; (Other) Federal Emergency Management Agency, Environmental Protection Agency, Bureau of Census and the National State Geographic Information Council.

\section{Comments}

Various bureaus for consideration provide the following comments:

NIST \& OMB might consider providing an XML schema for the A-119 survey; the schema could include a listing of the "voluntary consensus bodies" considered valid for purposes of the survey. Agencies could identify the standards they are using in each of their systems and partner with other agencies using those standards to further develop and maintain their systems through the relevant standards development organization.

NIST and OMB might consider identifying voluntary consensus standards deemed to be of high priority for government wide implementation. Potential candidates for such designation might include X.509 certificates for digital signature and XML, both of which support the President's E-Government initiatives and IT security (secure E-Government transactions). 
Continuing in the theme of high-priority standards supporting E-Government: The likelihood is increasing that agencies will be held accountable for having applications that are "interoperable," particularly for E-records management, in order to make records (information) more accessible for long term preservation, public access and for accessibility by disabled persons. It is not clear that the approximate 30 "business lines" identified in the Administration's E-Government strategy identify true communities of interest/practice, from which high-priority standards could emerge for rapid adoption. Further, a NIST/OMB strategy to rationalize E-Government "business lines" by specifying common data elements for agency adoption would work to form communities of interest/practice in order to begin easing the burden of information collection upon the public while at the same time maximizing the utility of the data. 


\section{DEPARTMENT OF JUSTICE (DOJ)}

1. Number of Government Unique Standards Used in Lieu of Voluntary Standards 0

2. Number of Voluntary Consensus Standards Substituted for Government Unique Standards

0

3. Number of Voluntary Consensus Standards used in FY 2001

59

4. Number of Agency Employees Participating In Voluntary Consensus Standards Activities

5

5. Number of Voluntary Consensus Standards Bodies In Which There is Agency Participation

3

6. Provide an Evaluation of the Effectiveness of Circular A-119 Policy and

Recommendations for any Changes

Circular A-119 policy is appropriate and has increased the awareness, value and usage of voluntary consensus standards.

7. Provide the Conformity Assessment Activities in Which the Agency has been Involved

The Office of Science and Technology of the National Institute of Justice (NIJ), U.S. Department of Justice, sponsors the Law Enforcement and Corrections Standards and Testing Program. The program responds to the mandate of the Justice System Improvement Act of 1979, which directed NIJ to encourage research and development to improve the criminal justice system and to disseminate the results to federal, state, and local agencies.

The Law Enforcement and Corrections Standards and Testing Program is an applied research effort that determines the technological needs of justice system agencies, sets minimum performance standards for specific devices, tests commercially available equipment against those standards, and disseminates the standards and the test results to 
criminal justice agencies nationally and internationally. The program operates through the Law Enforcement and Corrections Technology Advisory Council (LECTAC), consisting of nationally recognized criminal justice practitioners from federal, state, and local agencies, which assesses technological needs and sets priorities for research programs and items to be evaluated and tested.

The Office of Law Enforcement Standards (OLES) at the National Institute of Standards and Technology (NIST), which develops voluntary national performance standards for compliance testing to ensure that individual items of equipment are suitable for use by criminal justice agencies. The standards are based upon laboratory testing and evaluation of representative samples of each item of equipment to determine the key attributes, develop test methods, and establish minimum performance requirements for each essential attribute. In addition to the highly technical standards, OLES also produces technical reports and user guidelines that explain in nontechnical terms the capabilities of available equipment.

The National Law Enforcement and Corrections Technology Center (NLECTC) operated by a grantee, which supervises a national compliance-testing program conducted by independent laboratories. The standards developed by OLES serve as performance benchmarks against which commercial equipment is measured. The facilities, personnel, and testing capabilities of the independent laboratories are evaluated by OLES prior to testing each item of equipment, and OLES helps the NLECTC staff review and analyze data. Test results are published in Equipment Performance Reports designed to help justice system procurement officials make informed purchasing decisions.

This interagency cooperative effort results in improvement in the quality and consistency of various conformity assessment requirements and processes at the federal and state levels.

Reports prepared in FY 2001 include:

Flammable and Combustible Liquid Spill/Burn Patterns, by Anthony D. Putorti Jr., Jay A. McElroy, and Daniel Madrzykowski, March 2001

Users' Guide for Hand-Held and Walk-Through Metal Detectors, by Nicholas G. Paulter, January 2001

Trace Detection of Narcotics Using a Preconcentrator/Ion Mobility Spectrometer System, by John E. Parmeter and Gary A. Eiceman, April 2001

Development of NIST Standard Bullets and Casings Status Report, by J. Song and T.V. Vorburger, November 2000

Antenna System Guide, NIJ Guide 202-00, by W.A. Kissick, W.J. Ingram, J.M. Vanderau, and R.D. Jennings, April 2001

1999 Survey of Forensic Reference Materials, by NIST, March 2001

Guide to the Technologies of Concealed Weapon and Contraband Imaging and Detection (NIJ Guide 602-00), by Nicholas G. Paulter, February 2001 


\section{Provide any Examples or Case Studies of Standards Successes}

In collaboration with the Federal Bureau of Investigation (FBI), the National Institute of Standards and Technology (NIST) continued to focus its efforts on three areas vital to the exchange of criminal justice information. These areas are the development of standards, evaluations of new products and proposed standards, and the development of tools to measure effectiveness and encourage development of new commercial products.

In the area of standards, NIST successfully passed the American National Standards Institute (ANSI) audit of the standards development procedure. A web-based copy of the approved ANSI/NIST Standard "Data Format for the Interchange of Fingerprint, Facial, \& Scar Mark \& Tattoo Information [SMT]" was made available for convenient access by interested parties. This standard defines the content, format, and units of measurement used in the identification of a subject by fingerprint, facial, palm print or SMT data and is the tool that establishes interoperability between federal, state, local, and international users of Automated Fingerprint Identification Systems (AFIS). The JPEG 2000 international standard for facial image compression has been evaluated and an addendum to the ANSI/NIST standard is being prepared to allow for provision of these images. This will reduce the storage requirement for facial images without loss of image quality. Investigation of JPEG 2000 for the compression of fingerprint images is underway.

NIST performed a review of the proposed "Interstate Criminal History Transmission Specification - XML Version 2.01" prepared by the Joint Task Force on Rap Sheet Standardization; provided the Criminal Justice Information Services (CJIS) Division a report on the state-of-the art in palm print processing; and continued to test and provide evaluations of Wavelet Scalar Quantization (WSQ) fingerprint compression implementations to assure they are in compliance with FBI specifications.

NIST was active in developing tools that can be used to develop and evaluate commercial products. Special Database 27 provides FBI-developed minutiae from latent and ten-print images that were used for acceptance testing of the IAFIS system. This tool can be used to develop improved algorithms for fingerprint identification. NIST also produced the document "Latent Fingerprint Training with NIST Special Database 27 and Universal Latent Workstation [ULW]" to guide examiners in the use the data files with the ULW. It is expected that these tools will increase the effectiveness of those using the ULW to process crime scene fingerprints. Special Database 29 was developed and provides both flat and rolled fingerprint images captured at 500 pixels per inch and 1000 pixels per inch. This tool provides an essential component in evaluating higher resolution image capturing devices, compression of these images, and the effectiveness of searches made with flat fingerprint images as envisioned in border control and Department of Motor Vehicle (DMV) applications. A users guide to public domain software developed by NIST, relating to fingerprint image processing, was published to encourage commercial development of products of use to the criminal justice community.

\section{Comments}


The Department of Justice will be updating its approved information technology standards in FY 2002. These standards comprise the bulk of the voluntary consensus standards in use in FY 2001 as reported above. 


\section{DEPARTMENT OF LABOR (DOL)}

1. Number of Government Unique Standards Used in Lieu of Voluntary Standards 3

2. Number of Voluntary Consensus Standards Substituted for Government Unique Standards

0

3. Number of Voluntary Consensus Standards used in FY 2001

125

4. Number of Agency Employees Participating In Voluntary Consensus Standards Activities

76

5. Number of Voluntary Consensus Standards Bodies In Which There is Agency Participation

35

6. Provide an Evaluation of the Effectiveness of Circular A-119 Policy and

Recommendations for any Changes

None

7. Provide the Conformity Assessment Activities in Which the Agency has been Involved

None

8. Provide any Examples or Case Studies of Standards Successes

None

9. Comments

None 


\section{DEPARTMENT OF STATE (STATE)}

1. Number of Government Unique Standards Used in Lieu of Voluntary Standards 0

2. Number of Voluntary Consensus Standards Substituted for Government Unique Standards

0

3. Number of Voluntary Consensus Standards used in FY 2001

0

4. Number of Agency Employees Participating In Voluntary Consensus Standards Activities

8

5. Number of Voluntary Consensus Standards Bodies In Which There is Agency Participation

1

6. Provide an Evaluation of the Effectiveness of Circular A-119 Policy and

Recommendations for any Changes

Department of State (DoS) does not write standards within the meaning of Circular A119.

7. Provide the Conformity Assessment Activities in Which the Agency has been Involved N/A

8. Provide any Examples or Case Studies of Standards Successes

None

9. Comments

The DoS is not involved in the actual development of technical standards. 
The Department of State has a major policy role in telecommunications standards as obligated by international treaty, and coordination roles in other areas. The Bureau of Economic and Business Affairs (EB) represents the Department of State on the Interagency Committee on Standards Policy (ICSP), the Government Member Council, and the Information Infrastructure Standardization Panel (IISP) and its steering committee at the American National Standards Institute (ANSI). The Department is not involved in the actual development of technical standards.

The Department represents the United States of America administration under the treaty obligations found in the Convention of the International Telecommunication Union (ITU), Minneapolis, 1998, and the Inter-American Telecommunication Commission (CITEL) of the Organization of American States (OAS). The Department of State, through the EB Communications and Information Policy Deputate (CIP), provides the forum for development of positions and contributions for presentation at ITU and CITEL meetings where international telecommunication Recommendations (voluntary standards) and telecommunication standardization policies are written. The Department authorizes and/or hosts public meetings under the Federal Advisory Committee Act, where advice on telecommunication standardization and policy issues is offered by the private sector telecommunications industry. The Department also bases its decisions on advice from other public sector Agencies (DoD, National Institute of Standards and Technology (NIST), National Telecommunications and Information Administration (NTIA), National Aeronautics and Space Administration (NASA), and the Federal Communications Commission (FCC)). The Department coordinates, leads, and/or accredits United States delegations to ITU and CITEL technical and policy meetings.

More than 100 U.S. corporations are participating members of the ITU; more than 30 are associate members of CITEL's permanent Consultative Committee, under the sponsorship of the State Department. Those companies and interested Government agencies participate and play major roles in the ITU and CITEL Study Groups and Working Parties that actually write the standards. Within that process, a great deal of interaction takes place with other standards setting organizations, such as the International Organization for Standardization (ISO), ANSI, ANSI-accredited Committee T1, and the Telecommunications Industry Association.

In addition to accrediting and supporting delegations to the ITU and CITEL, the Department's International Organization Affairs Bureau (IO) accredits and funds participation by relevant specialized agencies (Departments of Agriculture, Commerce, Transportation, and NIST) and private sector groups in the deliberations of the Economic Commission for Europe (ECE) Working Party on Standardization, especially where they have a direct bearing on U.S. commercial interests. While the standards developed in the ECE are not officially adopted for use in the U.S. they serve as guides for adjusting product design and are widely taken into account in manufacturing plans. 


\section{DEPARTMENT OF TRANSPORTATION (DOT)}

1. Number of Government Unique Standards Used in Lieu of Voluntary Standards 0

2. Number of Voluntary Consensus Standards Substituted for Government Unique Standards

8

$\begin{array}{ll}\quad \text { Voluntary Standard } & \text { Government Standard } \\ \text { NPRM Signal and Train Control Systems } & \text { 49CFR 236 } \\ \text { ASTM } & \text { 49CFR 393.102 } \\ \text { Web Sling \& Tiedown Assoc. } & \text { 49CFR 393.102 } \\ \text { Cordage Institute } & \text { 49CFR 393.102 } \\ \text { AAR-S569-47 } & \text { 49CFR 232 } \\ \text { Underwriters Laboratories } & \text { 49CFR 393.95 } \\ \text { Nat. Assoc. of Chain Manufacturers } & \text { 49CFR 393.102 } \\ \text { Wire Rope Technical Board } & \text { 49CFR 393.102 }\end{array}$

3. Number of Voluntary Consensus Standards used in FY 2001 246

4. Number of Agency Employees Participating In Voluntary Consensus Standards Activities

177

5. Number of Voluntary Consensus Standards Bodies In Which There is Agency Participation 168

6. Provide an Evaluation of the Effectiveness of Circular A-119 Policy and Recommendations for any Changes

The general consensus is that Circular A-119 is working effectively and that the use of voluntary standards can save both time and money for regulatory agencies. We have no recommendations to change OMB Circular A-119 at this time. 
7. Provide the Conformity Assessment Activities in Which the Agency has been Involved

A number of DOT offices have adopted many voluntary standards in their regulations. Consequently, we assess conformance with the voluntary standards through inspections to ensure compliance with our regulations and any standards incorporated in those regulations.

8. Provide any Examples or Case Studies of Standards Successes

In certain situations where a government-unique standard does not exist or is not acceptable to the industry, DOT's Federal Aviation Administration (FAA) will consider the substitution of an existing government regulation intended for another purpose. An example would be applying existing Coast Guard (USCG) fire extinguisher standards to the aviation industry. This avoids lengthy and costly additional rulemaking proceedings.

9. Comments

None 


\section{DEPARTMENT OF THE TREASURY (TREASURY)}

1. Number of Government Unique Standards Used in Lieu of Voluntary Standards 2

Government Standard

Customs and Trade Automated Interface

Requirements (CATAIR)

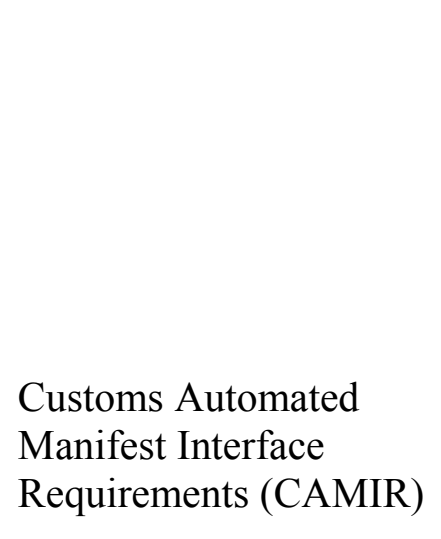

\section{Voluntary Standard}

2. Number of Voluntary Consensus Standards Substituted for Government Unique Standards 0

3. Number of Voluntary Consensus Standards used in FY 2001 
4. Number of Agency Employees Participating In Voluntary Consensus Standards Activities

67

5. Number of Voluntary Consensus Standards Bodies In Which There is Agency Participation

8

6. Provide an Evaluation of the Effectiveness of Circular A-119 Policy and Recommendations for any Changes

We believe that the guidelines prescribed in Circular A-119 are effective. Circular A119 has placed the focus on using voluntary consensus standards as opposed to the development of government unique standards. Wide use of voluntary consensus standards promotes the development of an increased number of standard compliant products facilitating the use of new technology and increasing flexibility to meet new requirements.

7. Provide the Conformity Assessment Activities in Which the Agency has been Involved

The standards the Department has adopted will involve conformity assessment activities, which include internal audit and eventual certification in conformance with acceptable practices.

8. Provide any Examples or Case Studies of Standards Successes

Between 1998 and 2001, the US Customs, Office of Information Technology, Program Office, used the government-unique standards: Year 2000 Computing Crises, An Assessment Guide (GAO/AIMD-10.1.14), Year 2000 Computing Crisis, A Testing Guide (GAO/AIMD-10.1.21 and Year 2000 computing Crisis, Business Continuity and Contingency Planning (GAO/AIMD-10.1.19). After a series of reviews by the GAO, issued the following report: Year 2000 Computing Crisis, Has Established Effective Year 2000 Program Controls (GAO/AIMD-99-37) and testified before Congress on 2/24/99 stating: Year 2000 Computing Crisis, Customs is Effectively Managing its Year 2000 Program (GAO/T-AIMD-99-85) and again on 6/29/99: Year 2000 Computing Crisis, Customs Is Making Good Progress (GAO/T-AIMD-99-225).

9. Comments

None 


\section{DEPARTMENT OF VETERANS AFFAIRS (VA)}

1. Number of Government Unique Standards Used in Lieu of Voluntary Standards 1

2. Number of Voluntary Consensus Standards Substituted for Government Unique Standards

0

3. Number of Voluntary Consensus Standards used in FY 2001

0

4. Number of Agency Employees Participating In Voluntary Consensus Standards Activities

12

5. Number of Voluntary Consensus Standards Bodies In Which There is Agency Participation

24

6. Provide an Evaluation of the Effectiveness of Circular A-119 Policy and Recommendations for any Changes

The Veterans Health Administration accepts and conforms to standards developed by the Joint Commission on Accreditation of Healthcare Organization (JCAHO) for Veterans Affairs' (VA) health care facilities. Voluntary consensus standard requirements are utilized in the regulatory, contractual and grants determinations executed by the Veterans Health Administration.

7. Provide the Conformity Assessment Activities in Which the Agency has been Involved

The VA does not engage in conformity assessment activities. VA strives to use industry based standards and commercial off-the-self products.

8. Provide any Examples or Case Studies of Standards Successes

N/A

9. Comments 
Federal regulations prescribe standards that must be used (e.g., EPA laboratory standards and OSHA monitoring/sampling standards). Regardless of what may be developed by conformity assessment, VA is not relieved of it obligation to use standards prescribed by regulations. When not obligated to use a prescribed regulatory or other (e.g., JCAHO) standard, VA organizations must retain the flexibility to use the standard that best meets its programmatic needs. 



\section{Appendix B:}

\section{Other Agency and Commission Reports}




\section{UNITED STATES INTERNATIONAL TRADE COMMISSION (USAID)}

1. Number of Government Unique Standards Used in Lieu of Voluntary Standards 0

2. Number of Voluntary Consensus Standards Substituted for Government Unique Standards

0

3. Number of Voluntary Consensus Standards used in FY 2001

0

4. Number of Agency Employees Participating In Voluntary Consensus Standards Activities

0

5. Number of Voluntary Consensus Standards Bodies In Which There is Agency Participation

0

6. Provide an Evaluation of the Effectiveness of Circular A-119 Policy and Recommendations for any Changes

USAID has no suggestions for changing Circular A-119.

7. Provide the Conformity Assessment Activities in Which the Agency has been Involved

USAID participates in the Contractor Performance System established by the National Institutes for Health, including participating as a member of the committee that determines information requirements. This may be considered a conformity assessment activity since it is standardizing the way that the participating agencies assess contractors' performance.

8. Provide any Examples or Case Studies of Standards Successes

Nothing to report.

9. Comments

N/A 


\section{CONSUMER PRODUCT SAFETY COMMISSION (CPSC)}

1. Number of Government Unique Standards Used in Lieu of Voluntary Standards 0

2. Number of Voluntary Consensus Standards Substituted for Government Unique Standards

1

Government Standard $\quad$ Voluntary Standard

ANSI/UL 325-2001 (in part) 16 CFR 1211

3. Number of Voluntary Consensus Standards used in FY 2001

1

4. Number of Agency Employees Participating In Voluntary Consensus Standards Activities

31

5. Number of Voluntary Consensus Standards Bodies In Which There is Agency Participation

9

6. Provide an Evaluation of the Effectiveness of Circular A-119 Policy and Recommendations for any Changes

During FY 2001, the Commission's efforts to enhance voluntary safety standards development was complemented by the overall Federal policy set forth in the Circular. At the end of the reporting period, the Commission's Voluntary Standards Coordinator was participating in the Interagency Committee on Standards Policy's review of possible recommendations for changes to the Circular.

7. Provide the Conformity Assessment Activities in Which the Agency has been Involved N/A

8. Provide any Examples or Case Studies of Standards Successes 
The CPSC staff provided technical support to the development of 17 new or revised voluntary safety standards that were completed in FY 2001. The Commission's

Directive to employees on "Communications with Voluntary Standards Groups and Organizations" was updated in September 2001.

\section{Comments}

The Consumer Product Safety Act (CPSA), as amended, requires the Commission to defer to issued voluntary standards, rather than promulgate mandatory standards, when the voluntary standards will eliminate or adequately reduce the risk of injury addressed and it is likely that there will be substantial compliance with the voluntary standards. In addition, the Commission is required, after any notice or advance notice of proposed rulemaking, to provide technical and administrative assistance to persons or groups who propose to develop or modify an appropriate voluntary standard. Additionally, the Commission is encouraged to provide technical and administrative assistance to groups developing product safety standards and test methods, taking into account Commission resources and priorities.

Since its inception in 1973, the Commission has promoted the development of voluntary product safety standards. Policy statements in support of voluntary standards were published by the CPSC in 1975 and 1978. These policy statements were updated in 1988 (16 U.S.C. 1031), and a staff directive on implementation of portions of these policy statements was promulgated in October 1989 and updated in September 2001. Since the principles set forth in the OMB Circular A-119 Rev. were published, the Commission has consistently supported them. The CPSC Voluntary Standards Coordinator, who also serves as the CPSC's Standards Executive for the purpose of implementing OMB Circular A-119 Rev., provides general oversight for staff involvement in existing standards projects. The Voluntary Standards Coordinator establishes agency views on standards issues and decisions through Commission response to staff briefing packages and recommendations. These views are reflected in the Commission's Operating Plan and Budget. Coordinating participation within the Commission and with others in voluntary standards activities is a responsibility of the Voluntary Standards Coordinator. Likewise the Voluntary Standards Coordinator is responsible for meeting reporting requirements applicable to voluntary standards involvement of Commission staff.

The Commission had 31 employees directly participating in the development of 59 consumer product safety standards during FY 2001. Among the 17 new or revised consumer product safety standards completed in FY 2001 were those dealing with baby gates and enclosures, infant swings, bunk beds, chain saws, swimming pool alarms, and public playground equipment.

For further information please contact the CPSC's Standards Executive: Mr. Colin B. Church, Voluntary Standards and International Activities Coordinator, U.S. Consumer 
Product Safety Commission, Room 600C, Washington, D.C. 20207, Tel. 301-504-0554 ext. 2229, Fax. 301-504-0407, E-mail: cchurch@cpsc.gov 


\section{ENVIRONMENTAL PROTECTION AGENCY (EPA)}

1. Number of Government Unique Standards Used in Lieu of Voluntary Standards

Government Standard

EPA Methods 1,2,2C,3,3B,4

EPA Method 2

EPA Method 18

EPA Method 25, 25A

EPA Method 25A

EPA Method 3

EPA Method 1,2,3,4
Voluntary Standard

ASTM D3154-00

ASTM D3796

ASTM D6060-96

ISO 14965:2000(E)

EN 12619:1999

ASME C00031

ASTM D3154-95
Explanation

Impractical alternative to EPA tests for purpose of the rule.

Impractical alternative to EPA test methods for the purposes of the rule

Impractical alternative to EPA test methods for the purpose of the rule

Impractical alternative to EPA test methods for the purpose of the rule.

Not practical due to lack of equivalency, detail, and/or quality assurance and/or quality control requirements.

EPA looked at this standard for both Pulp \& Paper Hazardous Air Pollutant rules and for the Small Municipal Waste Combustion rule. Too broad for regulatory use; covers EPA methods with too many variants.

EPA looked at this standard for both Pulp \& Paper Hazardous Air Pollutant rules and for the Small Municipal Waste Combustion rule. In both cases, the standard was not approved as an equivalent to EPA methods because it lacks quality control and quality assurance 
requirements appropriate to the rules.

EPA Method 5,17

EPA Perform.Spec.11

EPA Method 5i

EPA Method 10,10a

EPA Method 29

EPA Method 29
ASTM D3685/3685M95

ISO 10155:1995

ASTM D6331-98

CAN/CSA Z223.21M1978

ASTM D4358-94: 1999

ASTM E1741-95
EPA looked at this standard for both Pulp \& Paper Hazardous Air Pollutant rules and for the Small Municipal Waste Combustion rule. Contains sampling options beyond which would be considered acceptable for Method 5.

Does not contain detailed RATA procedures and does not produce particulate matter measurements like EPA methods.

This standard does not have paired trains as specified in Method 5 and does not include some quality control procedures specified in the EPA method and which are appropriate to use in this rule.

Lacks in detail and quality assurance/quality control requirements and provides no distinction between continuous and integrated sampling.

Key technical differences in chemical digestion processes and in filter methodology between Method 29 and the ASTM standard make the VCS impractical to use for the purposes of this rule.

Key technical differences in chemical digestion processes and in filter methodology between Method 29 and the ASTM standard make the VCS impractical to use for the 
purposes of this rule.

EPA Method 23

CEN EN 1948-3

EPA Method 29,101,101a

CAN/CSA Z223.26M87

EPA PS-2

ISO 7935:1992

ASME C00049

EPA Method 5, 17

EPA Method 2

EPA Method 2

EPA Method 2

EPA Method 24
ISO 10780

ASTM D3464-96

ASTM D 3464-96

ISO 118900-1
Provides additional sampling options other than what is acceptable in Method 23.

This standard is only applicable to background and near ambient levels of mercury and for low volume air sampling. The Quality Assurance is limited or not well documented. The standard is not an adequate alternative for the purposes of this rule.

The standard lacks in detail and quality assurance/quality control requirements. It is missing calibration drift requirements and has limited concentration range of applicability.

EPA looked at this standard for both Pulp \& Paper Hazardous Air Pollutant rules and for the Small Municipal Waste Combustion rule. Too flexible in allowing for more train configurations than is appropriate for purposes of this rule.

Impractical alternative to EPA test methods for the purposes of the rule

Impractical alternative for the purposes of the rule

Lacks sufficient supporting data to determine if standard is equivalent and therefore applicable to use along with EPA method.

Impractical alternative to EPA 
test method for the purposes of the rule.

EPA Method 25

EPA Method 2

EPA Method 5

EPA Method 3A

EPA Method 4

EPA Method 5

EPA Method 3A
EN 12619 (1999)

ASTM D3796-98

ASTM D4536-96

ASTM D5835-95

ASTM E337-84

CSA Z223.1-M1977

CAN/CSA Z223.2-M86
Impractical alternative to EPA test methods for the purposes of the rule.

Good procedure but not a complete alternative for method 2 and therefore impractical for use in this rule.

EPA looked at this standard for both Pulp \& Paper Hazardous Air Pollutant rules and for the Small Municipal Waste Combustion rule. Not practical due to lack of equivalency, documentation, validation data and other important technical and policy considerations.

EPA looked at this standard for both Pulp \& Paper Hazardous Air Pollutant rules and for the Small Municipal Waste Combustion rule. Lacks in quality assurance and quality control requirements.

Only covers small portion of EPA method 4 and therefore not practical for use in this rule.

Key technical differences and lack of detailed quality assurance quality control requirements make this impractical for this rule.

EPA looked at this standard for both Pulp \& Paper Hazardous Air Pollutant rules and for the Small Municipal Waste Combustion rule. Too general - lacks in detail and in quality control, quality 
EPA Method 25a

EN 12619:1999

EPA Method 1,2,5

EPA Method 3A

EPA Method 2

EPA Method 12, 29

EPA Method 26, 26a

EPA PS-1

ISO 9096:1992 assurance requirements.

Impractical for use in this rule because does not measure solvent process vapors in concentrations greater than 40ppm carbon.

EPA looked at this standard for both Pulp \& Paper Hazardous Air Pollutant rules and for the Small Municipal Waste Combustion rule. The method will not produce particulate matter measurements equivalent to EPA method 5.

ISO 10396:1993

EPA looked at this standard for both Pulp \& Paper Hazardous Air Pollutant rules and for the Small Municipal Waste Combustion rule. Similar to some EPA Methods, but lacks in quality assurance and quality control requirements.

ISO 10780:1994

Technical differences based on pilot tube shapes making standard impractical for use in this rule.

ASTM E1979-98

Key technical differences in chemical digestion processes and in filter methodology between Method 29 and the ASTM standard make the VCS impractical to use for the purposes of this rule.

EN 1911-1,2,3:1998

Key technical differences in sampling techniques and other technical differences make the EN standard impractical as an alternative to the EPA Methods.

ASTM D6216-98
The standard does not address all the requirements specified in PS1 . 
2. Number of Voluntary Consensus Standards Substituted for Government Unique Standards

1

\begin{tabular}{|l|l|}
\hline Voluntary Standard & Government Standard \\
\hline ASTM D4057 Standard Practice for Manual & 40 CFR part 80, Appendix G \\
\hline ASTM D4177 Standard Practice for & 40 CFR part 80, Appendix G \\
\hline
\end{tabular}

3. Number of Voluntary Consensus Standards used in FY 2001

64

4. Number of Agency Employees Participating In Voluntary Consensus Standards Activities

46

5. Number of Voluntary Consensus Standards Bodies In Which There is Agency Participation 20

6. Provide an Evaluation of the Effectiveness of Circular A-119 Policy and Recommendations for any Changes

EPA is working with NIST and other agencies to assist OMB in revising the language of the current Circular in order to enhance its effectiveness and facilitate its implementation.

7. Provide the Conformity Assessment Activities in Which the Agency has been Involved National Environmental Laboratory Accreditation Conference National Accreditation Program (NAP) for ISO 14001 Environmental Management 
Systems

ANSI-RAB (Registration Accreditation Board) for ISO 9000 Quality Management

Systems

ANSI-RAB Joint Oversight Board (for ISO 14001 and ISO 9000 programs)

Energy Star

\section{Provide any Examples or Case Studies of Standards Successes}

EPA's new standards web site will be completed shortly and will be the primary access point for the public regarding the Agency's voluntary standards activities. Case studies and success stories will be available on the web site, along with EPA standards' policies and current news. EPA expects that the web site will be available by the end of December, 2001. The URL for the web site will be made available to OMB, Congress and the public as soon as it is established.

\section{Comments}

Footnote to Above Section\#1:

A. Although EPA determined that the voluntary standards listed in the section are not practical for the purposes of the rules, EPA did not create any new governmentunique standards; the government standards listed were previously in effect.

B. In general the reason for not using the VCSs listed is: The VCS is not practical due to lack of equivalency, documentation, validation data and other important technical and policy considerations. The rules go into more complete technical detail; only a brief summary of the justification for non-use is given in this table.

C. EPA reports the use of government-unique standards and the justification for not using potentially applicable voluntary standards as the basis of context. EPA believes that the public, standards developing organizations and industry need to know the context in which the agency considered use of a voluntary standard in order to understand the actions of the agency, and in order to evaluate the potential of the standard for possible regulatory applications in future actions. The context will give standards developers a framework in which to consider updates of the standard. For example, industry may determine that use of a particular VCS in regulatory actions is a prime driver for updating that standard, or it may determine that market needs are best served by having both the regulatory and the voluntary standard.

Given this explanation, EPA reserves the right to make the determination of context and to report, when appropriate, multiple rejections of a single VCS. In other cases, the reason for rejection of a VCS in separate rules is so similar in context and involves the same EPA Method, that the use of the government method and consequent rejection of the VCS is counted only once. 


\section{FEDERAL COMMUNICATIONS COMMISSION (FCC)}

1. Number of Government Unique Standards Used in Lieu of Voluntary Standards 0

2. Number of Voluntary Consensus Standards Substituted for Government Unique Standards

0

3. Number of Voluntary Consensus Standards used in FY 2001

0

4. Number of Agency Employees Participating In Voluntary Consensus Standards Activities

5

5. Number of Voluntary Consensus Standards Bodies In Which There is Agency Participation

1

6. Provide an Evaluation of the Effectiveness of Circular A-119 Policy and

Recommendations for any Changes

The policies of Circular A-119 are clearly stated for application to the activities of the FCC, and the Commission recognizes the benefit of using voluntary consensus standards when applicable.

7. Provide the Conformity Assessment Activities in Which the Agency has been Involved

None

8. Provide any Examples or Case Studies of Standards Successes

None

9. Comments

This Web-based procedure for reporting works well. 
FEDERAL EMERGENCY MANAGEMENT AGENCY (FEMA)

No Report 


\section{FEDERAL TRADE COMMISSION (FTC)}

1. Number of Government Unique Standards Used in Lieu of Voluntary Standards 0

2. Number of Voluntary Consensus Standards Substituted for Government Unique Standards

0

3. Number of Voluntary Consensus Standards used in FY 2001

0

4. Number of Agency Employees Participating In Voluntary Consensus Standards Activities

0

5. Number of Voluntary Consensus Standards Bodies In Which There is Agency Participation

0

6. Provide an Evaluation of the Effectiveness of Circular A-119 Policy and

Recommendations for any Changes

See response to question 9.

7. Provide the Conformity Assessment Activities in Which the Agency has been Involved

See response to question 9.

8. Provide any Examples or Case Studies of Standards Successes

See response to question 9 .

9. Comments

The Federal Trade Commission is an independent agency of the United States government charged with enforcing competition and consumer protection laws. The Commission's only contact with voluntary consensus standards and the organizations which produce them is in connection with the enforcement of the Federal Trade 
Commission Act, which prohibits unfair methods of competition and unfair or deceptive acts or practices affecting commerce. The Commission does not promulgate its own standards or engage in other standards activities pertinent to OMB Circular A119. 


\section{GOVERNMENT SERVICES ADMINISTRATION (GSA)}

1. Number of Government Unique Standards Used in Lieu of Voluntary Standards

2

Government

Standard

FF-L-2740

KKK-1822E

\section{Voluntary \\ Standard}

UL 768

ASTM F-2020-1

\section{$\underline{\text { Explanation }}$}

The document covers combination locks used for the protection of classified, national security information. In testing locks under the voluntary standard it was found that the locks did not provide the level of protection required by Federal agencies.

F-2020-1 is currently being reviewed/compared to KKK1822E. Review to be completed by January 2 , 2002. If F-2020-1 is acceptable, it will be cited in future GSA procurements for "Ambulances" in lieu of Federal specification KKK$1822 \mathrm{E}$

2. Number of Voluntary Consensus Standards Substituted for Government Unique Standards

19

Voluntary Standard

ASTM D4317

MPI 5 or 7

MPI 51, 47, 48 or 49

MPI 8, 9, or 94

MPI 138, 141, 114 or 139

ASTM D98

\section{Government Standard}

A-A-3053

A-A-2336

A-A-2962

A-A-3067

A-A-2246

A-A-169 
ASTM D632

NFPA 1964

SAE AMS-C-22542

GPA (Gas Processors

SAE-AS 8662

ASTM D3656

ASTM D4111

ASTM D5433

ASTM D5434

ASTM F1085

ISEA/ANSI Z89.1

SAE/AMS 2431

MPI 28
A-A-1545

A-A-2279, A-A-2280, A-A-2281

MIL-C-22542

A-A-2897

MIL-K-8662E

L-S- 125

MIL-T-82291

DDD-T-511

DDD-T-531

V-M-96

A-A-2269

MIL-G-9954

A-A-3108

3. Number of Voluntary Consensus Standards used in FY 2001 25

4. Number of Agency Employees Participating In Voluntary Consensus Standards Activities

41

5. Number of Voluntary Consensus Standards Bodies In Which There is Agency Participation 107

6. Provide an Evaluation of the Effectiveness of Circular A-119 Policy and Recommendations for any Changes

We have no comments or recommendations for change concerning OMB Circular A-119.

7. Provide the Conformity Assessment Activities in Which the Agency has been Involved -ISO TC 29:

The US Technical Advisory Group (TAG) is responsible for determining the U.S position on IEC/ISO standards pertaining to technical committee or subcommittees in addition to the review of policy matters. The standards include hand tools and accessories for safety requirements relating to the elements of design, use, and selection of; performance, tolerances, and outline configurations of; including but not 
limited to, wrenches, pliers, screwdrivers, shears, punches, chisels, hammers, and toolboxes. The standards will include the development of requirements, the consideration of various types and classes of hand tools and accessories required for specified classes of service, and the tests needed to determine conformance with the service classification requirements.

\section{-Tool Fastener Working Group:}

To discuss the standardization and end use relationship between fasteners and hand tools. By active participation from: GSA, FSS Hardware SuperStore, Defense Industrial Center, Philadelphia, NG Standards Activities (AIA, SAE, ASME), Fasteners and Tool Manufactures, Designers, and End Users. Fastener and hand tools are an integrated system where the goal of this group is to improve the performance of fastener systems by evaluating at the tool-fastener interface, in addition to creating a Review Committee to evaluate and improve non-government standards.

\section{-Green Seal:}

Participated with Green Seal to develop a voluntary environmental preferred product standard for commercial adhesives (GS-36). Worked with GreenSeal, DoD and our suppliers to delineate coatings that have passed one or more of the GreenSeal criteria. "GreenSeal Certified" products are delineated on the GSA Hardware SuperStore web page under "Environmental Issues".

http://www.greenseal.org/

http://r6.gsa.gov/fss/hac/

-National Institute of Building Sciences (NIBS):

Master Painters Institute:

Scientific Certification Systems (SCS):

Provided input for a voluntary certification criterion for manufacturers of architectural and anti-corrosive paints. This was a joint effort by the National Institute of Building Sciences (NIBS), Master Painters Institute (MPI), ICI paint, Department of Defense, General Services Administration, Chemical Manufacturers' Association and Scientific Certification Systems. This criteria is based on International Organization for Standardization (ISO) Standard 14042, as prepared by Technical Committee ISO/TC 207, Environmental Management, Subcommittee SC 5, Life Cycle Assessment and has been adopted as a standard by Master Painters Institute (MPI). "SCS Certified" products are delineated on the GSA Hardware SuperStore web page under "Environmental Issues". http://www.scs1.com. http://www.hvacmall.com/listing/nibs.htm 
-Clean Air Act National Emission Standards for Hazardous Air Pollutants (CAA NESHAP) Compliance - for Shipbuilding and Aerospace coatings:

The Clean Air Act (40th Code of Federal Regulations, Subpart 63.741-63.753 and 63.780) designate "Shipbuilding and Ship Repair Facilities" and "Aerospace Manufacturing and Rework Facilities" as a regulated emissions source categories. Clean Air Act rules limit the volatile organic hazardous air pollutant (VOHAP) content of several types of solvents, coatings, strippers and maskants used within these industrial categories. Compliance is based on proper documentation that volatile organic compound (VOC) or VOHAP emissions were within allowable limits Shipbuilding and Ship Repair Facilities: Clean Air Act NESHAP shipbuilding compliance certificates were developed as a joint effort between the U.S. Naval Facilities Engineering Service Center (NFESC), U.S. Naval Sea Systems Command, U.S. Naval Supply Systems Command, U.S. Environmental Protection Agency and General Services Administration.

Aerospace Manufacturing and Rework Facilities: Clean Air Act NESHAP aerospace compliance certificates were developed as a joint effort between the U.S. Naval Facilities Engineering Service Center (NFESC), U.S. Naval Air Systems Command, U.S. Naval Supply Systems Command, U.S. Air Force Center for Environmental Excellence, U.S. Air Force Ogden Air Logistics Center, U.S. Environmental Protection Agency and General Services Administration.

http://www.r6.gsa.gov/fss/HAC/

[Environmental Issues]

http://www.epa.gov/ttn/uatw/shipb/shipguid.pdf

Pages E-18, E-32, E-33

-Hazardous Material Information System (HMIS) Functional Working Group:

Soon to be Hazardous Material Information Resource System (HMIRS)

The HMIS Functional Working Group (FWG) is chartered under the sponsorship of the HMIS Policy Working Group (PWG). Its role is to represent the users of hazardous materials information and management systems, which deal with Material Safety Data Sheets (MSDS) or related/associated technical information, and strive to ensure that the functional needs of those users are met. Also, the FWG prepares recommendations to the PWG on issues pertaining to the functional aspects of improvements to existing or future DOD hazardous materials information and management systems. The core FWG membership consists of voting representatives from the Army, Air Force, Navy, DLA, and GSA. http://www.dscr.dla.mil/hmis/HomePage.htm

-National Defense Industrial Association/ Department of Defense:

Attended the 27th Environmental Symposium and Exhibition - Austin, TX, April 23 26, 2001: Published and presented a paper on GSA's Procurement and Environmental Initiatives, and attended 20 technical sessions which covered the latest DoD strategic plans and policy on future environmental management. Technical sessions and 
associated networking also provided key point of contact information on the DoD Joint Group on Pollution Prevention, U.S. Army Ecology Conservation Center, and the U.S. Air Force Center for Environmental Excellence "Pro-Act" office.

http://environment.ndia.org/

-GSA Hardware SuperStore/ Supplier/ Customer Paints, Sealants and Coatings Business Development Partnership:

Attended Paints, Sealants and Coatings Coordination Meeting, Plaza Level Auditorium, Main Building, GSA Kansas City, June 13-14, 2001: Provided information to this forum on how the Qualified Products Listing (QPL) program differs from the Multiple Award Schedule. Explained to the group the status and purpose of Commercial Item Description A-A-3185, "Latex Paint with Post-Consumer Material Content". The GSA Hardware SuperStore Business Development Division (6FEM), Technical Services Division (6FEE), Stock and Special Order Acquisition Division (6FEP) and Commercial Products and Services Acquisition Division (6FEC) attended this meeting. In addition, many customers and suppliers attended the meeting, including Warner Robbins Air Logistics Center, Whiteman AFB, ICI Paint, Sherwin Williams, and PPG Paint.

-National Aerospace Defense Contractors Accreditation Program (NADCAP:

NADCAP represents major prime contractors, suppliers, and government agencies in aerospace, defense, and related industries throughout the United States and internationally. NADCAP is administered by the Performance review Institute (PRI), and independent for profit trade association affiliated with the Society of Automotive Engineers (SAE). Through NADCAP, PRI accredits subcontractors and suppliers to aerospace and industry consensus standards. Through NADCAP, PRI assures and enhances quality, saves valuable time and efforts and cuts direct and overhead costs by performing the following functions:

- Compiling audit criteria

- Securing acceptance of these lists as internationally recognized ASE Aerospace Standards

- Auditing suppliers' technical capabilities and conformance to applicable procedures and/or government agencies

- Focusing the responsibility for quality maintenance on the supplier and subcontractors

- Publishing a qualified manufacturer's List and making it available to primes

- $\quad$ Promoting the benefits of using accredited suppliers

GSA Hardware SuperStore is a prime member of the Sealants and Coating Groups and is also a member of Qualified Product Management Council (QPMC). 
-Society of Automotive Engineers (SAE:

GSA Hardware SuperStore is a member of the SAE, G8 - Aerospace Coatings Committee and G9 Aerospace Sealants Committee and actively participates in the development of Aerospace Material Standards. These committees are actively involved in the conversions of Military Specifications and the development of Aerospace Material Standards.

Serve a chairman of the G8 Laboratory Accreditation Sub-Committee, for development of a laboratory accreditation protocol consistent with ISO and IEC accreditation standards. This standard, AS5505, May 2001, provides interpretation of ISO/IEC 17025 and establishes additional requirements for accreditation of testing laboratories for evaluating organic coatings. This step was necessary for the development of the Qualified Manufacturers List (QML) program for G8 Aerospace Coatings.

-USDA, Forestry Service:

GSA/FSS Hardware SuperStore representative to the USDA, Forestry Service, Tree Marking Paint Standard Development Committee. Provided expert consultation for environmental, health and technical issues leading to development of the FS 2400-400 specification.

-Building Products Pre-Approval Program (BPPAP):

GSA/FSS Hardware SuperStore representative to the Building Products Pre-Approval Program (BPPAP) Committee of the National Institute for Building Sciences, Washington, DC. This committee coordinates the development of non-governmental architectural and industrial paint and coatings Standards with the Master Painters Institute. Through this committee, more than 26 Federal Specifications and Commercial Item Descriptions have been replaced with Master Painters Institute Standards.

The BPPAP committee, through Scientific Certifications Systems, a third party, internationally recognized certification organization, is pursuing development of Environmentally Preferred Purchasing, EPP, certification for products, mandated by Executive Order 13101. The BPPAP reviews and approves the protocol for EPP certification that SCS performs.

8. Provide any Examples or Case Studies of Standards Successes

None

9. Comments

None 


\section{GOVERNMENT PRINTING OFFICE (GPO)}

1. Number of Government Unique Standards Used in Lieu of Voluntary Standards

4

Government

Standard

FED-STD 209

MIL-STD 105

MIL-STD 1189

MIL-STD 498
Voluntary Standard

ISO $14644-1 \&$ ISO

14644-2

ANSI/ASQC Z1.4

ANSI/AIM X5-2 \& ANSI

X3.182

IEEE/EIA 12207.0, IEEE/EIA 12207.1, \& IEEE/EIA 12207.2

\section{$\underline{\text { Explanation }}$}

Second ISO standard not issued until end of FY2000; still appears in some contracts Cited in small number of contracts due to editing errors. These are gradually being corrected.

Cited in small number of contracts due to editing errors. These are gradually being corrected.

Cited in small number of contracts due to editing errors. These are gradually being corrected.

2. Number of Voluntary Consensus Standards Substituted for Government Unique Standards

0

3. Number of Voluntary Consensus Standards used in FY 2001

116

4. Number of Agency Employees Participating In Voluntary Consensus Standards Activities 
5. Number of Voluntary Consensus Standards Bodies In Which There is Agency Participation

6. Provide an Evaluation of the Effectiveness of Circular A-119 Policy and Recommendations for any Changes

The Circular provides effective procedures for the transition to use of voluntary consensus standards in government business. We have no recommendations for changes.

7. Provide the Conformity Assessment Activities in Which the Agency has been Involved

None

8. Provide any Examples or Case Studies of Standards Successes

None

9. Comments

The Circular provides effective procedures for the transition to use of voluntary consensus standards in government business. We have no recommendations for changes. 


\section{INTERNATIONAL TRADE COMMISSION (ITC)}

1. Number of Voluntary Consensus Standards Bodies in Which There is Agency Participation:

1

2. Number of Agency Employees Participating in Voluntary Consensus Standards Activities:

1

3. Number of Voluntary Consensus Standards Used in FY 2000:

0

4. Number of Voluntary Consensus Standards Substituted for Government-Unique Standards:

0

5. Number of Government-Unique Standards Used in Lieu of Voluntary Standards:

0

6. Provide an Evaluation of the Effectiveness of Circular A-119 Policy and Recommendations for Any Changes:

Circular A-119 does not have a significant impact on our operations and we have no basis for an evaluation.

7. Provide the Conformity Assessment Activities in Which the Agency has been Involved:

We are nominal members of the National Institute of Standards and Technology standards group, but do not participate in a substantial way. We collect data for trade investigations using whatever standards that prevail in whatever industry we are studying.

8. Provide Any Examples or Case Studies of Standards Successes:

$\mathrm{N} / \mathrm{A}$ 
9. Comments:

None. 


\section{NATIONAL AERONAUTICS AND SPACE ADMINISTRATION (NASA)}

1. Number of Government Unique Standards Used in Lieu of Voluntary Standards 0

2. Number of Voluntary Consensus Standards Substituted for Government Unique Standards

1

Government Standard Voluntary Standard

ANSI/UL 325-2001 (in part) 16 CFR 1211

3. Number of Voluntary Consensus Standards used in FY 2001

1

4. Number of Agency Employees Participating In Voluntary Consensus Standards Activities

31

5. Number of Voluntary Consensus Standards Bodies In Which There is Agency Participation

9

6. Provide an Evaluation of the Effectiveness of Circular A-119 Policy and Recommendations for any Changes

OMB Circular A-119 continues to provide stimulus for NASA's effort to improve its Technical Standards Management System, enhance the use of Voluntary Consensus Standards Products, and challenge the need for NASA-unique Technical Standards requirements.

7. Provide the Conformity Assessment Activities in Which the Agency has been Involved

As an acquisition oriented Agency, conformity assessment is a major element of our policies and procedures to assure the safety and mission success of NASA programs. NASA is continuously evaluating and improving our conformity assessment practices and procedures. 
NASA has a long-standing practice of working with other Government Agencies and the public sector to integrate best practices into our activities. NASA continues to work with the Department of Defense (DoD) and the aerospace industry to adopt and define consistent quality practices. NASA routinely utilizes other Government Agencies to assist us with Contract Administration Services (CAS) including substantial conformity assessment activities. The Defense Contract and Audit Agency, Defense Contract Management Agency, Office of Naval Research and other activities continue to provide conformity assessment services for NASA programs. These are ongoing relationships that utilize the expertise and infrastructure that are resident within these agencies and allow NASA to limit NASA internal assessments to areas where external capabilities are not available. The management and monitoring processes established for these CAS activities provides a mechanism to continually exchange ideas and best practices related to conformity assessment.

Finally, NASA is pursuing Star status in the Occupational Safety and Health Administration's (OSHA) Voluntary Protection Program (VPP). Participation in the VPP provides a mechanism for both improving internal safety practices and for utilizing the services of the OSHA programs to perform oversight inspections. To date, the Langley Research Center and the Johnson Space Center have achieved Star status and have been recognized by OSHA, the other NASA Centers are in various stages of preparation for assessment by OSHA.

\section{Provide any Examples or Case Studies of Standards Successes}

NASA has enhanced its use and support of Voluntary Consensus Standards (VCS) through the web-based NASA Technical Standards System, which currently has the capability to provide full text standards (on-line or hard copy) to all NASA users, notification when standards are modified, and direct links on applicable standards to "lessons learned" and other recommendations for their use. Full-text standards, including all the voluntary consensus standards adopted as NASA Preferred Technical Standards, are available at the desktop for internal NASA use. Technical standards are available from 108 Standards Developing Organizations. For those technical standards products not available electronically, a hard copy will be provided.

A limited pilot version of this System was implemented last year with favorable feedback leading to the Agency wide implementation this past June. Statistics to date indicate increasing use of VCS with approximately 6,000 people (NASA and Public) registering in four months to access the system. There have been approximately 15,000 logins to the system where over 12,000 technical standards have been downloaded to support NASA Programs/Projects. The Standards Update Notification System (SUNS) provides users with notices of updates (revisions, cancellations, superseded documents, etc.) to Technical Standards Products that they have identified as "in use" on their Programs/Projects. This system is integrated with the Agency wide Full-Text Technical Standards System to provide the latest full-text versions of the technical standards on demand. Where documents identified on Program/Project "watch lists" have not been 
adopted as NASA Preferred Technical Standards, they are automatically entered in the adoption screening process.

The System was made available Agency wide in October. To date, 124 Lessons Learned citations from the NASA Lessons Learned Information System (LLIS) site have been linked to 55 documents in the NASA Technical Standards System. Application Notes have been applied to 102 documents in the System. Continuing efforts to add Lessons Learned and Application Notes promises to be of great benefit in adapting VCS to NASA use. Approximately 50 additional links to other Lessons Learned Websites provide users with additional technical information from a variety of other Government and non-Government sources.

User response to these new capabilities has been outstanding, demonstrating the value of VCS information to NASA Programs and Projects. The metrics of these Systems shows increased use across the Agency in response to awareness activities at the various Centers. A NASA authored paper entitled "Lessons Learned and Standards - A Logical Marriage" was published in the November 2001 issue of ASTM

Standardization News. It focuses on the importance of the relationship between lessons learned and technical standards. Use of the NASA Technical Standards System - and access to VCS - has grown significantly due to the availability of technical standards products on-line and supporting information programs. Brochures and "mini-CDs" have been distributed within the Agency as well as at conferences and professional meetings. The Program has taken advantage of NASA Center's training opportunities to include short training courses on technical standards policy and use of the web site, which leads users to VCS. We fully expect these Awareness activities to increase the use of VCS to meet standards information needs, as well as increasing the effectiveness of NASA participation on Standards Developing Organization committees.

\section{Comments}

None 


\section{NATIONAL ARCHIVES AND RECORDS ADMINISTRATION (NARA)}

1. Number of Government Unique Standards Used in Lieu of Voluntary Standards

1

\section{Government \\ $\underline{\text { Standard }}$ \\ NARA data \\ standards}

\section{Voluntary Standard}

MARC - Machine Readable

Cataloguing

EAD - Encoded Archival

Description

APPM - Archives, Personal

Papers, and Manuscripts

ISAD $(G)$ - General International

Standard Archival Description

ISAAR(CPF) - International

Standard Archival Authority

Record for Corporate Bodies,

Persons and Families

\section{$\underline{\text { Explanation }}$}

These standards

do not meet the

precise needs of

our agency.

However, we

continue to bring

our individual

data elements

guidance closer

into line with

these voluntary

standards.

2. Number of Voluntary Consensus Standards Substituted for Government Unique Standards

0

3. Number of Voluntary Consensus Standards used in FY 2001

0

4. Number of Agency Employees Participating In Voluntary Consensus Standards Activities

5

5. Number of Voluntary Consensus Standards Bodies In Which There is Agency Participation

6

6. Provide an Evaluation of the Effectiveness of Circular A-119 Policy and Recommendations for any Changes 
NARA employees involved in standards-setting activities are cognizant of the importance of using voluntary technical consensus standards. Where possible we have incorporated by reference in our regulations voluntary standards rather than government unique standards.

7. Provide the Conformity Assessment Activities in Which the Agency has been Involved

NARA is in process of assessing our own compliance with records center standards that must be met by 2009. By 2009 all private companies will have to comply with these standards if they plan to house Federal government records in their facilities. The Deputy Archivist of the United States is actively involved in the development of an international standard addressing records management.

8. Provide any Examples or Case Studies of Standards Successes

When fires occurred at the Washington National Records Center at Suitland, Maryland, the NARA fire protection systems, based on our standards, confined the damage to a small area and with little loss or damage to records.

9. Comments

None 


\section{NATIONAL SCIENCE FOUNDATION (NSF)}

1. Number of Government Unique Standards Used in Lieu of Voluntary Standards 0

2. Number of Voluntary Consensus Standards Substituted for Government Unique Standards

0

3. Number of Voluntary Consensus Standards used in FY 2001

0

4. Number of Agency Employees Participating In Voluntary Consensus Standards Activities

3

5. Number of Voluntary Consensus Standards Bodies In Which There is Agency Participation

2

6. Provide an Evaluation of the Effectiveness of Circular A-119 Policy and Recommendations for any Changes

A-119 allows effective agency participation in standards activities. No changes are recommended.

7. Provide the Conformity Assessment Activities in Which the Agency has been Involved

None

8. Provide any Examples or Case Studies of Standards Successes

None

9. Comments

None 


\section{NUCLEAR REGULATORY COMMISSION (NRC)}

1. Number of Government Unique Standards Used in Lieu of Voluntary Standards 0

2. Number of Voluntary Consensus Standards Substituted for Government Unique Standards

0

3. Number of Voluntary Consensus Standards used in FY 2001

64

4. Number of Agency Employees Participating In Voluntary Consensus Standards Activities

139

5. Number of Voluntary Consensus Standards Bodies In Which There is Agency Participation

18

6. Provide an Evaluation of the Effectiveness of Circular A-119 Policy and

Recommendations for any Changes

The policy guidelines provided in OMB Circular A-119 for participating in voluntary consensus standards bodies and using voluntary consensus standards are generally consistent with longstanding NRC practices. The staff believes that these guidelines provide appropriate direction and encouragement for Federal agencies to develop internal agency-wide guidelines to implement P. L. 104-113 and OMB Circular A-119. These guidelines also provide sufficient and reasonable flexibility for each agency to make an independent case-by-case determination as to the usability of a particular standard within that agency's scope and responsibility.

7. Provide the Conformity Assessment Activities in Which the Agency has been Involved None

8. Provide any Examples or Case Studies of Standards Successes 
When fires occurred at the Washington National Records Center at Suitland, Maryland, the NARA fire protection systems, based on our standards, confined the damage to a small area and with little loss or damage to records.

\section{Comments}

The Nuclear Regulatory Commission (NRC) has been an active participant in the development and use of consensus standards since its establishment in 1975. The Commission's Strategic Assessment and Rebaselining Initiative in 1996 further increased NRC's focus on the use of standards. For nuclear reactor and nuclear materials safety, the strategy is to increase the involvement of licensees and others in the NRC regulatory process consistent with Public Law 104-113, "National Technology Transfer and Advancement Act of 1995" (P. L. 104-113). To do this, NRC will continue to encourage industry to develop codes, standards, and guides that NRC can endorse and the industry can carry out.

In FY 2001, NRC took several actions to increase the effectiveness and efficiency of our process for implementing P. L. 104-113 and OMB Circular A-119, "Federal Participation in the Development and Use of Voluntary Consensus Standards and in Conformity Assessment Activities." On January 17, 2001, NRC staff met with representatives from the standards development organizations (SDOs) that provide codes and standards for the nuclear industry. The NRC has been hosting these meetings on a semi-annual basis. The purpose of these meetings is to foster better communication and discuss standards under development, current needs, and priorities. The SDOs that the Department of Energy (DOE) interacts with are, in many cases, the same as the NRC. Thus, NRC and DOE decided to co-host a meeting, which was held on June 27, 2001. This joint format proved to be very beneficial, and the meeting participants requested that $\mathrm{NRC}$ and DOE co-host the next meeting. Hence, a joint NRC/DOE meeting has been scheduled for January 2002.

Consistent with NRC Management Directive 6.5, "NRC Participation in the Development and Use of Consensus Standards," which was created to provide direction to the NRC staff for implementing P. L. 104-113 and OMB Circular A-119, web-based training has been developed for NRC staff connected with the use of standards. The purpose of the training is to explain the requirements of P. L. 104-113 and OMB Circular A-119 in detail and provide guidance to the NRC staff relative to organizational responsibilities.

The NRC website [http://nrcweb.nrc.gov/NRC/REFERENCE/STANDARDS/], contains, among other things, the SDOs with which the agency interfaces, consensus standards used by the NRC, and NRC staff representatives on SDO committees. 


\section{Appendix C:}

\section{Charter of the Interagency Committee On Standards Policy}




\title{
DEPARTMENT OF COMMERCE
}

\author{
CHARTER \\ OF THE \\ INTERAGENCY COMMITTEE ON STANDARDS POLICY
}

\section{Establishment}

1. The Interagency Committee on Standards Policy (herein after referred to as the Committee) is established to advise the Secretary of Commerce and the heads of other Federal agencies in matters relating to standards policy.

2. The Committee fulfills the mandates set out in paragraph 13.b of the Office of Management and Budget (OMB) Circular No. A-119, "Federal Participation in the Development and Use of Voluntary Consensus Standards and in Conformity Assessment Activities," in its revision of February 19, 1998.

3. The Committee reports to the Secretary of Commerce through the Director of the National Institute of Standards and Technology.

\section{Purpose}

The purpose of the Committee is to ensure effective participation by the Federal Government in domestic and international standards and conformity assessment activities and to promote the adherence to uniform policies by Federal agencies in the development and use of standards and in conformity assessment activities. Well-considered Federal policies reflecting the public interest can expedite the development and adoption of standards that stimulate competition, promote innovation, and protect the public safety and welfare. The establishment and application of appropriate standards for the characteristics or performance of goods, processes, and services can contribute significantly to national and international prosperity, economic growth, and public health and safety. The establishment of such standards can also further national goals for environmentally sound and energy efficient materials, products, systems, services, or practices. Heightened national and international awareness of the importance of standards activities, as reflected by enactment of the National Technology Transfer and Advancement Act of 1995 (P.L. 104-113, signed into law March 7, 1996), and recommendations presented in the National Research Council's report "Standards, Conformity Assessment, and Trade into the 21st Century" (National Academy Press, 1995) call for the Committee to intensify its efforts to identify the broad roles and appropriate interactions of agencies in exercising the Government's authority. 


\section{Objective}

The objective of the Committee shall be to promote effective and consistent standards and conformity assessment policies in furtherance of U.S. domestic and foreign goals and, to this end, to foster cooperative participation by the Federal Government and U.S. industry and other private organizations in standards activities, including the related activities of product testing, management system registration, certification, and accreditation programs.

\section{$\underline{\text { Functions }}$}

1. As appropriate, the Committee shall gather, analyze, and maintain current information about standards; product testing; management system registration; accreditation and certification; and related regulations, rules, policies, and activities:

(a) conducted within or established by Federal agencies;

(b) conducted by private domestic and foreign national standards bodies and by regional and international private and intergovernmental organizations engaged in such programs; and

(c) pertaining to the relationships among agencies of the Federal Government with industry and the various national, regional, and international organizations engaged in such programs.

2. On the basis of such information and when appropriate with respect to the activities named in paragraph one above, the Committee shall make recommendations to the Secretary of Commerce to:

(a) strengthen coordination of standards-related and conformity assessment-related policies and activities among the Federal agencies;

(b) improve the efficiency within the Federal Government of standardization efforts with the U.S. private sector, as well as with regional and international organizations, both private and governmental;

(c) promote standards-related policies, including directories of personnel participating in standards activities, within the Federal Government consistent with statutory obligations in regard to interactions with non-Federal Government organizations;

(d) ensure effective representation of the Federal Government at significant regional and international standards-related meetings and conferences;

(e) promote the use of internationally acceptable standards and related activities with a view to increasing trade and economic integration and development;

(f) monitor U.S. technical obligations as a signatory to the World Trade Organization, the U.S.-Canada Free Trade Agreement, the North American Free Trade Agreement, and other treaties encompassing standards-related trade issues; 
(g) encourage the development of agency strategic plans for managing and monitoring use of voluntary standards and participation in standards-related activities;

(h) promote the use of standards that serve national goals related to increased use of the metric system of measurement and environmentally sound and energy efficient materials, products, systems, services, and practices; and

(i) assess and improve the adequacy of such agency plans and activities.

\section{Membership}

1. Together with the Department of Commerce the following agencies constitute the membership of the Committee:

Department of Agriculture

Department of Defense

Department of Education

Department of Energy

Department of Health and Human Services

Department of Housing and Urban Development

Department of the Interior

Department of Justice

Department of Labor

Department of State

Department of Transportation

Department of the Treasury

Department of Veterans Affairs

Consumer Product Safety Commission

Environmental Protection Agency

Federal Communications Commission

Federal Emergency Management Agency

Federal Trade Commission

General Services Administration

International Trade Commission

Office of Management and Budget

National Aeronautics and Space Administration

National Archives and Records Administration

National Communications Systems (Dept. of Defense) (non-voting member)

National Science Foundation

Nuclear Regulatory Commission

U.S. Agency for International Development

U.S. Government Printing Office (legislative liaison - non-voting member)

U.S. Postal Service

Office of the U.S. Trade Representative 
The head of each member agency shall ensure representation by a responsible highlevel policy official (Senior Executive Service or higher) that serves as the agency representative on the Committee. Such agency representative shall also serve as the "Standards Executive" as defined in section 15 of OMB Circular No. A-119. Appointments to the Committee shall be for an indefinite term.

2. Agency representatives may designate alternates of equivalent senior status to serve in their absence.

3. Experts from organizations within the member agency may be designated by agency representatives to serve on task groups established by the Committee.

4. Other Federal agencies may become members of the Committee upon application to or invitation by the Secretary of Commerce.

\section{$\underline{\text { Administrative Provisions }}$}

1. The Director of the National Institute of Standards and Technology (NIST) or the Director's designee shall chair the Committee.

2. NIST shall provide administrative arrangements for the Committee including secretarial services, calling of meetings, arranging for a meeting place, and preparation of an agenda, discussion material, and reports.

3. The Committee shall meet at least three times each year. Other meetings may be called at the discretion of the Chair or at the written request of five (5) members of the Committee.

4. The Committee may establish task groups as appropriate.

5. Attendance at Committee meetings by at least one half of the designated members of the Committee shall constitute a quorum. Decisions internal to the Committee's operations, such as formation of a task group, shall be made by a majority of those present and voting. Voting on Committee business and proposals shall be limited to designated agency members. Decisions concerning Committee recommendations to the Secretary of Commerce on governmental policy or other matters set out in paragraph two of the section entitled "Functions" shall require ratification by twothirds of the members present and voting. Dissenting positions of the decision may be made a matter of record. The Chair shall not vote except in the case of a tie vote.

6. The annual cost of operating the Committee is estimated at $\$ 25,000$ (with overhead), which includes 0.10 staff year for staff support.

7. The Committee shall submit an annual report to the Secretary of Commerce so that the Secretary may satisfy the reporting requirements set forth in OMB Circular 
No. A-119, as applicable to the Secretary, and in P.L. 104-113, as applicable to the head of each agency. Each such report shall also summarize the Committee's activity during the period covered and shall include a listing of all recommendations formulated by the Committee during that period.

\title{
Duration
}

The need and mission of the Committee shall be reexamined three years after the date of this Charter to determine the need for the Committee's continuation.

\author{
/signed/ \\ Secretary of Commerce
}

Dated: October 26, 2000 


\section{Appendix D:}

\section{Membership of the \\ Interagency Committee on Standards Policy}

Fiscal Year 2001 
Agency for International Development

Standards Executive

Consumer Product Safety Commission

Standards Executive

Consumer Product Safety Commisssion

Standards Executive Representative

Executive Office of the President

OMB/ICSP Liaison

Executive Office of the President

Standards Executive

Federal Emergency Management Agency

Standards Executive

Federal Trade Commission

Standards Executive

General Services Administration
Ms. Kathleen O'Hara

Acting Deputy Director

Office of Procurement

Agency for International Development

Mr. Colin Church

Coordinator

Voluntary Standards \& International

Activities

Consumer Product Safety Commission

Ms. Jacquie Elder

Acting Assistant Executive Director

Consumer Product Safety

Commisssion

Ms. Jacqueline Zeiher

OMB/ICSP Liaison

Office of Management and Budget

Executive Office of the President

Ms. Suzanne Troje

Director, Technical Trade Barriers

U.S. Trade Representative

Executive Office of the President

VACANT

Office of the Director

Federal Emergency Management

Agency

Mr. Alain Sheer

Director of Marketing Practices

Federal Trade Commission 
Standards Executive

General Services Administration

Standards Executive Representative

International Trade Commission

Standards Executive

National Aeronautics and Space Administration

Standards Executive

National Aeronautics and Space Administration

Standards Executive Representative

National Archives and Records Administration

Standards Executive

National Communications Systems

Standards Executive

National Institue of Standards and Technology Committee Chair
Office of the Administrator

General Services Administration

Mr. Charles Gallagher

Director

Environmental and Engineering Policy

(FCOE)

General Services Administration

Mr. Stephen McLaughlin

Acting Director

Office of Administration

International Trade Commission

VACANT

National Aeronautics and Space

Administration

Mr. Richard Weinstein

National Aeronautics and Space

Administration

Ms. Mary Ann Hadyka

National Archives and Records

Administration

Mr. Dale Barr

Chief

Technology and Standards Division

National Communications Systems

Dr. Belinda Collins

Deputy Director

Technology Services

National Institue of Standards and

Technology 
National Institute of Standards and Technology Committee Secretariat

National Institute of Standards and Technology Committee Vice Chair

National Institute of Standards and Technology NIST Support

National Institute of Standards and Technology NIST Support

National Institute of Standards and Technology NIST Support

National Institute of Standards and Technology NIST Support

National Science Foundation Standards Executive
Mr. Kevin McIntyre

ICSP Team Leader

Technical Standards Activities Group

National Institute of Standards and

Technology

Ms. Mary Saunders

Director

Office of Standards Services

National Institute of Standards and

Technology

Mr. Michael Moore

NIST Associate

Technical Standards Activities Group

National Institute of Standards and

Technology

Ms. Maureen Breitenberg

Global Standards and Information

Programs

National Institute of Standards and

Technology

Ms. MaryJo DiBernardo

Global Standards and Information

Programs

National Institute of Standards and

Technology

Ms. JoAnne Overman

Program Manager

Technical Standards Activities Group

National Institute of Standards and

Technology

Dr. William Butcher

Senior Engineering Advisor

National Science Foundation 
Nuclear Regulatory Commission

Standards Executive

Nuclear Regulatory Commission

Standards Executive Representative

U.S. Department of Agriculture

Standards Executive

U.S. Department of Agriculture

Standards Executive Representative

U.S. Department of Defense

Standards Executive

U.S. Department of Defense

Standards Executive Representative

U.S. Department of Education

Standards Executive
Mr. Michael Mayfield

Director

Division of Engineering Technology

Nuclear Regulatory Commission

Mr. Frank Cherny

Technical Assistant to the Director

Divsion of Engineering Technology

Nuclear Regulatory Commission

Dr. Greg Parham

Associate Chief Information Officer

Office of Information

U.S. Department of Agriculture

Ms. Sandra Ginyard

Program Officer

Office of the Chief Information

Officer

U.S. Department of Agriculture

Mr. Gregory Saunders

Director

Defense Standardization Program

Office

U.S. Department of Defense

Ms. Trudie Williams

Defense Standardization Program

Office

U.S. Department of Defense

Mr. Arthur Graham

Deputy Chief Information Officer

Office of the Chief Information

Officer

U.S. Department of Education 
U.S. Department of Education

Standards Executive Representative

U.S. Department of Energy

Standards Executive

U.S. Department of Energy

Standards Executive Representative

U.S. Department of Health and Human Services Standards Executive

U.S. Department of Health and Human Services Standards Executive Representative
Mr. Barry Stone

Chief Engineer, Enterprise

Architecture

Office of the Chief Information

Officer

U.S. Department of Education

Mr. Richard Black

Director

Office of Nuclear Safety Policy and

Standards

U.S. Department of Energy

Mr. Richard Serbu

Manager

DOE Technical Standards Programs

U.S. Department of Energy

Ms. Janet Showalter

Director

International Scientific Activities and Standards

U.S. Department of Health and Human Services

Dr. John Lucas

Associate Director of Standards

U.S. Department of Health and

Human Services
U.S. Department of Housing and Urban Development Standards Executive
VACANT

Office of the Secretary

U.S. Department of Housing and Urban Development

U.S. Department of Housing and Urban Development Mr. David Engel 
Standards Executive Representative

U.S. Department of Justice

Standards Executive

U.S. Department of Justice

Standards Executive Representative

U.S. Department of Labor

Standards Executive

U.S. Department of Labor

Standards Executive Representative

U.S. Department of State

Standards Executive

U.S. Department of State

Standards Executive Representative

U.S. Department of the Interior
Director

Affordable Housing Research

\& Technology Division

U.S. Department of Housing and Urban Development

Mr. William Burdett

Senior Enterprise Architect

Information Management and Security

Staff

U.S. Department of Justice

Mr. Michael Carr

Justice Management Division

U.S. Department of Justice

Mr. Steven Witt

Director

OSHA Health Standards Programs

U.S. Department of Labor

Ms. Barbara Bielaski

Safety Specialist

OSHA Office of Policy

U.S. Department of Labor

Ms. Marian Gordon

Director

Telecommunications and Information

Standards

U.S. Department of State

Mr. Julian Minard

Telecommunications and Information Standards

U.S. Department of State

Mr. Steve King 
Alternate

U.S. Department of the Interior Primary

U.S. Department of the Treasury Standards Executive

U.S. Department of the Treasury Standards Executive Representative

U.S. Department of Transportation Standards Executive

U.S. Department of Transportation Standards Executive Representative

U.S. Department of Veteran's Affairs Alternative Representative

U.S. Department of Veteran's Affairs Standards Executive
Office of the Chief Information Officer

U.S. Department of the Interior

Mr. Daryl White

Chief Information Officer

Office of the Chief Information

Officer

U.S. Department of the Interior

Mr. James Flyzik

Deputy Assistant Secretary and Chief Information Officer

Office of the Secretary

U.S. Department of the Treasury

Ms. Helen Whatley

U.S. Department of the Treasury

Ms. Linda Lawson

U.S. Department of Transportation

Mr. Robert Stein

U.S. Department of Transportation

Mr. Pierre Lundy

U.S. Department of Veteran's Affairs

Mr. Gary Krump

Deputy Assistant Secretary for

Acquisition \& Management

Office of the Secretary

U.S. Department of Veteran's Affairs

Dr. Mary McKiel

Director 
EPA Standards Programs

U.S. Environmental Protection

Agency

U.S. Environmental Protection Agency

Standards Executive Representative

Mr. Craig Annear

Attorney

Office of General Counsel

U.S. Environmental Protection

Agency

U.S. Federal Communication Commission

Standards Executive

Mr. Michael Crowe

Chief

Office of Engineering and Technology

U.S. Federal Communication

Commission

U.S. Government Printing Office

Standards Executive

Mr. Robert Thomas

Manager

Quality Control and Technical

Department

U.S. Government Printing Office

U.S. Government Printing Office

Standards Executive Representative

U.S. Postal Service

Standards Executive

U.S. Postal Service

Standards Executive Representative

Mr. Bill Griggs

Acting Manager

Configuration Management

U.S. Postal Service

Ms. Sylvia Subt

Quality Control and Technical

Department

U.S. Government Printing Office

VACANT

Office of the Postmaster General

U.S. Postal Service 



\section{Appendix E:}

\section{List of National Institute of Standards and Technology Publications \\ Related to Public Law 104-113}




\title{
STANDARDS AND CONFORMITY ASSESSMENT RELATED PUBLICATIONS
}

\author{
Office of Standards Services \\ National Institute of Standards and Technology \\ Gaithersburg, Maryland 20899-2100
}

\section{NTTAA PUBLICATIONS:}

The National Technology Transfer and Advancement Act - Plan for Implementation

(NISTIR 5967)

Toward a National Standards Strategy - Conference Report (NISTIR 6290)

Toward A National Standards Strategy: Conference Summary Report (NISTIR 6259) by

Walter G. Leight and Krista J. Johnsen Leuteritz, published September 23, 1998

Towards Strategic Management of Standards Activities at NIST (NISTIR 6292)

Conference on Using Voluntary Standards in the Federal Government - September 8, 1997

Using Voluntary Standards in the Federal Government (NISTIR 6086)

1998 Federal Standards Workshop: Standards Management - A World of Change and

Opportunities - Conference Handbook -- A joint DOE, NIST, EPA, NASA,

Partnership in RMS, FDA publication

1998 Federal Technical Standards Workshop Proceedings (CONF-980822) - A joint DOE,

NIST, EPA, NASA, Partnership in RMS, FDA publication

1998 Annual Report on the Implementation of Office of Management and Budget (OMB)

Circular A-119 and P.L. 104-113, March 16, 2000 (NISTIR 6493)

1997 Annual Report on the Implementation of Office of Management and Budget (OMB)

Circular A-119 and P.L. 104-113, October, 1999 (NISTIR 6412)

\section{INTRODUCTORY PUBLICATIONS ON STANDARDS AND CONFORMITY} ASSESSMENT ACTIVITIES:

The ABC's of Standards-Related Activities in the United States (NBSIR 87-3576)

The ABC's of Certification Activities in the United States (NBSIR 88-3821) 
The ABC's of the U.S. Conformity Assessment System (NISTIR 6014)

Laboratory Accreditation Activities in the United States (NISTIR 4576)

Questions and Answers on Quality, the ISO 9000 Standard Series, Quality System Registration, and Related Issues (NISTIR 4721)

More Questions and Answers on the ISO 9000 Standard Series and Related Issues (NISTIR 5122)

The U.S. Certification System from a Governmental Perspective (NISTIR 6077)

ISO Environmental Management Standardization Efforts (NISTIR 5638-1)

\section{NACLA PUBLICATIONS:}

Report on NIST-NACLA MOU Workshop, July 6, 2000 (NISTIR 6540)

Report on the Open Forum on Establishment of the National Council for Laboratory Accreditation (NACLA) at the National Institute of Standards and Technology, January 7, 1997 (NISTIR 6008)

Examination of Laboratory Accreditation Programs in the United States and the Potential Role for a National Laboratory Accreditation System (NIST GCR 97-714)

Proceedings of the Open Forum on Laboratory Accreditation at the National Institute of Standards and Technology, October 13, 1995 (NIST SP 902)

\section{DIRECTORIES:}

Directory of International and Regional Organizations Conducting Standards-Related Activities (NIST SP 767)

Directory of European Regional Standards-Related Organizations (NIST SP 795)

Standards Activities of Organizations in the United States (NIST SP 806, 1996 Edition)

Directory of Federal Government Certification and Related Programs (NIST SP 739, 1999 Edition)

Directory of U.S. Private Sector Product Certification Programs (NIST SP 903)

Directory of Federal Government Laboratory Accreditation/Designation Programs

(NIST SP 808) 
Directory of State and Local Government Laboratory Accreditation/Designation Programs (NIST SP 815)

Directory of Professional/Trade Organization Laboratory Accreditation/Designation Programs (NIST SP 831)

Standards Setting in the European Union - Standards Organizations and Officials in EU Standards Activities (NIST SP 891, 1997 Edition)

Profiles of National Standards-Related Activities (NIST SP 912)

An Overview of the Development of Technical Infrastructure in the Asia-Pacific Region: The Work of the Asia-Pacific Economic Cooperation (APEC) Sub-committee on Standards and Conformance (SCSC) and the Specialist Regional Bodies (SRBs) (NISTIR 6325)

Free Trade Area of the Americas (FTAA) Conformity Assessment Infrastructure (NIST SP 941)

Semi-Annual Listing of North American Quality System Registration Organizations (NAQSRO)

Annual Directory of DOC Memberships on Outside Standards Committees

\section{NVLAP PUBLICATIONS:}

NIST Handbook 150: NVLAP Procedures and General Requirements

Directory of Accredited Laboratories

NVLAP Program-Specific Handbooks

NVLAP Policy Guides:

PG-1-1998: NVLAP Traceability Policy (March 1998)

PG-2-1998: Accreditation Documents for Laboratories Whose Accreditation Has Been

Suspended, Revoked, or Otherwise Terminated (May 1998)

PG-3-1999: Delegation of Authority from the Director of NIST to the Chief of

NVLAP (November 1999)

\section{MISCELLANEOUS PUBLICATIONS:}

TBT Agreement Activities of the National Institute of Standards and Technology 
Environmental Management Systems Voluntary Project Evaluation Guidance (NISTIR 6120)

A Selective Review of Testing Laboratory Accreditation Movements in the United States (NIST GCR 98-740)

Survey on the Implementation of ISO/IEC Guide 25 by National Laboratory Accreditation Programs (NISTIR 5473)

Government's Role in Standards-Related Activities: Analysis of Comments (NISTIR 4367)

\section{MAGAZINE ARTICLES:}

Collins, B.L., A Standards Infrastructure for the Future. Mechanical Engineering, 122, No. 4, April 2000, pp. 86-92, and Enjeuex, 200, January 2000, pp. 63-74.

Leight, W.G., Collins, B.L., Setting the Standards. Mechanical Engineering, 122, No. 2, February 2000, pp. 46-52.

Leight, W.G., Preserving the Miracle. Partnership in RMS Standards: A Newsletter for Professionals, January 2000, pp. 1-6.

Collins, B.L., Federal Government Coordination on Standards - The Role of NIST and the Interagency Committee on Standards Policy. The Standards Forum, 7, No. 3, December 1999, pp. 1, 15-16.

Collins, B.L., Standards and Government Regulations in the United States. Warnings and Risk Communications, Chapter 12. Taylor and Francis Ltd., 1999.

Collins, B.L., Federal Government Coordination on Standards - The Role of NIST and the Interagency Committee on Standards Policy. ASTM Standardization News, 27, May 1999, pp. 20-21.

Collins, B.L., Update on the activities of the National Cooperation for Laboratory Accreditation. Accreditation and Quality Assurance: Journal for Quality, Comparability and Reliability in Chemical Measurement, $\underline{3}$, September 1998, pp. 351355.

Collins, B.L., National Cooperation of Laboratory Accreditation. Radioactivity \&

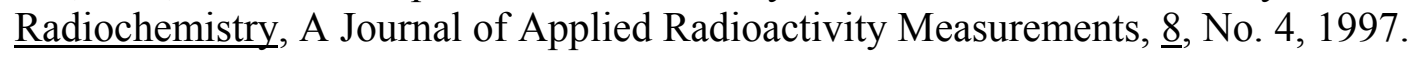

Collins, B.L., NIST to Lead in NTTAA Implementation. ANSI Reporter, April 1997, p. 3. 
Collins, B.L., The National Technology Transfer and Advancement Act - Plan for Implementation. NISTIR 5967, January 1997.

Collins, B.L., National Cooperation of Laboratory Accreditation. CIRMS Annual Meeting Abstracts, Radioactivity \& Radiochemistry, $\underline{8}$, 1997, pp. 16-17.

Collins, B.L., Laboratory Accreditation: The Need for a National Infrastructure. Cal Lab, November-December 1996, pp. 18-22.

Collins, B.L., Helping Reduce Technical Barriers to Trade. Proceedings of CPSC Conference on Bringing Standards Together: An International Framework. July 18, 1996, pp. 48-53.

Collins, B.L., The Consensus Process in Standards Development. Proceedings of the Joint Conference on Standard Setting in Large-Scale Assessments, 1995, pp. 203-219.

Breitenberg, M., Conformity Assessment: An Important Policy Issue. ASTM Standardization News, November 1997, pp. 20-23.

Johnsen Leuteritz, K., Toward Strategic Management of Standards Activities at NIST. ASTM Standardization News, December 1999, cover article. Reprinted in DOE's "The Standards Forum," March 2000.

Johnsen Leuteritz, K., The New MOU. ASTM Standardization News,

Johnsen Leuteritz, K., The Church of Accreditation. American Society for Quality, February 1999.

Overman, J., NIST and Strategic Standardization. ANSI Reporter, September 2000.

Collins, B.L., Federal Government Coordination on Standards -- The Role of NIST and the Interagency Committee on Standards Policy. ASTM Standardization News, December 1999.

Johnsen Leuteritz, K., Standards Summit: A First Step Toward a National Strategy. Energy and Environment Update, American Society for Quality, October 1998.

Johnsen Leuteritz, K., Why the Work of the Multi-State Working Group Matters to Federal Agencies. Energy and Environment Update, American Society for Quality, May 1998. 